ORNL/TM-2000/242

Chemical Technology Division

\title{
Strategy for Characterizing Transuranics and Technetium Contamination in Depleted UF 6 Cylinders
}

\author{
J. R. Hightower \\ L. R. Dole \\ D. W. Lee* \\ G. E. Michaels ${ }^{\dagger}$ \\ M. I. Morris
}

D. G. O'Connor

S. J. Pawel ${ }^{\S}$

R. L. Schmoyer*

L. D. Trowbridge

V. S. White

*Energy Division, ORNL

${ }^{\dagger}$ Nuclear Technology Program Office, ORNL

${ }^{\ddagger}$ Engineering Technology Division, ORNL

${ }^{\S}$ Metals and Ceramics Division, ORNL

October 2000

Prepared by the

OAK RIDGE NATIONAL LABORATORY

Oak Ridge, Tennessee 37831-6285

managed by

UT-BATTELLE, LLC

for the

U.S. DEPARTMENT OF ENERGY

under contract DE-AC05-00OR22725 


\section{CONTENTS}

ACRONYMS AND ABBREVIATED FORMS $\ldots \ldots \ldots \ldots \ldots \ldots \ldots \ldots \ldots \ldots \ldots$

EXECUTIVE SUMMARY $\ldots \ldots \ldots \ldots \ldots \ldots \ldots \ldots \ldots \ldots \ldots \ldots \ldots \ldots \ldots$ vii

1. DESCRIPTION OF PROBLEM $\ldots \ldots \ldots \ldots \ldots \ldots \ldots \ldots \ldots \ldots \ldots \ldots \ldots \ldots$

2. CONCLUSIONS AND RECOMMENDATIONS $\ldots \ldots \ldots \ldots \ldots \ldots \ldots \ldots \ldots \ldots$

3. BACKGROUND INFORMATION ON Pu, Np, AND Tc CONTAMINATION . . . . . 3

3.1 CHEMICAL BEHAVIOR OF Am, Np, Pu, AND Tc ............... 3

3.2 KNOWN SAMPLING RESULTS $\ldots \ldots \ldots \ldots \ldots \ldots \ldots \ldots \ldots \ldots \ldots$

3.3 ESTIMATED CONCENTRATIONS DISPERSED IN UF

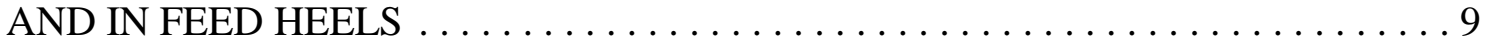

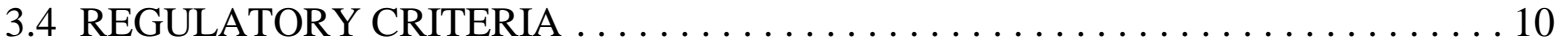

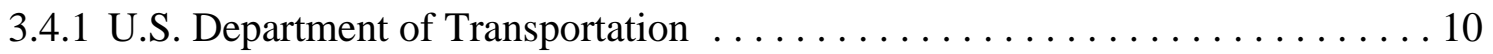

3.4 .2 International Atomic Energy Agency . . . . . . . . . . . . . . . . . 11

3.4.3 U.S. Nuclear Regulatory Commission . . . . . . . . . . . . . . . . . . . . 11

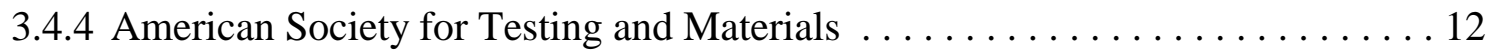

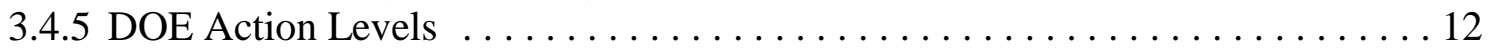

3.4.6 Threshold Quantities for DOE Category 2 Nuclear Facilities . . . . . . . . . 13

3.4.7 Comparison of Bounding Limits with Regulatory Criteria . . . . . . . . . . . . 14

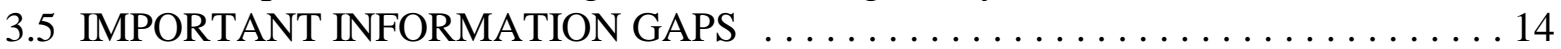

4. CHARACTERIZATION INFORMATION NEEDED BY VENDORS $\ldots \ldots \ldots \ldots \ldots$

4.1 VENDORS' DESIGN REQUIREMENTS $\ldots \ldots \ldots \ldots \ldots \ldots \ldots \ldots \ldots \ldots \ldots \ldots \ldots$

4.2 CHARACTERIZATION INFORMATION NEEDED $\ldots \ldots \ldots \ldots \ldots \ldots \ldots \ldots \ldots$

4.3 POTENTIAL COST CONSEQUENCE FOR ENCOUNTERING CONTAMINANT CONCENTRATIONS HIGHER THAN A

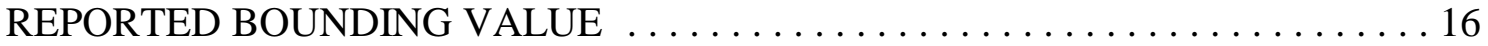

4.4 OTHER CHARACTERISTICS THAT SHOULD BE INCLUDED

IN CYLINDER CHARACTERIZATION $\ldots \ldots \ldots \ldots \ldots \ldots \ldots \ldots \ldots \ldots \ldots \ldots \ldots$

4.4.1 Radiochemical Impurities (Other than $\mathrm{Np}, \mathrm{Pu}, \mathrm{Am}$, and $\mathrm{Tc}$ ) . . . . . . . . . 18

4.4.2 Impurities with the Potential to Affect Conversion Processes . . . . . . . . . . 18

4.4.3 Cylinder Handling Characteristics . . . . . . . . . . . . . . . . . . . . 19

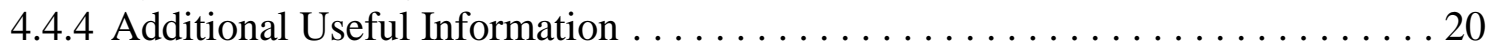

5. METHODOLOGY FOR ANALYSIS OF CYLINDER CONTENTS . . . . . . . . . 20

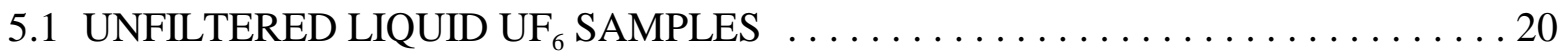

5.2 FILTERED LIQUID UF ${ }_{6}$ SAMPLES $\ldots \ldots \ldots \ldots \ldots \ldots \ldots \ldots \ldots \ldots \ldots \ldots \ldots \ldots \ldots \ldots \ldots_{\ldots} \ldots \ldots \ldots \ldots$

5.3 GENERATION OF HEELS BY EMPTYING CYLINDERS $\ldots \ldots \ldots \ldots \ldots \ldots \ldots .21$

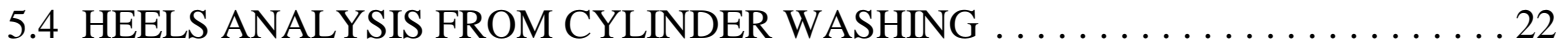

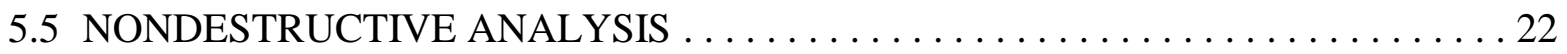




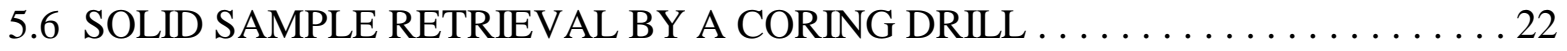

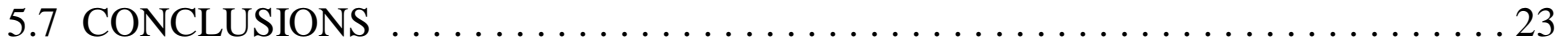

6. RECOMMENDED CHARACTERIZATION STRATEGY $\ldots \ldots \ldots \ldots \ldots \ldots \ldots \ldots$

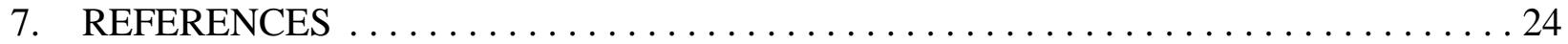

\section{APPENDIXES}

Appendix A. Task Statement for Developing a Characterization Strategy . . . . . . . . A-1

Appendix B. Statistical Analysis of Cylinder Sampling . . . . . . . . . . . . . . . . B-1

Appendix C. Upper Bound Estimates of $\mathrm{Pu}, \mathrm{Np}$, and Tc Concentrations

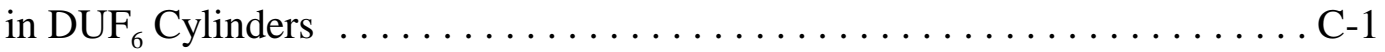

Appendix D. Other Characterization Information $\ldots \ldots \ldots \ldots \ldots \ldots \ldots \ldots \ldots \ldots \ldots$

Appendix E. Options for Sampling and Analysis of DUF D $_{6}$ Cylinder Contents . . . . . . . . E-1

Appendix F. Identification and Selection of Populations of DUF 6 Cylinders

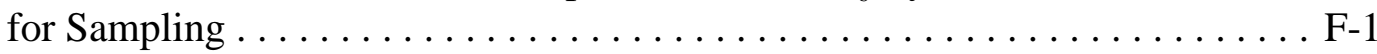




\section{ACRONYMS AND ABBREVIATED FORMS}

\begin{tabular}{|c|c|}
\hline ALI & annual limit on intake \\
\hline ANL & Argonnne National Laboratory \\
\hline ANSI & American National Standards Institute \\
\hline ASME & American Society of Mechanical Engineers \\
\hline ASTM & American Society for Testing and Materials \\
\hline B\&PV & Boiler and Pressure Vessel (Code) \\
\hline CFR & Code of Federal Regulations \\
\hline $\mathrm{DAC}$ & derived air concentration \\
\hline DOE & U.S. Department of Energy \\
\hline DOT & U.S, Department of Transportation \\
\hline $\mathrm{DUF}_{6}$ & depleted uranium hexafluoride \\
\hline $\mathrm{EM}$ & Office of Environmental Management (DOE) \\
\hline ETTP & East Tennessee Technology Park \\
\hline GDP & gaseous diffusion plant \\
\hline IAEA & International Atomic Energy Agency \\
\hline LLNL & Lawrence Livermore National Laboratory \\
\hline LMES & Lockheed Martin Energy Systems, Inc. \\
\hline MT & metric tons \\
\hline NBIC & National Board Inspection Code \\
\hline NDA & nondestructive analysis \\
\hline NRC & U.S. Nuclear Regulatory Commission \\
\hline ORGDP & Oak Ridge Gaseous Diffusion Plant (site is now East Tennessee Technology Park) \\
\hline ORNL & Oak Ridge National Laboratory \\
\hline PCB & polychlorinated biphenyl \\
\hline PNNL & Pacific Northwest National Laboratory \\
\hline PORTS & Portsmouth Gaseous Diffusion Plant \\
\hline PGDP & Paducah Gaseous Diffusion Plant \\
\hline RFP & request for proposals \\
\hline SAIC & Science Applications International Corporation \\
\hline SRS & Savannah River Site \\
\hline TRU & transuranic \\
\hline UCB & upper confidence bound \\
\hline USEC & U.S. Enrichment Corporation \\
\hline WAC & waste acceptance criteria \\
\hline WIPP & Waste Isolation Pilot Plant \\
\hline
\end{tabular}




\section{EXECUTIVE SUMMARY}

This report summarizes results of a study performed to develop a strategy for characterization of low levels of radioactive contaminants [plutonium $(\mathrm{Pu})$, neptunium $(\mathrm{Np})$, americium $(\mathrm{Am})$, and technetium $(\mathrm{Tc})]$ in depleted uranium hexafluoride $\left(\mathrm{DUF}_{6}\right)$ cylinders at the gaseous diffusion plants in Oak Ridge, Tennessee; Paducah, Kentucky; and Piketon, Ohio. In these gaseous diffusion plants, this radioactivity came from enriching recycled uranium (the so-called "reactor returns") from Savannah River, South Carolina, and Hanford, Washington, reactors. Results of this study will be used to support a request for proposals to design, build, and operate facilities to convert the $\mathrm{DUF}_{6}$ to more chemically stable forms. These facilities would need to be designed to handle any transuranic contaminants that might be present in order to (1) protect the workers' health and safety and (2) protect the public and the environment.

To arrive at recommendations for the combination of process knowledge and sampling and analysis that is appropriate for characterization of the inventory of DUF $_{6}$ cylinders, an evaluation was performed that considered several questions. These questions and their answers are summarized below:

- What do the U.S. Department of Energy and vendors need to know about possible contaminants (and to what degree of accuracy) for the design of safe facilities?

The designer of the conversion plant needs to know (1) the quantities of the contaminants contained in the cylinders that might be fed into the conversion process equipment and (2) how much of the contaminant will remain in the cylinders. Subsequently, the vendors will need to design the conversion facility (1) to reduce or eliminate contaminants from the conversion process downstream of the feed area or to manage the contamination if it is introduced to the conversion process and (2) to provide means for safely handling empty contaminated cylinders and disposing of waste streams generated.

- What information exists about contamination levels in $\mathrm{DUF}_{6}$ cylinders?

Transuranic contamination in the $\mathrm{DUF}_{6}$ cylinders will exist as fluoride compounds that are both insoluble in liquid $\mathrm{DUF}_{6}$ and nonvolatile. The contamination will exist primarily as (1) small particulates more or less uniformly dispersed throughout the DUF $_{6}$ contents and (2) small quantities of consolidated residues ("heels") from the original feedstock to the cascades present in a relatively small, but unknown, number of cylinders. A large body of process history on transuranics in the gaseous diffusion process has been compiled, reviewed, and analyzed, including the results from historical sampling of more than $150 \mathrm{DUF}_{6}$ cylinders for dispersed transuranics. Recent measurements on $\mathrm{DUF}_{6}$ cylinders and two heels cylinders were also included in the analysis. All existing samples of DUF ${ }_{6}$ cylinders show nondetectable or very low levels of transuranics dispersed in the DUF $_{6}$. All available evidence indicates that the radiological controls that will be needed to safely contain the uranium itself will provide the needed protection against the very low levels of transuranic contamination present as the dispersed form in $\mathrm{DUF}_{6}$. However, the concentrations of transuranic contamination associated with feed material heels that may be present in some cylinders are sufficiently high that additional radiological 
controls should be considered. The total quantities of transuranics and technetium contained in the entire inventory of $\mathrm{DUF}_{6}$ fall below the DOE Category 2 nuclear facility threshold.

- $\quad$ Are additional sampling and analysis needed to more fully understand the contents of the DUF $_{6}$ cylinders?

After careful review and analysis of the compiled information and the expected chemical behavior of the transuranics, the principal conclusion (confirmed by peer review) is that even without additional sampling, sufficient information exists within the current body of knowledge to provide vendors with an adequate basis for design of facilities that can operate safely. Bounding values of concentrations of transuranics and technetium in DUF $_{6}$ and in feed material heels were estimated that are consistent with existing measurements.

- Is statistical sampling necessary? Other considerations include the following:

S Is it useful to describe the stockpile as being subdivided into smaller populations that have different levels of risk of contamination?

$\mathrm{S} \quad$ And if statistical sampling is appropriate, by trading off the cost of sampling with the additional confidence one gains by sampling, how many cylinders should be sampled?

Although a statistical sampling effort was found not to be necessary, a protocol had been developed in case it might be needed on a high-priority population. A cost-benefit analysis, taking into account the high cost of sampling a cylinder and the low expected cost of added radiological controls needed to handle any transuranics beyond levels determined by measurement, led to selecting a relatively low number (12) of additional cylinders in that population that would be justified for sampling.

- $\quad$ For the sampling efforts described above, what type of contaminant measurement methods will yield the desired information?

The best technique for obtaining the needed information with regard to the concentrations of the dispersed form of transuranics in $\mathrm{DUF}_{6}$ cylinders is by direct sampling of liquid $\mathrm{DUF}_{6}$, which involves heating the cylinder in a steam autoclave to melt the solid DUF . The best approach for determining the concentration of transuranics that would be present in the residual "heels" is to identify existing cylinders that have been emptied previously (leaving the feed material "heel" behind) and then wash the material from one of these cylinders using aggressive chemical solutions and analyze the wash solution for the contaminants. The only existing equipment for performing these measurements is owned by the U.S. Enrichment Corporation, and its availability is severely restricted. Therefore, only limited measurements, if needed, could be made to meet the desired procurement schedule. 
- What alternative strategies should be considered to accommodate time and budget constraints?

It is felt that no further measurements on $\mathrm{DUF}_{6}$ cylinders are needed in order to go forward with the procurement action.

- In addition to transuranic contamination, what other characteristics of the cylinder inventory should be measured that would be needed by vendors to prepare their bids?

In addition to the characterization of cylinder contents, a separate characterization of cylinder coatings should be performed to determine the extent and levels of polychlorinated biphenyl (PCB) contamination on coatings. An additional study is required to define the necessary characterization program for PCBs.

In addition, the cylinder inventory should be assessed for compliance with U.S. Department of Transportation regulations and the American Society of Mechanical Engineers pressure vessel code that affect a cylinder's ability to be readily transported off-site and undergo heating and unloading in autoclaves. Verification would include a review of existing information and collection of additional information (i.e., actual volumes from cylinder nameplates) to strengthen reliability of the compliance indicators in the cylinder inventory database. An additional study is required to define the necessary program to accomplish these tasks. 


\section{DESCRIPTION OF PROBLEM}

The large stocks of depleted uranium hexafluoride $\left(\mathrm{DUF}_{6}\right)$ at the Oak Ridge Gaseous Diffusion Plant (ORGDP; the site is now called the East Tennessee Technology Park) in Oak Ridge, Tennessee, the Paducah Gaseous Diffusion Plant (PGDP) in Paducah, Kentucky, and the Portsmouth Gaseous Diffusion Plant (PORTS) in Piketon, Ohio, are currently under consideration for conversion to a more stable chemical form. Recent concerns have arisen as to whether some portion of the depleted uranium stockpile may have low levels of radioactive contaminants [plutonium ( $\mathrm{Pu})$, neptunium $(\mathrm{Np})$, americium $(\mathrm{Am})$, and technetium $(\mathrm{Tc})$ ] due to a history of processing recycled uranium from defense production sites. Uncertainty exists about the extent of contamination by these nuclides, and additional chemical sampling of DUF 6 cylinders is desirable to obtain data that will reduce the uncertainty associated with contamination levels of $\mathrm{Pu}, \mathrm{Np}$, and $\mathrm{Tc}$.

The objective of this paper is to define an appropriate strategy for characterization of the contamination in $\mathrm{DUF}_{6}$ cylinders that was introduced into the gaseous diffusion plants during the process of enriching recycled uranium (the so-called "reactor returns") [see Appendix A]. This information will be used in a U.S. Department of Energy (DOE)-issued request for proposals (RFP) for conversion services from the private sector, thereby permitting potential vendors to design, build, and operate facilities to convert the $\mathrm{DUF}_{6}$ to more chemically stable forms. These facilities must be designed to handle any transuranic (TRU) contaminants that might be present in a manner that (1) protects the workers' health and safety and (2) protects the public and the environment.

Characterization of materials streams destined for treatment in the manner contemplated for the DUF $_{6}$ generally relies on information obtained from process knowledge, sampling and analysis, or a combination of both. The term process knowledge means applying information relative to the characteristics of the waste in light of the materials or the processes used, including details about origin, storage, and use of the materials.

To arrive at recommendations for the combination of process knowledge and sampling and analysis that is appropriate for characterization of the inventory of DUF $_{6}$ cylinders, this report is designed to answer the following questions:

- What do DOE and vendors need to know about possible contaminants and to what degree of accuracy?

- What information exists about contamination levels in $\mathrm{DUF}_{6}$ cylinders?

- Is statistical sampling appropriate, and is it useful to describe the stockpile as being subdivided into smaller populations that have different levels of risk of contamination?

- By trading off the cost of sampling with the additional confidence one gains by sampling, how many cylinders should be sampled?

- What type of contaminant measurement methods will yield the desired information? 
- What alternative strategies should be considered to meet time and budget constraints?

- In addition to TRU contamination, what other characteristics of the cylinder inventory should be measured that would be needed by vendors to prepare their bids?

An earlier draft of this report was subjected to peer review by subject experts at Lawrence Livermore National Laboratory (LLNL) and Argonne National Laboratory (ANL) [Ref. 1]. This report has been revised and improved as a result of these reviews as well as subsequent additional information.

\section{CONCLUSIONS AND RECOMMENDATIONS}

A careful review and analysis have been completed of a large body of process history on transuranics in the gaseous diffusion process, including the results from historical sampling of more than $150 \mathrm{DUF}_{6}$ cylinders for dispersed transuranics, and the expected chemical behavior of the transuranics. The principal conclusion (confirmed by peer review [Ref. 1]) from this review and analysis is that even without additional sampling, sufficient information exists within the current body of knowledge to provide vendors with an adequate basis for design of facilities that can operate safely.

To provide added confidence in the evaluation of characterization needs, one cylinder with heels from reactor return feed material (which should contain the highest expected levels of any TRU material that might be present) has been sampled by washing and analyzing the wash solution. These analyses confirmed estimates of the expected higher concentrations of transuranics and technetium contained in the heels material.

In any future measurements to be made on $\mathrm{DUF}_{6}$ cylinders, the constituents that should be analyzed for are as follows: ${ }^{237} \mathrm{~Np},{ }^{238} \mathrm{Pu},{ }^{239} \mathrm{Pu},{ }^{241} \mathrm{Am},{ }^{236} \mathrm{U}$, and ${ }^{99} \mathrm{Tc}$.

Additional characterization needs include a separate assessment of the outer surfaces of cylinders to determine the extent and levels of polychlorinated biphenyl (PCB) contamination on their surface coatings. In this case, the principal populations to examine include the total inventories at each of the three gaseous diffusion plants. Therefore, an additional study is required to define the necessary characterization program for PCBs.

The cylinder inventory should be assessed for compliance with U.S. Department of Transportation (DOT) regulations and the American Society of Mechanical Engineers (ASME) pressure vessel codes. Compliance with these codes affects the ability of a cylinder to be readily transported off-site and undergo heating and unloading in the proposed conversion plant's autoclaves. This verification would include a review of existing information and collection of additional information (i.e., actual volumes from cylinder nameplates) to strengthen reliability of the compliance indicators in the cylinder inventory database. Also, an additional study is required to define the necessary characterization program to accomplish these tasks. 


\section{BACKGROUND INFORMATION ON Pu, Np, AND Tc CONTAMINATION}

\subsection{CHEMICAL BEHAVIOR OF Am, Np, Pu, AND Tc}

The reactor returns from Hanford and Savannah River contained traces of plutonium and neptunium that had not been completely separated from the uranium in the REDOX and PUREX processes. In the last stages of Oak Ridge and Paducah feed preparation plants that treated reactor returns $\left(\mathrm{UO}_{3}\right)$, a fluorine flame-tower reactor converted $\mathrm{UF}_{4}$ to $\mathrm{UF}_{6}$. In this step, a significant amount of fine "ash" (consisting primarily of unreacted $\mathrm{UF}_{4}$ ) contaminated with the transuranics and fission products (principally ${ }^{99} \mathrm{Tc}$ ) could have been transported into the feed cylinders, providing a pathway for these contaminants to be introduced into the enrichment cascades.

During fluorination of $\mathrm{UF}_{4}$ to $\mathrm{UF}_{6}$, volatile fluoride compounds such as $\mathrm{PuF}_{6}, \mathrm{NpF}_{6}$, and $\mathrm{TcO}_{3} \mathrm{~F}$ were formed. After separation from the atmosphere of the fluorinator, these volatile plutonium and neptunium hexafluorides reacted with the unreacted $\mathrm{UF}_{4}$ in the ash to form nonvolatile $\mathrm{PuF}_{4}$ and $\mathrm{NpF}_{4}$ compounds. While canister filters caught most of this ash, some TRU-containing $\mathrm{UF}_{4}$ ash may have been transported into the feed cylinders. The volatile hexafluorides of these transuranics reacted with metal surfaces of the feed cylinders, and the nonvolatile reduced forms plated out on the surfaces. Finally, some of the surviving volatile hexafluoride TRU compounds were transported from the feed cylinders into the enrichment cascades.

Technetium behaves similarly to uranium chemically and forms very stable volatile compounds. These technetium compounds did not accumulate in the feed cylinders, although some technetium contamination did remain. Technetium was preferentially transferred with $\mathrm{UF}_{6}$ into the cascades, where it tended to migrate to the top of the cascades to be withdrawn with the enriched product.

In feeding the $\mathrm{UF}_{6}$ made from recycled uranium to the cascades, there was a partial separation of the $\mathrm{Pu}, \mathrm{Np}$, and Tc from the $\mathrm{UF}_{6}$ introduced into the cascades. Smith [Ref. 2] estimated that no more than $85 \%$ of the Tc and only 10 to $40 \%$ of the $\mathrm{Np}$ and $\mathrm{Pu}$, respectively, were carried (as entrained or as volatile species) from the feed cylinders into the cascades. The remainder remained in the form of nonvolatile compounds in the feed cylinder heels, the small amount of relatively nonvolatile material typically left behind when the contents of a cylinder are vaporized for transfer. At the PGDP, reactor returns heels remain in 104 otherwise empty cylinders [Ref. 3]. Some of the recycled uranium $\mathrm{UF}_{6}$ feed cylinders with their heels remaining were used to store tails [Ref. 4]. The number of cylinders thus affected is presently unknown, and the cylinders can be identified only by a review of the archived information. This requires a manual search of archived information, some of which is known to be stored in contamination areas. People knowledgeable about the operations during this period have estimated that the number of such cylinders is in the range of a few hundred. No previous sampling information on TRU concentrations in the feed materials heels was identified.

Only small fractions of the transuranics and fission products introduced to the cascades are expected to have reached the tails. Plutonium and neptunium were probably introduced into the 
cascades as $\mathrm{PuF}_{6}$ and $\mathrm{NpF}_{6}$ from the feed cylinders. Both $\mathrm{PuF}_{6}$ and $\mathrm{NpF}_{6}$ react strongly with the metal surfaces of the cascades and plate out in the piping and in stages very near the point of introduction [Ref. 4]. Therefore, very little of the plutonium and neptunium is expected to have migrated through the diffusion cascade to the $\mathrm{DUF}_{6}$. Most of the volatile ${ }^{99} \mathrm{Tc}$ species $\left(\mathrm{TcO}_{3} \mathrm{~F}\right.$ or, less likely, $\mathrm{TcF}_{6}$ ) were removed through the diffusion plants' purge cascades, or they report to the product streams because they have much lower molecular weights than the ${ }^{238} \mathrm{UF}_{6}$. Thus, only a very small fraction of the ${ }^{99} \mathrm{Tc}$ in the recycled uranium is expected to appear in the $\mathrm{DUF}_{6}$.

Within the $\mathrm{DUF}_{6}$ cylinders, the volatile $\mathrm{PuF}_{6}$ and $\mathrm{NpF}_{6}$ compounds are readily reduced to the nonvolatile $\mathrm{PuF}_{4}$ and $\mathrm{NpF}_{4}$ compounds by reaction with the metal container and impurities in the DUF $_{6}$. Therefore, neptunium and plutonium in DUF $_{6}$ cylinders are expected to be present in these reduced nonvolatile forms because of exposure over many years to the reducing environment offered by the metal cylinder walls and impurities in the $\mathrm{DUF}_{6}$. Americium does not form volatile fluorides [Ref. 5] and thus, if present, would be in the nonvolatile $\mathrm{AmF}_{3}$ form. The $\mathrm{AmF}_{3}, \mathrm{PuF}_{4}$, and $\mathrm{NpF}_{4}$ exist as small particulates that are readily filtered by porous metal filters [Ref. 6]. Although they would not be transferred as a volatile form into the conversion process with the $\mathrm{DUF}_{6}$, they would be susceptible to entrainment into the process equipment unless excluded by filtration using porous metal filters.

Thus, TRU contamination in the $\mathrm{DUF}_{6}$ cylinders will exist as fluoride compounds that are both insoluble in liquid $\mathrm{UF}_{6}$ and nonvolatile. The contamination will be present in two main forms: (1) as small particulates more or less uniformly dispersed throughout the DUF ${ }_{6}$ contents and (2) in small quantities of consolidated residues (heels) from the original feedstock to the cascades present in a relatively small, but unknown, number of cylinders.

\subsection{KNOWN SAMPLING RESULTS}

In March 1984, Smith summarized the historical impacts of recycled uranium on the Paducah cascade [Ref. 2]. He reported sampling and analyzing two Paducah DUF 6 cylinders in June 1973 for ${ }^{99} \mathrm{Tc},{ }^{237} \mathrm{~Np}$, and ${ }^{239} \mathrm{Pu}$. In FY 1973, recycled uranium constituted $65 \%$ of the total feed to the cascade. In June 1973, when these samples were taken, over $96 \%$ of the total cascade feed consisted of recycled uranium. These samples were taken by withdrawing an aliquot of liquid $\mathrm{DUF}_{6}$ from a heated cylinder and sending small portions of the material to a laboratory for constituent analyses. The results would then represent contaminants dispersed in the DUF 6 but would not represent any consolidated heel material left from previous operations involving the cylinder. The technetium levels measured in the two DUF $_{6}$ cylinders were below the detection limit $(<1 \mathrm{ppb})$ of these analyses. In the same month, the technetium level in a product cylinder was $20,000 \mathrm{ppb}$, the highest ever measured on that stream. Also in these two cylinders that were analyzed in June 1973, neptunium and plutonium concentrations were found to be $<1$ and $<0.01$ $\mathrm{ppb}$, respectively (both below limits of detection).

These observations are particularly important because they indicate that even under the most severe conditions of input of transuranics into the cascades, the contaminants were not detectable in the tails stream. 
In a letter from C. R. Beverly to J. C. Hodges, "Np-237, Pu-239/240, and Tc-99 in Paducah Gaseous Diffusion Plant (PGDP) Tails and Product," dated March 19, 1992 [Ref. 7], the following statements are made:

"In summary, Tc-99 has never been positively identified in Paducah tails $\mathrm{UF}_{6}$, based on 153 cylinders analyzed in the period from 1972 through 1991." The information supporting this statement identified results from 37 tails cylinders filled during the period 1972-1981 and 116 tails cylinders filled during the period 1982-1991.

"Np-237 has never been detected in PGDP tails and has not been detected in PGDP product since 1980." Information supporting this statement identified results from 40 tails cylinders analyzed during the period 1973-1982 and 111 tails cylinders analyzed during the period 1983-1991.

"In summary, plutonium has never been detected in Paducah tails $\mathrm{UF}_{6}$ and it is questionable whether it has been detected in Paducah product $\mathrm{UF}_{6}$." Information supporting this statement identified results from 60 tails cylinders analyzed during the period 1973-1982 and 116 tails cylinders analyzed during the period 1983-1991.

PGDP summaries of DUF 6 analyses for FY 1981-1990 and FY 1992-1993 were available for this study [see Appendix B]. These summaries include some DUF 6 cylinders from ORGDP and PORTS that were sent to PGDP. None of these years is from the era when substantial amounts of recycled uranium were processed at the PGDP, although recycled uranium made up $<<1 \%$ of the feed that was processed from 1986-1989 [Ref. 4]. Out of 153 DUF $_{6}$ cylinder samples from the three plants, neptunium was only detected once-at $5 \mathrm{ppb}$, also the limit of detection for neptunium in 1986. Plutonium was not detected in any of 152 samples. (The detection limit was $0.01 \mathrm{ppb}$.) Out of 219 samples, technetium was detected only twice at $0.01 \mathrm{ppm}$, the limit of detection for technetium in FY 1991-1992. Otherwise, it was not detected. If it is assumed that the samples were truly random, these results indicate a 98\% probability that no more than $2.5 \%$ of the cylinders generated during this period of reporting at Paducah have concentrations of the three contaminants greater than the detection limit.

Table 1 shows results of characterization measurements taken during the period December 1999 through August 2000 on 14 selected DUF 6 cylinders and heels cylinders stored at the PGDP and PORTS [Ref. 8].

Cylinder no. 003174, an empty cylinder with $13 \mathrm{lb}$ of heel material remaining, had been filled at the PGDP feed plant with $\mathrm{UF}_{6}$ prepared from recycled uranium material sometime after the purchase date of the cylinder, June 1954. After the original charge in this cylinder had been fed to the cascades, the cylinder was filled with enriched product from Paducah and shipped to PORTS, where this material was fed to the Portsmouth cascade for further enrichment. The cylinder was similarly refilled with enriched product and emptied two more times without any washing, leaving its original heel of reactor returns feed material combined with heels left from emptying enriched product three times into the cascades. The heels material in this cylinder was dissolved by washing with an acidic wash solution, and the solution was analyzed for the dissolved constituents. The results of the measurements on this cylinder show, as expected, the highest measured values for all of the TRU and technetium contaminants that were observed in 


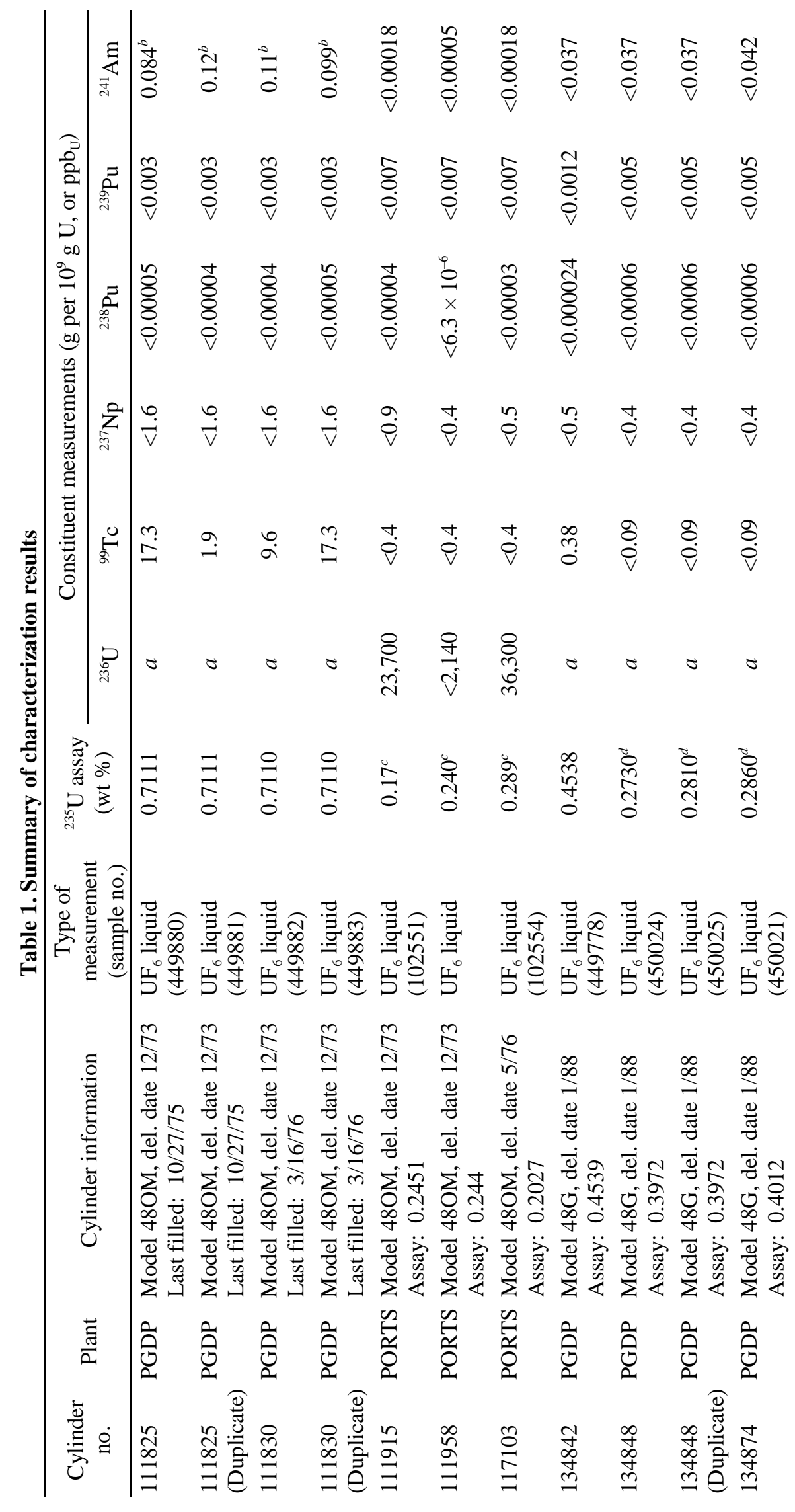




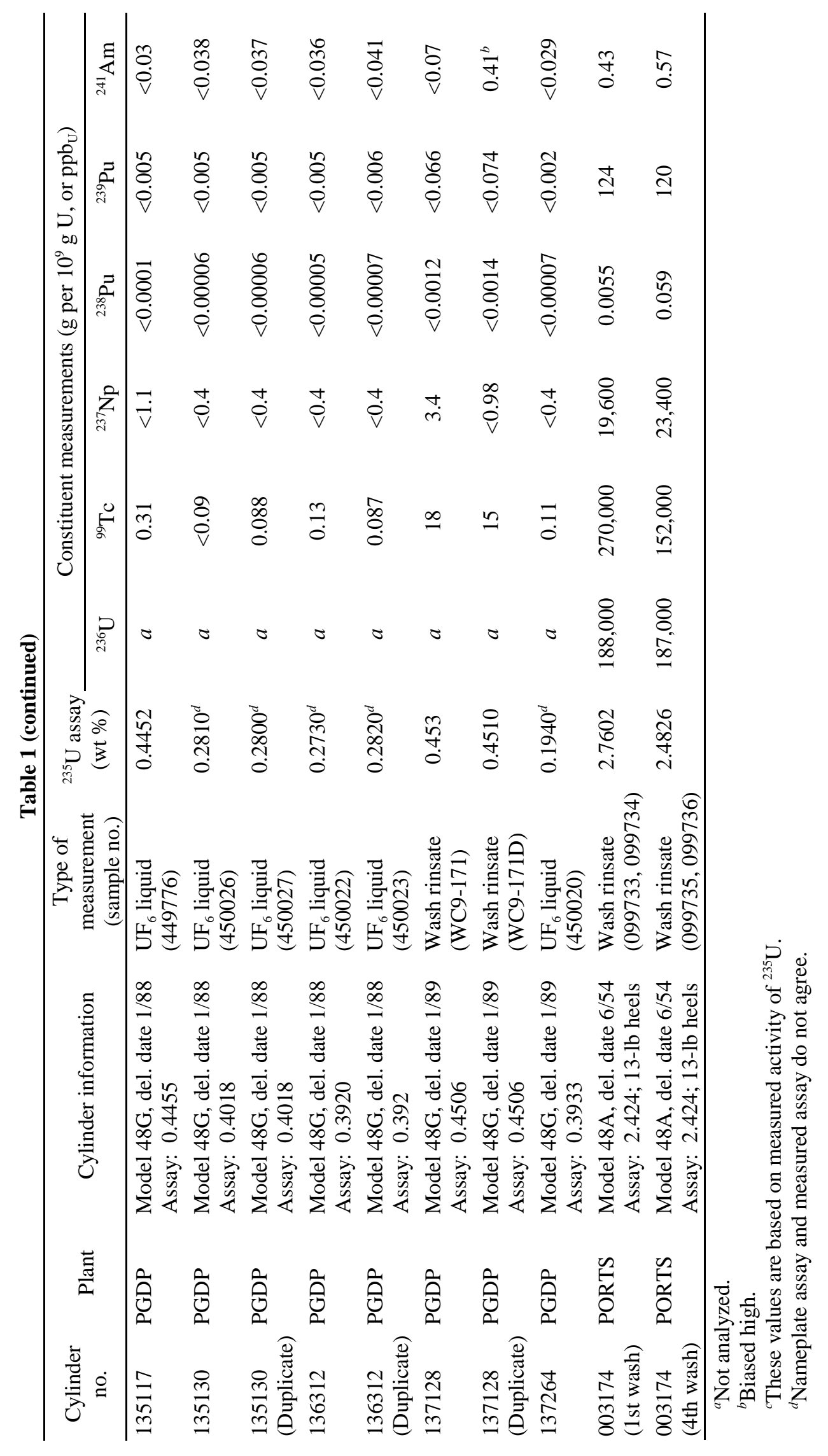


this series of measurements. Table 1 shows results of the first and fourth washes of a series intended to dissolve the heel material from the cylinder. Concentrations of the contaminants in the wash solution were a factor of 400-500 lower in the fourth wash than in the first wash, but the concentrations normalized to total uranium (shown in Table 1) remained relatively constant from the first to the fourth wash. The normalized concentrations of $\mathrm{Np}, \mathrm{Pu}$, and $\mathrm{Am}$ are representative of those in solids that would result if the wash solution were evaporated to dryness. All concentrations are above the suggested DOE action limits discussed in Sect. 3.4, and they are sufficiently high that the solids, if not blended with lower-concentration material, would need to be managed as TRU waste.

A second cylinder (no. 137128) containing heels material, which was from the PGDP, was analyzed similarly. This cylinder was purchased in January 1989, a period when recycled uranium material was not being fed to the gaseous diffusion plants. Duplicate samples of wash water from washing heels material in this cylinder indicated detectable levels of ${ }^{237} \mathrm{~Np}$ in one sample but not in the other; detectable levels of ${ }^{241} \mathrm{Am}$ in one but not the other; and detectable levels of ${ }^{99} \mathrm{Tc}$ in a solution containing $39,200 \mathrm{pCi} / \mathrm{mL}{ }^{238} \mathrm{U}$. These detectable levels of ${ }^{237} \mathrm{~Np}$ and ${ }^{241} \mathrm{Am}$ would be equivalent to concentrations in the evaporated solids from the wash water of 3.4 and $0.41 \mathrm{~g}$ per billion grams of uranium, respectively, or 0.0024 and $1.3 \mathrm{nCi}$ per gram of uranium, respectively. These concentrations are well below the limit of $100 \mathrm{nCi}$ per gram of waste that dictates management as TRU waste. The concentration of ${ }^{241} \mathrm{Am}$ is above the suggested DOE action limit of $0.039 \mathrm{ppb}$ (Sect. 3.4). However, the measured values for ${ }^{241} \mathrm{Am}$ are reportedly "biased high" in this sample because of analytical interferences from other radionuclides with similar gamma spectra. Thus, it is suspected that ${ }^{241} \mathrm{Am}$, if actually present, is found in much lower concentrations than reported. The detection of ${ }^{99} \mathrm{Tc}$ indicates that recycled uranium is present; however, the concentrations do not pose any additional radiological risks.

Samples of liquid $\mathrm{UF}_{6}$ from two natural uranium feed cylinders (nos. 111825 and 111830) from the PGDP indicated measurable concentrations of ${ }^{99} \mathrm{Tc}$ (as high as $17 \mathrm{ppb}_{\mathrm{U}}$ ) and ${ }^{241} \mathrm{Am}$ (as high as $0.12 \mathrm{ppb}_{\mathrm{U}}$ ). These two cylinders - which were filled in 1975 and 1976, respectively —are not DUF $_{6}$ cylinders, nor were they filled with $\mathrm{UF}_{6}$ made from recycled uranium. The technetium and americium contents were introduced as a result of cross-contamination from the feed plant at Paducah, which produced this $\mathrm{UF}_{6}$ and also processed recycled uranium. The measured values for ${ }^{241} \mathrm{Am}$ are reportedly "biased high" because of analytical interferences from other radionuclides with similar gamma spectra. Thus, it is suspected that ${ }^{241} \mathrm{Am}$, if actually present, is found in much lower concentrations than reported.

Samples of liquid DUF ${ }_{6}$ from three PORTS tails cylinders (nos. 111915, 111958, and 117103) that were probably filled in the 1973-1976 period did not show detectable levels of the contaminants of interest. This interval represents the period in which significant reactor returns were being processed through the PORTS.

Six DUF $_{6}$ cylinders from PGDP (nos. 134842, 134848, 134874, 135117, 135130, and 136312) that were filled later than 1988 (not during periods of reactor returns feed) had liquid $\mathrm{UF}_{6}$ samples withdrawn and analyzed. Through use of more sensitive analytical techniques than used previously, the results of these analyses indicated detectable levels of ${ }^{99} \mathrm{Tc}\left(0.087-0.38 \mathrm{ppb}_{\mathrm{U}}\right)$ in 
four of the six cylinders. The TRU contaminants $\mathrm{Np}, \mathrm{Pu}$, and Am were included in the analysis but were not detected.

Americium historically has never been considered a significant contaminant, and most evaluations have not included it in analyses [Ref. 9]. From both reactor production and PUREX process decontamination considerations, the contamination in the recycled uranium sent to the gaseous diffusion plants to be converted to $\mathrm{UF}_{6}$ feed would be expected to be (on a mass basis) as follows: $\mathrm{Np}>\mathrm{Pu}>\mathrm{Am}$. In addition, americium does not form a volatile fluoride in the fluorination process [Ref. 5]. Therefore, even if americium were present in the feed, it would not be expected to have been fed into the cascade. Facility characterization measurements that have detected ${ }^{241} \mathrm{Am}$ have indicated its presence in concentrations roughly half that of ${ }^{239} \mathrm{Pu}$.

It has been suggested that the presence of americium in isolated contamination spots may be due to loss from damaged industrial-grade smoke detectors located in all cells of the cascades. However, a more likely possibility is that its parent ${ }^{241} \mathrm{Pu}$ may have been fed after being contained in the reactor return feed in significant activities but overlooked [Ref. 7]. This may have occurred because, unlike ${ }^{238} \mathrm{Pu}$ and ${ }^{239 / 240} \mathrm{Pu}$, which are alpha emitters, ${ }^{241} \mathrm{Pu}$ has only a very weak (19-keV) beta emission and, therefore, is difficult to measure. As evidence of the presence of

${ }^{241} \mathrm{Pu}$, Rucker cites information on shipments to the Mound Site of ${ }^{239} \mathrm{Pu}$ stock from productions at the Savannah River Site prior to 1962. This information indicated the following mass percentages of $\mathrm{Pu}: 95 \%{ }^{239} \mathrm{Pu}, 4.2 \%{ }^{240} \mathrm{Pu}$, and $0.8 \%{ }^{241} \mathrm{Pu}$. Because of the shorter half-life of ${ }^{241} \mathrm{Pu}$ (14.4 years compared with 24,119 years for ${ }^{239} \mathrm{Pu}$ ), the activity of ${ }^{241} \mathrm{Pu}$ in the original material was 14 times that of the ${ }^{239} \mathrm{Pu}$ activity. A fraction of the ${ }^{241} \mathrm{Pu}$ in reactor returns uranium that was fluorinated in the Paducah feed plant could have made its way into the $\mathrm{UF}_{6}$ feed cylinders as ${ }^{241} \mathrm{PuF}_{6}$ and subsequently into the cascades. The ${ }^{241} \mathrm{Pu}$ would decay in time, producing ${ }^{241} \mathrm{Am}$. This scenario, however, does not explain the presence of ${ }^{241} \mathrm{Am}$ in $\mathrm{DUF}_{6}$ cylinders that were not previously used as feed cylinders.

The conclusion derived from the information summarized above is this: under the most severe loading of reactor returns to the cascades, no measurable $\mathrm{Tc}, \mathrm{Np}$, or $\mathrm{Pu}$ was found dispersed in the $\mathrm{DUF}_{6}$ stream. Therefore, the most significant sources of transuranics in DUF 6 cylinders will occur from cross-contamination from unwashed recycled feed and product cylinders.

\subsection{ESTIMATED CONCENTRATIONS DISPERSED IN DUF ${ }_{6}$ AND IN FEED HEELS}

Based on the large number of observations of $\mathrm{Pu}, \mathrm{Np}$, and $\mathrm{Tc}$ in $\mathrm{DUF}_{6}$ cylinders and the expected behavior of these materials in the cascades, bounding concentrations of $\mathrm{Pu}, \mathrm{Np}$, and Tc dispersed in such cylinders are expected to be near or below the detection limits of these nuclides as discussed in Appendix C. These values are summarized in Table 2.

Based on the mass balance studies of Smith [Ref. 2] and Parks [Ref. 4], estimates (see Appendix $\mathrm{C}$ ) of bounding concentrations of $\mathrm{Pu}, \mathrm{Np}$, and $\mathrm{Tc}$ that would be present in the feed materials heels left in some of the $\mathrm{DUF}_{6}$ cylinders are shown in Table 3. 
Table 2. Bounding concentrations of dispersed contamination in the $\mathrm{DUF}_{6}$ cylinders

\begin{tabular}{cc}
\hline Contaminant & $\begin{array}{c}\text { Upper concentration bounds } \\
\left(\mathrm{ppb}_{\mathrm{U}}\right)\end{array}$ \\
\hline${ }^{238} \mathrm{Pu}$ & 0.00012 \\
${ }^{239} \mathrm{Pu}$ & 0.043 \\
${ }^{237} \mathrm{~Np}$ & 5.2 \\
${ }^{99} \mathrm{Tc}$ & 15.9 \\
${ }^{241} \mathrm{Am}$ & 0.0013 \\
\hline
\end{tabular}

Table 3. Bounding concentrations contamination in the $\mathrm{UF}_{6}$ feed heels material

\begin{tabular}{cc}
\hline Contaminant & $\begin{array}{c}\text { Upper concentration bounds } \\
\left(\mathrm{ppb}_{\mathrm{U}}\right)\end{array}$ \\
\hline${ }^{238} \mathrm{Pu}$ & 5 \\
${ }^{239} \mathrm{Pu}$ & 1,600 \\
${ }^{237} \mathrm{~Np}$ & 54,000 \\
${ }^{99} \mathrm{Tc}$ & $5,700,000$ \\
${ }^{241} \mathrm{Am}$ & 0.57 \\
\hline
\end{tabular}

The values for plutonium and neptunium in Table 3 are well above the action limits discussed in Sect. 3.4, confirming that the design of cylinder-washing facilities may need to consider radiological controls in addition to those required for containment of uranium but they are not so high that prohibitively expensive measures in the cylinder washing plants would be required to wash the cylinders and manage the wastes from the washing operation safely. The values for plutonium and neptunium are also sufficiently high enough that these heels material must be managed as TRU wastes.

\subsection{REGULATORY CRITERIA}

Several regulatory criteria and technical standards for uranium isotopic purity are available as described in Appendix A of the project plan for determination of the historical generation and flow of recycled uranium in the DOE complex [Ref. 10]. 


\subsubsection{U.S. Department of Transportation}

The definitions in 49 CFR 173 contain the following statement: "Unirradiated uranium means uranium containing not more than $10^{-6}$ grams of plutonium per gram of ${ }^{235} \mathrm{U}$ and a fission product activity of not more than $9 \mathrm{MBq}\left(0.24\right.$ milliCuries) of fission products per gram of ${ }^{235} \mathrm{U}$." For the lowest enrichment of uranium considered here $(0.2 \%)$, these values correspond to $2 \mathrm{~g}$ of plutonium per billion grams of total uranium $\left(\mathrm{ppb}_{\mathrm{U}}\right)$ and $28,000 \mathrm{ppb}_{\mathrm{U}}$ for ${ }^{99} \mathrm{Tc}$.

\subsubsection{International Atomic Energy Agency}

International Atomic Energy Agency (IAEA) Safety Standards Series, No. ST-1, "Regulations for the Safe Transport of Radioactive Material," 1996 edition, states the following: "Unirradiated uranium shall mean uranium containing not more than $2 \times 10^{3} \mathrm{~Bq}$ of plutonium per gram of ${ }^{235} \mathrm{U}$, not more than $9 \times 10^{6} \mathrm{~Bq}$ of fission products per gram of ${ }^{235} \mathrm{U}$, and not more than $5 \times 10^{-3} \mathrm{~g}$ of ${ }^{236} \mathrm{U}$ per gram of ${ }^{235} \mathrm{U}$." For depleted uranium $\left(0.2 \%{ }^{235} \mathrm{U}\right)$, these limits translate to the same fission product limit as in 49 CFR 173 on a total uranium basis, $10 \mathrm{ppm}{ }^{236} \mathrm{U}$ per total uranium and $4 \mathrm{~Bq}$ (or $108 \mathrm{pCi}$ ) of plutonium per gram of total uranium. (This corresponds to $1.8 \mathrm{ppb}_{\mathrm{U}}$ ${ }^{239} \mathrm{Pu}$.)

\subsubsection{U.S. Nuclear Regulatory Commission}

In Part (g), 10 CFR 20.1204, Determination of Internal Exposure, states: When a mixture of radionuclides in air exists, licensees may disregard certain radionuclides in the mixture if:

(1) The licensee uses the total activity of the mixture in demonstrating compliance with the dose limits in $\$ 20.1201$ and in complying with the monitoring requirements in $\S 20.1502(b)$;

(2) The concentration of any radionuclide disregarded is less than $10 \%$ of its derived air concentration (DAC); and

(3) The sum of these percentages for all of the radionuclides disregarded in the mixture does not exceed $30 \%$.

Under this regulation, the additional internal exposures of workers to small radionuclide air concentrations may be disregarded.

In Part (b), 10 CFR 20.1502 states: "Each licensee shall monitor (see \$20.1204) the occupational intake of radioactive material by and assess the committed effective dose equivalent to: (1) Adults likely to receive, in 1 year, an intake in excess of 10 percent of the applicable annual limits on intake (ALI) in Table 1, Columns 1 and 2, of appendix B to $\$ 20.1001-20.2402 . .$. ."

In the Appendixes to 10 CFR 20, tables of ALIs and DACs are given, with the information that these are algebraically related - the ALI divided by $2.4 \times 10^{9}$ yields the DAC. This regulation is consistent with 10 CFR 20.1204 , previously quoted, in that $10 \%$ of an estimated exposure within regulatory limits is not considered to be significant. 
The phrase "unimportant quantities of source material" is defined in 10 CFR 40.13. Paragraph (c)(5) exempts from this part "uranium contained in counterweights installed in aircraft, rockets, projectiles, missiles, or stored or handled in connection with installation or removal of such counterweights...," provided that these are labeled as "depleted uranium" and were manufactured under a specific license issued by the U.S. Nuclear Regulatory Commission (NRC) or the U.S. Atomic Energy Commission.

Depleted uranium armor for the M1 series main battle tank is supplied by DOE for installation by Army contractors. The original NRC licenses for the Army, its vendors, and contractors did not contain provisions for trace constituents. These licenses have been amended [Ref. 10] to include the following paragraph: "Transuranics and ${ }^{99} \mathrm{Tc}$ contaminants in uranium depleted in ${ }^{235} \mathrm{U}$ will not exceed a total of $100 \mathrm{pCi} / \mathrm{g}$ of each transuranic and not to exceed $500 \mathrm{pCi} / \mathrm{g}$ total for all transuranics. [The contamination will not exceed $500 \mathrm{pCi} / \mathrm{g}$ of ${ }^{99} \mathrm{Tc}$.]" It should be noted that a fundamental philosophy in this regulatory context is that impacts that are less than $10 \%$ of the guides do not have to be accounted for or recorded. However, for depleted uranium simultaneously containing contaminants of ${ }^{99} \mathrm{Tc},{ }^{238} \mathrm{Pu},{ }^{239} \mathrm{Pu},{ }^{237} \mathrm{~Np}$, and ${ }^{241} \mathrm{Am}$ - with each present at the limit - an increase of approximately $19 \%$ in potential inhalation dose over that of depleted uranium alone would occur.

\subsubsection{American Society for Testing and Materials (ASTM)}

"Standard Specification for Uranium Hexafluoride for Enrichment," ASTM Standard C 787-96 [Ref. 11], defines "commercial natural uranium" as being distinct from "virgin natural uranium." Commercial natural uranium, by this industry standard, should contain less than $20,000 \mathrm{ppb}{ }^{236} \mathrm{U}$ and less than $1 \mathrm{ppb}{ }^{99} \mathrm{Tc}$. The standard states that the ${ }^{236} \mathrm{U}$ limit is a threshold for more detailed isotopic analysis and is not a limit for worker radiological protection. Virgin natural uranium does not contain detectable amounts of ${ }^{236} \mathrm{U}$. This standard also sets limits of $0.84 \%$ $\left(8.4 \times 10^{6} \mathrm{ppb}\right)$ for the maximum ${ }^{236} \mathrm{U}$ content and $500 \mathrm{ppb}$ for the maximum ${ }^{99} \mathrm{Tc}$ content of reprocessed uranium. It specifies a limit for total alpha activity from $\mathrm{Np}$ and $\mathrm{Pu}$ allowed in "reprocessed $\mathrm{UF}_{6}$ " of 1500 disintegrations per minute (dpm) per gram of U for the combined alpha activity from $\mathrm{Np}$ and $\mathrm{Pu}$. If the only transuranic element present is ${ }^{237} \mathrm{~Np},{ }^{239} \mathrm{Pu}$, or ${ }^{241} \mathrm{Am}$, this activity level corresponds to $1000 \mathrm{ppb}^{237} \mathrm{~Np}, 11 \mathrm{ppb}{ }^{239} \mathrm{Pu}$, and $12.5 \mathrm{ppb}^{241} \mathrm{Am}$.

\subsubsection{DOE Action Levels}

This section discusses the action levels for the impurities ${ }^{99} \mathrm{Tc},{ }^{237} \mathrm{~Np},{ }^{239} \mathrm{Pu}$, and other TRU isotopes in recycled uranium at which additional radioactive protection practices should be reevaluated. These limits for impurities are the levels plant operators will accept and handle in recycled uranium without having to consider the radiological threat of the impurity. These thresholds, which are isotope specific, are called "suggested action levels." The action level for an impurity is a threshold for consideration of the impurity as a radiological threat separate from uranium. Even at these thresholds, no specific actions may be necessary beyond a reevaluation of the radiological protection practices.

The draft results of a study of the flow of TRU nuclides within the system of gaseous diffusion plants [Ref. 10] that is currently in progress are now being reviewed by DOE. Appendix A of 
this study has assessed that for inhalation exposure, ${ }^{99} \mathrm{Tc}$ at any concentration in a uranium stream (where it is assumed that radiological controls appropriate for uranium are being applied) poses no additional exposure risk over that posed by the uranium itself. Thus, we would expect that the vendors would not need to provide any additional radiological controls in the conversion plants to reduce risks from the ${ }^{99} \mathrm{Tc}$ that might be present in the $\mathrm{DUF}_{6}$ cylinders.

The study also developed action levels (based on inhalation exposure) for ${ }^{236} \mathrm{U},{ }^{237} \mathrm{~Np}$, several $\mathrm{Pu}$ isotopes, and ${ }^{241} \mathrm{Am}$. The value of these action levels depends on the chemical form of material and its chemical behavior in lung tissue. This study reports that the most-restrictive action limits (expressed as grams per billion grams of uranium, $\mathrm{ppb}_{\mathrm{U}}$ ) in depleted uranium are as follows:

$\begin{array}{lc}{ }^{237} \mathrm{~Np} & 189 \\ { }^{238} \mathrm{Pu} & 0.0115 \\ { }^{239} \mathrm{Pu} & 2.17 \\ { }^{240} \mathrm{Pu} & 0.585 \\ { }^{241} \mathrm{Pu} & 0.0066 \\ { }^{241} \mathrm{Am} & 0.039\end{array}$

These limits are appropriate for materials designated as "lung retention class D," which includes heels materials likely to be found in empty $\mathrm{DUF}_{6}$ cylinders. Some compounds in this class are $\mathrm{UF}_{6}, \mathrm{UO}_{2} \mathrm{~F}_{2}$, and $\mathrm{UO}_{2}\left(\mathrm{NO}_{3}\right)_{2}$. These limits are reported to be more conservative than those found in 10 CFR 20.1204.

\subsubsection{Threshold Quantities for DOE Category 2 Nuclear Facilities}

DOE nuclear facilities are designated Category 1, Category 2, or Category 3, depending on the hazard associated with the specific facility. Category 1 nuclear facilities include Class A reactors, and nonreactor nuclear facilities are Category 2 or Category 3, depending on hazards and operations. Category 3 is defined to encompass facilities that are primarily laboratory operations, as well as low-level-waste handling facilities and research equipment that possess less than the Category 2 quantities of material and are considered to represent a low hazard. DOE Order 5480.23 states that facilities should be classified as Category 3 if only the potential for "significant localized consequences exists." Essentially all industrial facilities have a potential for significant localized consequences because the possibility of injury to workers from typical industrial accidents is always present. However, Category 3 facilities pose additional hazards due to the presence of radionuclides. To establish a system based on inventories, DOE has modified the U.S. Environmental Protection Agency definitions of reportable quantities for radionuclides contained in 40 CFR 302.4, Appendix B. The values for radionuclides represent levels of material which, if released, would produce less than 10-rem doses at $30 \mathrm{~m}$ based on 24-h exposure.

Category 2 threshold quantities are given in DOE-STD-1027-92, and Table 4 summarizes these values for selected radionuclides. Table 4 compares the Category 2 facility threshold values with

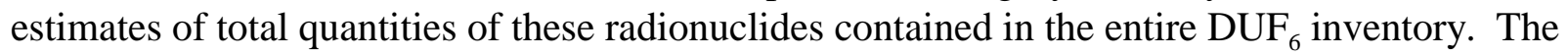
maximum inventory value for ${ }^{238} \mathrm{U}$ shown assumes that in a $\mathrm{DUF}_{6}$ conversion facility, the portion of the operation that would contain the highest inventory of uranium-other than the DUF $_{6}$ 
Table 4. Comparison of Category 2 radiological facility threshold quantities with estimated total inventories

\begin{tabular}{ccc}
\hline Radionuclide & $\begin{array}{c}\text { Threshold quantity } \\
(\mathrm{g})\end{array}$ & $\begin{array}{c}\text { Maximum inventory } \\
(\mathrm{g})\end{array}$ \\
\hline${ }^{238} \mathrm{U}$ & $7.10 \times 10^{8}$ & $6.7 \times 10^{6 a}$ \\
${ }^{99} \mathrm{Tc}$ & $2.3 \times 10^{8}$ & $804,000^{b}$ \\
${ }^{239} \mathrm{Pu}$ & 900 & $24^{b}$ \\
${ }^{237} \mathrm{~Np}$ & $8.3 \times 10^{4}$ & $17,800^{b}$ \\
${ }^{241} \mathrm{Am}$ & 16 & $c$ \\
\hline
\end{tabular}

${ }^{a}$ Assumes that the inventory of the DUF $_{6}$ feed station and cylinder wash facility consists of 10 full 48 -in. cylinders at any one time.

${ }^{b}$ See Table C.4 in Appendix C.

${ }^{c}$ Data are not available.

cylinder and product storage yards-would be the $\mathrm{DUF}_{6}$ feed station, where it is assumed that a total of ten cylinders would be present in autoclaves and hot-air furnaces and in standby for loading. This table indicates that it is physically impossible for any conversion facility to exceed the Category 2 thresholds; therefore, these facilities can be managed as Category 3.

\subsubsection{Comparison of Bounding Limits with Regulatory Criteria}

The bounding concentrations estimated for transuranics and technetium dispersed in $\mathrm{DUF}_{6}$ and residing in the feed heels in some DUF $_{6}$ cylinders are summarized in Table 5. Values are also compared with some of the regulatory limits previously discussed.

\subsection{IMPORTANT INFORMATION GAPS}

Compilations of previously documented measured concentrations of $\mathrm{Np}, \mathrm{Pu}$, and Tc in PGDP DUF $_{6}$ cylinders prior to 1973 have not been found; thus, little information exists in this regard to guide the strategy. No information on feed or tails quantities, equivalent to that compiled for PGDP, was available for this study from ORGDP or PORTS. 
Table 5. Comparison of contaminant concentrations with various regulatory limits

\begin{tabular}{|c|c|c|c|c|c|c|c|}
\hline \multirow{2}{*}{ Nuclide } & \multirow{2}{*}{$\begin{array}{l}\text { Bounding } \\
\text { concentration } \\
\text { in } \mathrm{UF}_{6} \\
\left(\mathrm{ppb}_{\mathrm{U}}\right)\end{array}$} & \multirow{2}{*}{$\begin{array}{c}\text { Bounding } \\
\text { concentration } \\
\text { in feed heels } \\
\left(\mathrm{ppb}_{\mathrm{U}}\right)\end{array}$} & \multicolumn{2}{|c|}{$\begin{array}{l}\text { NRC license } \\
\text { limit }^{a}\end{array}$} & \multirow{2}{*}{$\begin{array}{l}\text { DOE } \\
\text { action } \\
\text { limits }^{a} \\
\left(\mathrm{ppb}_{\mathrm{U}}\right)\end{array}$} & \multicolumn{2}{|c|}{ ASTM C787-96 } \\
\hline & & & $\mathrm{pCi} / \mathrm{g} \mathrm{U}$ & $\mathrm{ppb}_{\mathrm{U}}$ & & $\begin{array}{c}\mathrm{dpm} / \mathrm{g} \\
\mathrm{U}\end{array}$ & $\mathrm{ppb}_{\mathrm{U}}$ \\
\hline${ }^{238} \mathrm{Pu}$ & 0.00012 & 5 & 100 & 0.006 & 0.012 & 1500 & 0.039 \\
\hline${ }^{239} \mathrm{Pu}$ & 0.043 & 1,600 & 100 & 1.6 & 2.2 & 1500 & 10.9 \\
\hline${ }^{237} \mathrm{~Np}$ & 5.2 & 54,000 & 100 & 142 & 189 & 1500 & 958 \\
\hline${ }^{99} \mathrm{Tc}$ & 15.9 & $5,700,000$ & 500 & 29 & $\mathrm{~N} / \mathrm{A}^{c}$ & N/A & 500 \\
\hline${ }^{241} \mathrm{Am}$ & 0.0013 & 0.57 & 100 & 0.029 & 0.039 & 1500 & 0.20 \\
\hline
\end{tabular}

${ }^{a}$ See Ref. 10.

${ }^{b}$ See Ref. 11.

${ }^{c} \mathrm{~N} / \mathrm{A}=$ not applicable.

\section{CHARACTERIZATION INFORMATION NEEDED BY VENDORS}

Assessments of the needed information were based on limited discussions with persons knowledgeable of design considerations. The information would be required for detailed design and operating considerations and for cost estimates, which will be the basis of bids. The specific information with respect to characteristics of the cylinder inventory that vendors need to prepare an accurate bid is best defined by the vendors themselves. However, it was not feasible to solicit their input on this subject without compromising the integrity of a subsequent procurement.

\subsection{VENDORS' DESIGN REQUIREMENTS}

Vendors' design requirements with respect to transuranics and fission products are most likely to include the selection and design of equipment and procedures for (1) radiological controls and health physics and (2) disposition of effluent streams. The former area includes the protection of personnel (e.g., via protective clothing and shielding) and environmental issues concerning conversion plant operations and the eventual decontamination and decommissioning of the plant. The latter area includes the final disposition of the converted forms of the depleted uranium; the disposal of the empty cylinders; and the treatment and disposal of waste streams, including cylinder wash solutions.

\subsection{CHARACTERIZATION INFORMATION NEEDED}

The selection and design of equipment and procedures needed for protection of both personnel and the environment will require knowledge of the quantities of contaminants in the total inventory of $\mathrm{DUF}_{6}$ cylinders and the pattern of contaminant distribution among the cylinders. 
Further information is needed on how contaminants are distributed within cylinders and how the various contaminant species are likely to behave when cylinders are emptied during the feeding of $\mathrm{DUF}_{6}$ into the conversion process. As each cylinder is emptied, the designer needs to know (1) the quantity of the contaminants originally contained in the cylinder that will be carried over into the conversion process equipment and (2) how much of the contaminant will remain in the cylinder. The vendors will need to design the conversion facility to address restriction of contaminants from the conversion process downstream of the feed area (or to manage such material if it is introduced) and to provide means for safely handling contaminated cylinders and disposition of waste streams generated. The completeness of this information affects the safety factors employed in the designs and, consequently, can reduce costs. This has the effect of minimizing added costs from overdesign or vendor change orders.

Thus, characterization of the cylinders must include measurements of the quantities and distribution of transuranics and fission products. Specifically, the characterization should provide measurements of (1) quantities of these contaminants present in the $\mathrm{DUF}_{6}$ that can be volatilized or entrained into the conversion plant and (2) quantities that remain in the emptied cylinders (either attached to cylinder walls or as nonvolatile, consolidated heels).

During the development of this characterization strategy, statistical sampling approaches were investigated because use of such techniques could minimize the extent of testing if further sampling and analysis were required. Statistical methodology could maximize the estimated information concerning the distribution of the TRU and technetium contaminants and, at the same time, require testing of only a limited number of additional cylinders. Although further sampling and analysis (beyond that performed for this study) were determined to be unnecessary, Appendix B describes the statistical methodology developed for this purpose.

\subsection{POTENTIAL COST CONSEQUENCE FOR ENCOUNTERING CONTAMINANT CONCENTRATIONS HIGHER THAN A REPORTED BOUNDING VALUE}

In developing this strategy, it is assumed that in the RFP, vendors have access to the existing process knowledge and the results of the characterization of the Tc, $\mathrm{Np}, \mathrm{Pu}, \mathrm{Am}$, and other constituents for which a level of contaminant content is stated. It is also assumed that this level has some uncertainty and that somewhat higher values could be encountered during the course of processing the entire inventory of $\mathrm{DUF}_{6}$ cylinders. Thus, vendors should be notified of the potential presence of these contaminants so that they can design the conversion plants to handle the materials safely. The question to be addressed is this: What additional costs will the vendor incur if some cylinders have higher contaminant levels than those provided to them by the characterization program?

Prudent designs will provide filters in the $\mathrm{DUF}_{6}$ feed stream to the conversion plant to limit carryover of contaminant particulates into the conversion plant. (No truly volatile gaseous TRU contaminants are expected, based on the chemistry of the contaminants.) These filters would restrict contamination from the TRU nuclides to upstream equipment. Particulates could contain not only the nuclides previously mentioned but also the decay products of uranium. Such filters prevent additional decontamination and decommissioning costs associated with the majority of 
the conversion process equipment at the end of the plant life and help minimize the costs of radiological controls during operations.

Truly volatile technetium species may be encountered that would pass through a simple filter used to trap transuranics. As discussed previously, technetium is not expected to present additional exposure risks during conversion operations and eventual decontamination and decommissioning of the process equipment. If elevated levels of technetium could interfere with any potential beneficial uses that are contemplated for the depleted uranium, then equipment for chemically trapping technetium species might be specified in the RFP.

The other affected areas are those for cylinder handling and washing. These areas are assumed to be designed for safe handling of contaminants and safe disposal of the wastes. Equipment designs are affected primarily by the total quantities of materials to be handled and to only a minor extent by their contaminant concentrations per se. The primary exposure hazards come from inhalation and ingestion, rather than from external exposure to penetrating ionizing radiation. Thus, the protective measure that the processes must provide is containment, rather than shielding. Total quantities of these contaminants are expected to be very small compared with those for other wastes that the same equipment must process. (Only a small fraction of the quantities shown in Table C.5 in Appendix $\mathrm{C}$ is expected to be present in the limited number of cylinders containing reactor return feed heels remaining in the inventory.) Therefore, it is not likely that appreciable additional costs will be incurred for handling higher concentrations of these materials in a limited number of cylinders.

When transuranics are concentrated in cylinder heels, the possibility exists for generation of TRU wastes. When the $\mathrm{DUF}_{6}$ is vaporized from a tails cylinder into the conversion process, any nonvolatile contaminants are likely to become concentrated in the small quantity of residual heels by factors of about 400 - the contaminants originally contained in about 10 metric tons (MT) of $\mathrm{UF}_{6}$ are finally contained in about $50 \mathrm{lb}$ of $\mathrm{UF}_{6}$ in the heels (see Table C.4, Appendix C). Further accumulation of heels can occur if contents of cylinders are introduced into the cascades and the cylinders are reused without cleaning. Thus, small initial concentrations of transuranics (possibly below detection limits) can result in residual waste solids that must be handled as TRU waste (where total TRU activity is $100 \mathrm{nCi} / \mathrm{g}$ or higher in the solids). For example, ${ }^{241} \mathrm{Am}$ at an initial (undetectable) concentration of only $0.075 \mathrm{ppb}$ might be concentrated in heels material to a concentration of $30 \mathrm{ppb}$. At this concentration, its specific activity in the solid heel is $100 \mathrm{nCi} / \mathrm{g}$, which means that the material must be managed as a TRU waste. Only direct measurements of concentrations of transuranics in heels can predict the extent to which TRU waste will be generated.

Generation of TRU waste has only minimal cost impact on the conversion program. All direct costs associated with transportation and disposal of TRU wastes at the Waste Isolation Pilot Plant (WIPP) would be borne by the DOE Environmental Management Program. Incremental costs to DOE for disposal, however, have been estimated at $\$ 5072$ per cubic meter for contacthandled TRU waste and $\$ 21,448$ per cubic meter for remote-handled TRU waste [Ref. 12]. Assuming $20 \mathrm{~kg}$ of waste generation per cylinder and a factor-of-3 volume increase for waste treatment, these incremental costs would translate to TRU disposal costs of $\$ 100$ per cylinder if the waste were contact handled (likely) or $\$ 400$ per cylinder if the waste required remote 
handling (less likely). The costs for characterization to ensure compliance with the WIPP waste acceptance criteria (WAC) and packaging for transportation to WIPP would be incurred by the conversion program.

\subsection{OTHER CHARACTERISTICS THAT SHOULD BE INCLUDED IN CYLINDER CHARACTERIZATION}

We have evaluated the need for or desirability of analyzing for cylinder contaminants in addition to $\mathrm{Pu}, \mathrm{Np}, \mathrm{Am}$, and Tc [see the "Other Chemical Impurities" section in Appendix D] and for other characteristics that potential bidders need to know. The results of the evaluation are summarized in Sects. 4.4.1-4.4.4.

\subsubsection{Radiochemical Impurities (Other than Np, Pu, Am, and Tc)}

Several fission products directly related to reactor return feed bear sufficient chemical similarity to $\mathrm{UF}_{6}$ that a concern existed that these radioistopes could (to a degree) accompany the $\mathrm{UF}_{6}$ in the feed stream. The fission products ${ }^{95} \mathrm{Zr},{ }^{103} \mathrm{Ru},{ }^{106} \mathrm{Ru},{ }^{141} \mathrm{Ce},{ }^{144} \mathrm{Ce}$, and ${ }^{125} \mathrm{Sb}$ have been cited as isotopes of potential concern. However, when viewed from the perspective of decades, the halflives of these species are fairly short. The likelihood of any of these species being present in the tails in appreciable quantity does not appear to warrant a sampling campaign directed at their detection.

Analyses of recent $\mathrm{DUF}_{6}$ cylinders revealed the presence of ${ }^{241} \mathrm{Am}$. Americium isotopes, which are produced by beta decay of plutonium, would be expected in the reactor return streams processed in the feed plants. Fluorides of americium are nonvolatile and could have been introduced into feed cylinders and, from there, into the cascades by entrainment processes. Americium-241 results from beta decay of ${ }^{241} \mathrm{Pu}$. Its presence in the cascades could also be explained by volatilization of ${ }^{241} \mathrm{PuF}_{6}$ into the cascades and its subsequent decay. Thus, any future analyses of cylinder contents should include tests for detection of ${ }^{241} \mathrm{Am}$.

\subsubsection{Impurities with the Potential to Affect Conversion Processes}

The evaluation of this category revealed no recognized impurities that could interfere with conversion processes per se. A special case of chemical contamination of cylinders involves PCBs. In a small subset of the cylinders, PCB contamination has been found on the external surfaces of cylinders at ORGDP. Although this contamination would not have a direct impact on the conversion process, it would be of concern in dealing with the effluents from autoclaving. Cylinders that have PCB-contaminated coatings will need to be identified and cleaned prior to heating in autoclaves, or the autoclave effluents must to be treated to destroy PCBs. Vendors need to know the extent of such contamination to design the most effective approach for dealing with PCBs. 


\subsubsection{Cylinder Handling Characteristics}

Sufficient information and modeling methods for estimating distributions of wall thicknesses for the cylinder inventory already exist [see the "Physical Condition of Cylinders" section in Appendix D]. It does not appear necessary to gather additional information on wall thickness in the proposed characterization program.

The ability to feed $\mathrm{DUF}_{6}$ to conversion facilities at design rates is very dependent on (1) how the condition of the feed cylinders rates with respect to conformance with pressure vessel codes, (2) whether the cylinders are filled in excess of their rated capacity, and (3) whether they are stored under excess pressure. Figure 1 shows an approximate summary of conditions of the cylinder inventory with respect to information required to qualify them for heating in autoclaves for sampling or feeding to a conversion plant. This figure shows that a majority of cylinders manufactured in the 1950s, 1960s, 1970s, and 1980s exceed their standard fill limit (i.e., are overfilled). Cylinders manufactured before 1973 have noncertified fill volumes, and only a sporadic few are code stamped. Cylinders manufactured in the 1940s have no fabrication information.

A thorough understanding of these conditions is required prior to design and construction of the cylinder feed facility. To determine how many cylinders qualify for emptying via steam autoclaves, a comprehensive summary and analysis should be performed to provide the following information: (1) how many cylinders have deficiencies in certification, (2) how many are

ORNL DWG 2000-116

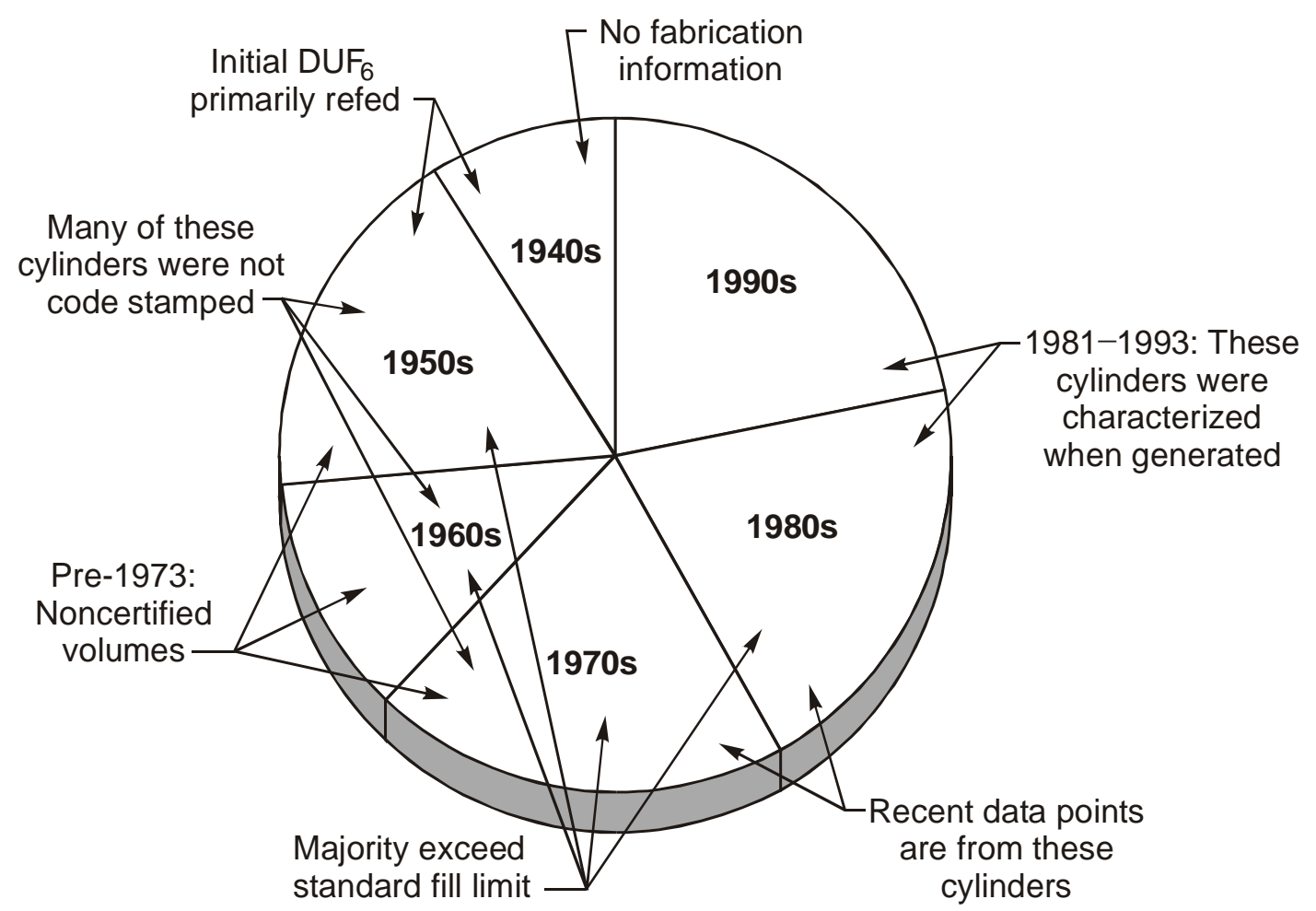

Fig. 1. Conformance characteristics of $\mathrm{DUF}_{6}$ cylinders by fabrication date. 
overfilled and overpressurized, and (3) how many are damaged. This information is necessary to assess the mix of hot-air furnaces and steam autoclaves required to achieve the desired feed rates. This study has uncovered numerous difficulties in identifying cylinders that can be heated in autoclaves for liquid sampling.

\subsubsection{Additional Useful Information}

The isotope ${ }^{236} \mathrm{U}$ would be expected to form in the recycled uranium. The characterization program should assay for this isotope as an indicator of the presence and extent of reactor return material associated with a $\mathrm{DUF}_{6}$ cylinder.

\section{METHODOLOGY FOR ANALYSIS OF CYLINDER CONTENTS}

Because the contents of $\mathrm{DUF}_{6}$ cylinders are fed to the conversion plant, the designer needs to know (1) the quantity of the cylinder contaminants that will be carried over into the conversion process equipment and (2) how much of the contaminant will remain in the cylinders. The vendors need to design the conversion facility (1) to address restriction of contaminants from the conversion process downstream of the feed area (or management of contamination if such material is introduced) and (2) to provide a means for safely handling contaminated cylinders and disposing of waste streams generated.

Thus, characterization must include measurements of the quantities and distribution of transuranics and fission products within cylinders. Specifically, characterization of the cylinder contents should provide information on (1) quantities of the contaminants of interest in the $\mathrm{DUF}_{6}$ that can be volatilized or entrained into the conversion plant and (2) quantities that remain in the emptied cylinders (either attached to cylinder walls or in the form of nonvolatile heels).

The types of analytical procedures and the information that is gained from each of these are discussed in Sects. 5.1-5.7.

\subsection{UNFILTERED LIQUID DUF 6 SAMPLES}

These samples will measure both soluble and insoluble species that are assumed to be well dispersed throughout the liquid $\mathrm{DUF}_{6}$ contained in the cylinder. From these measured concentrations, the total amount of soluble and insoluble transuranics dispersed in the liquid $\mathrm{DUF}_{6}$ can be calculated. These samples will not provide information on insoluble material sequestered in an existing insoluble heel or on material attached to the metal surface of the cylinder. Insoluble transuranics dispersed in the liquid $\mathrm{DUF}_{6}$ are also nonvolatile. Insoluble (nonvolatile) transuranics can be transferred from cylinders to the conversion plant only as entrained solid particulates during conditions of high vapor flow rates.

Based on the December 1999 sampling campaign performed by Bechtel Jacobs Company LLC, the cost per cylinder for sampling and analysis is $\$ 10,000$ for cylinders that are relatively accessible and present no handling problems in the autoclave. 
Advantages. Converting the $\mathrm{DUF}_{6}$ to a liquid provides for a high probability that the sample will be homogeneous and representative. However, if the contaminants remain associated with massive heels solids, they will not be retrieved as part of the sample. The equipment for this type of measurement currently exists.

Disadvantages. This approach could only indicate concentrations of contaminants dispersed in the $\mathrm{DUF}_{6}$ and thus would not provide needed information on how much material would remain in the empty cylinders. Because the cylinders must be heated in an autoclave to convert the $\mathrm{DUF}_{6}$ to a liquid, the cylinder must be in good physical condition and meet the acceptance criteria for autoclaving. The only existing autoclaves that are available to do this are owned and managed by the U.S. Enrichment Corporation (USEC), which is not currently authorized to sample and test all models of cylinders of interest. USEC has indicated that it would require 6 months to modify its regulatory authorizations and procedures, at an approximate cost of $\$ 120,000$. Autoclaves are in use at PORTS and PGDP but not at the East Tennessee Technology Park (formerly ORGDP). Therefore, any cylinders stored at the East Tennessee Technology Park that are selected for sampling would have to be transported to PORTS or PGDP, which adds to the cost. The sampling schedule would be limited by autoclave availability, which is dictated by USEC's need for the autoclaves.

\subsection{FILTERED LIQUID DUF 6 SAMPLES}

The technique for filtered samples is described in ASTM C761-96 [Ref. 13]. These samples will measure the soluble forms of transuranics remaining in the liquid $\mathrm{DUF}_{6}$ after the insoluble material has been filtered out. The soluble forms of the transuranics have the potential to be volatile and thus would be transferred as vapor species in the $\mathrm{DUF}_{6}$, even at low vapor flow rates from cylinders to the conversion plant. Costs, advantages, and disadvantages are identical to those described in Sect. 5.1.

\subsection{GENERATION OF HEELS BY EMPTYING CYLINDERS}

After taking filtered and unfiltered liquid $\mathrm{DUF}_{6}$ samples, the cylinder would be emptied to provide access to an existing heel if the cylinder had one from prior use and to generate a representative heel from insoluble constituents dispersed in the $\mathrm{DUF}_{6}$. In these measurements, it is important that cylinders be heated in autoclaves to drive off the vapor at high rates typical of the feed rates expected in a conversion plant. Vaporizing the $\mathrm{DUF}_{6}$ at high rates enhances the extent to which transuranics that are dispersed in the $\mathrm{DUF}_{6}$ would be entrained in the vapor and provides a design basis for the loading of any filtration systems that may be contemplated in the conversion plant. If hot-air furnaces are required to vaporize the contents of a cylinder (for cases where the cylinder could not be pressurized to the levels achieved in autoclave heating), the vaporization rates would be much lower and the extent of TRU entrainment would also be lower. With both methods of emptying the cylinders, most of the transuranics would be expected to remain as heels in the otherwise empty cylinder. 


\subsection{HEELS ANALYSIS FROM CYLINDER WASHING}

The composition of a heel that remains in a cylinder would be determined by dissolving the heel in a wash solution and then sampling and analyzing the solution. It is assumed that the heel constituents of interest are completely dissolved in the wash solution. In addition to constituent concentrations in the wash solution, other measurements to be made are (1) the initial quantity of heels left after cylinder emptying (obtained by weighing the cylinder before and after emptying), (2) the final quantity of heels left after washing (also obtained by weighing the cylinder after washing), and (3) the quantity of the wash solution that was used and analyzed. Item (2) will be a measure of the completeness of material balance and a measure of potential errors in this type of measurement.

\subsection{NONDESTRUCTIVE ANALYSIS}

Nondestructive analysis (NDA) techniques such as external gamma spectroscopy, directional neutron analysis, or neutron interrogation are potentially attractive for determining the presence of radioactive nuclides in closed containers because the measurements can be performed quickly (two cylinders per hour) and inexpensively (\$200 per cylinder). However, these techniques lack the required sensitivity to detect plutonium and neptunium at low overall concentrations $(0.002-350 \mathrm{ppb}$ expected) in a matrix that is predominantly uranium. The techniques are most suitable for bulk-type measurements of constituents whose concentrations are above the range of the most optimistic levels of detection, 500-1000 ppb. Thus, NDA techniques are not suitable for this application.

\subsection{SOLID SAMPLE RETRIEVAL BY A CORING DRILL}

Using this approach, a solid sample of approximately $500 \mathrm{~g}$ would be captured through the cylinder access port using a coring drill. This method and the equipment to perform the process do not currently exist; however, Oak Ridge National Laboratory has proposed a concept that could be developed. The estimated cost (in FY 2000 dollars) for development of the methodology and equipment is $\$ 438,000$, with the work to be accomplished over a 6-month period. The estimated cost for performing the sampling and analysis once the device is operational is approximately $\$ 3400$ per sample.

Advantages. The samples could be retrieved from the cylinders in the field. There would be no limitations due to the condition of the cylinder that might prevent transportation or heating in an autoclave. Schedule constraints could be minimized by fabricating several field-sampling devices and obtaining samples from multiple cylinders in parallel.

Disadvantages. This approach could only indicate concentrations of contaminants dispersed in the $\mathrm{UF}_{6}$ and thus would not be able to provide all the information that vendors need. Questions have been raised concerning how representative a small core sample would be of the entire cylinder contents. Because this technique has not been performed before, the possibility of failure is not negligible. Failure would significantly impact the overall project schedule and cost. No equipment currently exists; consequently, a lag time would exist before any sampling can 
begin using this methodology. This approach must be accepted in the Bechtel Jacobs Company's safety basis, new operating procedures must be developed and approved, and operators must be trained regarding these new procedures.

\subsection{CONCLUSIONS}

The only method for analyzing cylinder contents that provides all the highest-quality information that vendors need involves (1) retrieval of liquid samples using autoclaves prior to emptying a DUF $_{6}$ cylinder, followed by (2) cylinder washing for heels analysis. This would be the preferred approach if additional sampling is needed, but a long period of time would be required to achieve results.

An acceptable alternative is to retrieve liquid $\mathrm{DUF}_{6}$ samples from $\mathrm{DUF}_{6}$ cylinders and to analyze constituents in heels from existing empty cylinders; however, this approach will produce information of much more limited use. Another disadvantage is the lengthy schedule required for sampling cylinder models of interest.

\section{RECOMMENDED CHARACTERIZATION STRATEGY}

A large body of process history on transuranics in the gaseous diffusion process has been compiled, reviewed, and analyzed, including the results from historical sampling of more than $150 \mathrm{DUF}_{6}$ cylinders for dispersed transuranics. All existing samples of these cylinders show nondetectable or very low levels of transuranics in the DUF $_{6}$. Consequently, all available evidence indicates that no additional radiological controls are needed. The controls to safely contain the uranium itself will provide adequate protection against the very low levels of TRU contamination present. Recent measurements of the TRU constituents in heel materials have been made. The results confirm previous estimates that the TRU concentrations are sufficiently high that radiological controls must be provided to accommodate the added exposure risk that these materials would introduce.

Analysis and review of the compiled information and the expected chemical behavior of the TRU constituents lead to the following conclusion: even without additional sampling, sufficient information exists within the current body of knowledge to provide vendors with an adequate basis for design of facilities that can operate safely. Thus, no additional cylinder sampling is recommended.

If such sampling were ever required, the best approach to measuring the concentrations of the dispersed forms of transuranics in $\mathrm{DUF}_{6}$ cylinders is direct sampling of liquid DUF . This process involves heating the cylinder in a steam autoclave to melt the solid DUF ${ }_{6}$. The best approach for analyzing for the concentration of transuranics that would be present in the residual heels is to (1) identify existing cylinders that have been emptied previously, leaving the feed material heel behind; (2) wash that material from the cylinder; and (3) analyze the wash solution for the contaminants. 
The constituents to be analyzed for in any measurements made on cylinders are ${ }^{237} \mathrm{~Np},{ }^{238} \mathrm{Pu}$, ${ }^{239} \mathrm{Pu},{ }^{241} \mathrm{Am},{ }^{236} \mathrm{U}$, and ${ }^{99} \mathrm{Tc}$.

A separate characterization of cylinder coatings should also be performed to determine the extent and levels of PCB contamination. The populations to examine would be the total inventories at each of the three gaseous diffusion plants. An additional study is required to define the necessary characterization program for PCBs.

Furthermore, a verification of the compliance of the cylinder inventory with DOT regulations and the ASME pressure vessel codes should be performed. Compliance with these codes determines the ability of a cylinder to be readily transported off-site and to undergo heating and unloading into the proposed conversion facility. This verification includes a review of existing information and collection of additional data (i.e., actual volumes from cylinder nameplates) to strengthen the reliability of the compliance indicators in the cylinder inventory database.

\section{REFERENCES}

1. Brumburgh, G. P., Avci, H. I., Steindler, M. J., Bowers, D. L., Sengupta, S. K., and Randlich, E., A Peer Review of the Strategy for Characterizing Transuranics and Technetium Contamination in Depleted UF ${ }_{6}$ Tails Cylinders, Lawrence Livermore National Laboratory, Livermore, Calif., June 13, 2000.

2. Smith, R. F., Historical Impact of Reactor Tails on the Paducah Cascade, KY/L-1239, Paducah, Ky., March 1984.

3. Environmental Management and Enrichment Facilities, Recycled Uranium Mass Balance Project, Paducah Gaseous Diffusion Plant Site Report, Final Draft, Bechtel Jacobs Company LLC, BJC/PGDP-167, June 14, 2000.

4. Parks, J. W., et al., Recycled Uranium Processed at the Oak Ridge, Paducah, and Portsmouth Gaseous Diffusion Plants, U.S. Department of Energy, Oak Ridge Operations, Oak Ridge, Tenn., September 30, 1999 (Draft).

5. Gibson, J. K., and Haire, R. G., J. Alloys Compounds 181, 23 (1992).

6. Pulley, H., and Harris, R. L., Removal of Trace Quantities of Neptunium and Plutonium Fluorides from Uranium Hexafluoride, KY-662, Paducah Gaseous Diffusion Plant report, Paducah, Ky., May 15, 1975.

7. Beverly, C. R., Paducah Gaseous Diffusion Plant, "Np-237, Pu-239/240, and Tc-99 in Paducah Gaseous Diffusion Plant (PGDP) Tails and Product," letter to J. C. Hodges, Paducah Gaseous Diffusion Plant, March 19, 1992.

8. Taylor, M. S., Bechtel Jacobs Company LLC, personal communications to J. R. Hightower, ORNL, February 10, April 9, and September 11, 2000. 
9. Rucker, T. L., Isotopic Distribution of Contamination Found in the U.S. Department of Energy Gaseous Diffusion Plants, Science Applications International Corporation, Oak Ridge, Tenn., unpublished report prepared for the Reindustrialization Program (Bechtel Jacobs Company LLC) and the National Center of Excellence for Metal Recycle (U.S. Department of Energy), October 29, 1999.

10. Office of Environment, Safety, and Health, U.S. Department of Energy, Historical Generation and Flow of Recycled Uranium in the DOE Complex, Project Plan, February 2000. [This report may be accessed at the following URL: http//tis.eh.doe.gov/legacy/mbp/mbp.html. Click on the link to "Project Plan" to view the body of the report; click on the link to "Appendix A" to view "Prioritization of Uranium Flows" (the first appendix).]

11. "Standard Specification for Uranium Hexafluoride for Enrichment," ASTM C787-96, Sect. 5.6, American Society for Testing and Materials, Philadelphia, Pa., 1999.

12. Riner, G. L., U.S. Department of Energy, Oak Ridge Operations, personal communication to J. R. Hightower, ORNL, February 3, 2000.

13. "Standard Test Methods for Chemical, Mass Spectrometric, Spectrochemical, Nuclear, and Radiochemical Analysis of Uranium Hexafluoride," ASTM C761-96, American Society for Testing and Materials, 2000. 
Appendix A

Task Statement for Developing a Characterization Strategy

Project

Title:

DUF $_{6}$ Cylinder Sampling and Analysis Strategy

Estimated Cost (not to exceed): $\quad \$ 45,000 \quad$ (B\&R CD 1015010$)$

\section{Task Description:}

The objective of this task is to develop a strategy to sample a statistically significant number of DUF $_{6}$ cylinders to support a release of a request for proposal for a fixed price contract for conversion services. This task will determine the constituents/conditions that must be characterized to provide vendors information needed for design of conversion facilities. As a minimum $\mathrm{Np}, \mathrm{Pu}$, and $\mathrm{Tc}$ concentrations and cylinder condition (parameters that would determine if autoclaves or hot air furnaces would be used for emptying) should be included. Other contaminants/conditions that would be important should be identified and evaluated. Identify characterization information that is known, information that is not known, and the implications of not knowing and how to resolve important issues. Identify and discuss the issues that must be considered to determine the confidence levels to be set for establishing statistical sampling patterns, and recommend confidence levels to use. Based on existing sampling information and other available pertinent information on historical enrichment plant operations, propose appropriate population subsets for statistical sampling. Determine the resulting numbers of cylinders to be statistically sampled. Review options for carrying out sampling of the cylinders and performing needed constituent analyses and recommend approaches for accomplishing these activities.

Provide opportunity for frequent feedback on progress.

\section{Key Deliverable:}

5-10 page Strategy Paper

Program Element(s) Supported?

(Cylinder Management, Conversion, Use, Storage, Disposal)

Expected Completion Date and Priority (Hi/Med/Low):

Organization Completing Work:
21 working days from project authorization High 
Field Task

Manager Philip I. Stumbo

email_pis@oro.doe.gov

phone (865) 576-1828

fax
ORNL Task

Manager J. R. Hightower

email_hightowerjr@ornl.gov

phone (865)574-6777

fax (865) 574-0638

\section{HQ Task}

Manager Robert R. Price

email robert.r.price@hq.doe.gov

phone 301/903-9527

fax $301 / 903-4905$

Approved by: (Original signed by A. F. Tavares)

Date: $\quad 1 / 19 / 00$

$* * * * * * * * * * * * * * * * * * * * * * * * * * * * * * * * * * * *$

Copy to: George Benedict, OR

A. Tavares, NE-30

N. Buschman, NE-30

M. Scott, NE-30

Field Task Manager

HQ Task Manager

ORNL Task Manager 


\section{Appendix B}

\section{Statistical Analysis of Cylinder Sampling}

Although a statistical sampling effort was found not to be necessary, a protocol was developed under an early assumption that such sampling, in addition to the large number of samples already taken, might be needed on at least one high-priority population.

\section{B.1 Statistical Evaluation of Available PGDP Np, Pu, and Tc DUF ${ }_{6}$ Analysis Data} (R. L. Schmoyer)

PGDP DUF $_{6}$ analysis summaries for individual years FY 1981 and 1990 and a summary of FY 1992-1993 [Refs. B.1-B.11] are available. These reports also contain information on some of the ORGDP and PORTS tails since they were used as feed to PGDP for several years. Over the years, substantial amounts of reactor returns were processed at the PGDP, as represented by these data, although kilogram quantities of reactor returns were processed during the period 1986-1989.

Table B. 1 summarizes the $\mathrm{Np}, \mathrm{Pu}$, and Tc analyses. There was one neptunium detect at $5 \mathrm{ppb}$ in 1986 and two technetium detects at 0.01 ppm in FY 1992-1993; otherwise, there were no detects. To gain a better understanding of what the data in this table mean collectively, assume the assays represent random samples from a large population of $\mathrm{DUF}_{6}$ cylinders. Then a $98 \%$ upper confidence bound (UCB) for the probability that the neptunium concentration in any cylinder from that large population would exceed $5 \mathrm{ppb}$ (based on 0 exceeding in 153 samples) is 0.0252. Similarly, a 98\% UCB for the probability that the plutonium concentration in any cylinder would exceed $0.01 \mathrm{ppb}$ (based on 0 in 152) is 0.0254 . For technetium, a $98 \%$ UCB for the probability that the technetium concentration in any cylinder from the population would exceed $0.01 \mathrm{ppm}$ (based on 0 in 219) is 0.0177 .

\section{B.2 Statistical Sampling (R. L. Schmoyer)}

Statistical sampling of cylinders is likely to be a process of approximation and compromise. Ideally, one or more relatively small subpopulations of cylinders will be identified as representing worst cases (e.g., recycled uranium feed material stored in unwashed former feed cylinders). Random samples from those populations will then be used as a basis for conservative conclusions about the population of cylinders in general.

In practice, implementing this strategy is probably not going to be straightforward. First, obtaining the records necessary for identifying cylinder subpopulations may be difficult. A thorough study of cylinder records has not been made. We understand there is a catalog of records for each cylinder at Paducah, but despite a visit to the K-25 records vault, it cannot be determined that a similar catalog exists for Oak Ridge. Oak Ridge has complete logs of cylinder analyses, but inferring the histories of individual cylinders from these records would be timeconsuming and laborious. For the sake of efficiency, however, legacy records should be used 
Table B.1. Np, Pu, and Tc radiochemical measurements in $\mathrm{DUF}_{6}$ cylinders

\begin{tabular}{|c|c|c|c|c|c|c|c|}
\hline \multirow{2}{*}{ FY and plant } & \multicolumn{3}{|c|}{$\begin{array}{c}\text { Number of } \\
\text { samples }\end{array}$} & \multicolumn{3}{|c|}{ Detection limits } & \multirow{2}{*}{ Notes } \\
\hline & $\mathrm{Np}$ & $\mathrm{Pu}$ & $\mathrm{Tc}$ & $\begin{array}{c}\mathrm{Np} \\
(\mathrm{ppb})\end{array}$ & $\begin{array}{c}\mathrm{Pu} \\
(\mathrm{ppb})\end{array}$ & $\begin{array}{c}\mathrm{Tc} \\
(\mathrm{ppm})\end{array}$ & \\
\hline $81 \mathrm{PAD}$ & 3 & 3 & 3 & 1 & 0.01 & 0.01 & No detects \\
\hline $82 \mathrm{PAD}$ & 6 & 5 & 5 & 5 & $0.005-0.01$ & 0.01 & No detects \\
\hline 82 ORGDP & 3 & 3 & 3 & 5 & $0.005-0.01$ & 0.01 & No detects \\
\hline 82 PORTS & 5 & 5 & 5 & 5 & $0.005-0.01$ & 0.01 & No detects \\
\hline 83 PAD & 13 & 13 & 12 & 5 & 0.01 & 0.01 & No detects \\
\hline 83 ORGDP & 3 & 3 & 8 & 5 & 0.01 & 0.01 & No detects \\
\hline 83 PORTS & 4 & 4 & 19 & 5 & 0.01 & 0.01 & No detects \\
\hline $84 \mathrm{PAD}$ & 12 & 12 & 13 & 5 & 0.01 & 0.01 & No detects \\
\hline 84 ORGDP & 3 & 3 & 9 & 5 & 0.01 & 0.01 & No detects \\
\hline 84 PORTS & 4 & 4 & 16 & 5 & 0.01 & 0.01 & No detects \\
\hline 85 PAD & 11 & 11 & 11 & 5 & 0.01 & 0.01 & No detects \\
\hline 85 ORGDP & 4 & 4 & 33 & 5 & 0.01 & 0.01 & No detects \\
\hline 86 PAD & 12 & 12 & 12 & 5 & 0.01 & 0.01 & One Np hit at $5 \mathrm{ppb}$ \\
\hline $87 \mathrm{PAD}$ & 13 & 13 & 13 & 5 & 0.01 & 0.01 & No detects \\
\hline 88 PAD & 12 & 12 & 12 & 5 & 0.01 & 0.01 & No detects \\
\hline $89 \mathrm{PAD}$ & 15 & 15 & 15 & 3 & 0.01 & 0.01 & No detects \\
\hline $90 \mathrm{PAD}$ & 13 & 13 & 13 & 5 & 0.01 & 0.01 & No detects \\
\hline 92-93 PAD & 17 & 17 & 17 & 5 & 0.01 & 0.01 & Two Tc hits at $0.01 \mathrm{ppm}$ \\
\hline All & 153 & 152 & 219 & $1-5$ & $0.005-0.01$ & 0.01 & $\begin{array}{l}\text { One Np detect; two Tc } \\
\text { detects }\end{array}$ \\
\hline
\end{tabular}


whenever reasonable, although it may require considerable effort. Records themselves (as opposed to cylinders) might even be sampled.

A second reason sampling will be difficult is physical inaccessibility of cylinders relative to other cylinders, which is likely to render impractical truly random sampling of the cylinder populations. A third reason sampling will be difficult is the weak structural integrity of some of the cylinders, which makes them impractical or unsuitable for sampling. Any difference between the content of the cylinders unsuited for sampling and others in the population (or subpopulation) renders approximate conclusions about the population as a whole.

Let $C$ denote the contaminant concentration in a cylinder selected randomly from a population (or subpopulation) of cylinders. For $c \geq 0$, let $P(C>c)$ denote the probability that $C$ exceeds $c$. This discussion focuses on estimates of $P(C>c)$ for various $c$, rather than, for example, concentration means and standard deviations. Formulating the problem in terms of $P(C>c)$ is appropriate in this setting where we expect to see mostly nondetects, and detects, if any, well below action levels. Also, as opposed to sampling from the general cylinder population, targeting cylinders from subpopulations that suggest an increased likelihood of contamination leads to a more sensitive approach to detecting cylinders of special concern. (If the targeted population is small enough, the approach also leads to a more efficient bounding characterization of the cylinder target population, simply by virtue of the smaller population size.)

Whether at Portsmouth, Paducah, or Oak Ridge, certain time periods and activities, such as reactor return processing or retirement of (potentially unwashed) feed cylinders to $\mathrm{DUF}_{6}$ storage, do suggest an increased likelihood of cylinder contamination. We have identified a cylinder subpopulation of approximately 9100 cylinders at Paducah (combined from several time periods) as worst in the sense of having the highest contaminant concentrations. Similar conclusions for Portsmouth and Oak Ridge are much more tentative, but all 4800 cylinders at Oak Ridge could be targeted and approximately 1000 at Portsmouth.

The extent of sampling should balance sampling costs with the payback for having sample analysis results. At this stage, however, payback, which involves contingency costs of retrofit processing equipment, is difficult to estimate, and even the sampling (e.g., transfer) costs are uncertain. Therefore, this sampling recommendation is based on qualitative reckoning and opinion about payback and sampling costs and focuses on sampling error rather than minimization of costs. A more formal analysis of both costs and sampling error can lead to a different conclusion (see Sect. B.5).

\section{B.3 Theoretical Background for Statistical Sampling (R. L. Schmoyer)}

For each population, the analysis results will be used to test the hypothesis that $P\left(C>c^{\prime}\right)=p$ against the alternative $P\left(C>c^{\prime}\right)=p$. The value of $c^{\prime}$ is typically taken to be some number in the vicinity of either the largest concentration observed in the sample or the largest detection limit. This value will not be specified here. A reasonable value of $p$ depends on the cost of encountering a cylinder with $C>c^{\prime}$ during processing of wastes from washing empty cylinders. Because we expect our choice of $c^{\prime}$ (e.g., as the maximum observed concentration) to be low enough that incremental processing costs associated with $C>c^{\prime}$ are likely to be small, we take $p=0.05$. For a population of 9100 cylinders, we are thus testing the hypothesis that 455 cylinders 
or fewer have $C>c^{\prime}$; for a population of $4800, p=0.05$ translates to 240 cylinders; for a population of $1000, p=0.05$ translates to 50 cylinders.

The statistical error rates of the hypothesis test are the probability of a Type I error - deciding that $P\left(C>c^{\prime}\right)>0.05$ when in fact $P\left(C>c^{\prime}\right) \leq 0.05$ - and the probability of a Type II error deciding that $P\left(C>c^{\prime}\right) \leq 0.05$ when in fact $P\left(C>c^{\prime}\right)>0.05$. In practice, Type I error probabilities are usually specified, often as 0.05 , and sample sizes are then chosen to balance sampling costs against Type II error probabilities (and Type II error costs, if they can be quantified). When dealing with small sample sizes and discrete events, such as whether or not an observed concentration $C$ exceeds a certain value $c^{\prime}$, error probabilities are not continuous. They assume discrete values. In general, there is no discrete-event test whose Type I error probability is exactly 0.05 . Rather, error probabilities must be selected from choices available.

In the case of samples of 20 from a population of 9100, Type I error probabilities in the vicinity of 0.05 are 0.015 and 0.075 . The test with the 0.015 Type I error probability rejects when three or more samples are found with $C>c^{\prime}$; the test with the 0.075 Type I error probability rejects when two or more samples are found with $C>c^{\prime}$. The test with Type I error probability of 0.075 is more conservative in the sense that it errs on the side of deciding that $C>c^{\prime}$. It is recommended that the test with the 0.075 Type I error probability be used. Table B.2 lists several of the Type II error probabilities for that test.

Table B.2. Type II error probabilities for a test based on 20 samples that rejects when $C>c^{\prime}$ in two or more samples (population size $=9100$ )

\begin{tabular}{|c|c|c|}
\hline $\begin{array}{c}\text { Number in subpopulation of } \\
9100 \text { cylinders with } C>c^{\prime}\end{array}$ & $\begin{array}{c}P\left(C>c^{\prime}\right) \text { (proportion in } \\
\left.\text { subpopulation with } C>c^{\prime}\right)\end{array}$ & $\begin{array}{c}\text { Type II error } \\
\text { probability }\end{array}$ \\
\hline 682 & 0.075 & 0.55 \\
\hline 910 & 0.10 & 0.39 \\
\hline 1820 & 0.20 & 0.07 \\
\hline 3640 & 0.40 & 0.0005 \\
\hline
\end{tabular}

The case of samples of 20 from a population of 4800 is essentially the same as that from a population of 9100 (because, as far as the statistical properties of the tests are concerned, the populations are essentially infinite). The Type I error probabilities in the vicinity of 0.05 are, again, 0.015 and 0.075 . The test with the 0.015 Type I error probability rejects when three or more samples are found with $C>c^{\prime}$; the test with the 0.075 Type I error probability rejects when two or more samples are found with $C>c^{\prime}$. Table B.3 is the analogue of Table B.2 for a population of 4800 . 
Table B.3. Type II error probabilities for a test based on 20 samples that rejects when $C>c^{\prime}$ in two or more samples (population size $=4800$ )

\begin{tabular}{|c|c|c|}
\hline $\begin{array}{c}\text { Number in subpopulation of } \\
4800 \text { cylinders with } C>c^{\prime}\end{array}$ & $\begin{array}{c}\mathrm{P}\left(C>c^{\prime}\right) \text { (proportion in } \\
\left.\text { subpopulation with } C>c^{\prime}\right)\end{array}$ & $\begin{array}{c}\text { Type II error } \\
\text { probability }\end{array}$ \\
\hline 360 & 0.075 & 0.55 \\
\hline 480 & 0.10 & 0.39 \\
\hline 960 & 0.20 & 0.07 \\
\hline 1920 & 0.40 & 0.0005 \\
\hline
\end{tabular}

Thus, for population sizes of either 9100 or 4800 , when $P\left(C>c^{\prime}\right)$ is 0.20 or more, the Type II error probability is 0.07 or less. In the context of what we expect about sampling and contingency costs, this Type II error rate is believed to be sufficiently small.

Because only 1000 cylinders are in the targeted subpopulation at Portsmouth, it is recommended that fewer cylinders at Portsmouth be sampled. For a population of 1000, the choices for Type I error probabilities are 0.011 (reject for two or more $C>c^{\prime}$ ) and 0.085 (reject for one or more $C>c^{\prime}$ ). It is recommended that the test with the 0.085 Type I error probability be used. This test has Type II error properties shown in Table B.4.

Table B.4. Type II error probabilities for a test based on ten samples that rejects when $C>c^{\prime}$ in one or more samples (population size $=1000$ )

\begin{tabular}{|c|c|c|}
\hline $\begin{array}{c}\text { Number in subpopulation of } \\
1000 \text { cylinders with } C>c^{\prime}\end{array}$ & $\begin{array}{c}P\left(C>c^{\prime}\right) \text { (proportion in } \\
\left.\text { subpopulation with } C>c^{\prime}\right)\end{array}$ & $\begin{array}{c}\text { Type II error } \\
\text { probability }\end{array}$ \\
\hline 75 & 0.075 & 0.46 \\
\hline 100 & 0.10 & 0.35 \\
\hline 200 & 0.20 & 0.11 \\
\hline 400 & 0.40 & 0.006 \\
\hline
\end{tabular}

When $P\left(C>c^{\prime}\right)$ is 0.20 or greater, the Type II error probability is 0.11 or less. Again, in the context of expected sampling and contingency costs, this is believed to be sufficient.

Let $Z$ denote the maximum concentration or detection limit seen in a set of either 10 or 20 cylinder samples. It is likely that for each of the contaminants of concern, $Z$ will be substantially below the action level for the contaminant. For a sample size of 20 from a population of either 9100 or 4800 , and for zero observed samples with $C>Z$, the $95 \% \mathrm{UCB}$ for $P(C>Z)$ is 0.14 and the $90 \%$ UCB is 0.11 . These UCBs are adequately small. For a population of 1000 and sample 
size of 10 , the $95 \%$ UCB is 0.26 and $90 \%$ UCB is 0.20 . These UCBs are high. If, however, we combine all 50 cylinder samples from the three plants and take $Z^{*}$ to be the maximum $Z$ of the three, then assuming that the combined samples still emulate a random sample, the $95 \%$ UCB for $P\left(C>Z^{*}\right)$ based on all 50 is 0.06 and the $90 \% \mathrm{UCB}$ is 0.045 . Therefore, the sample sizes suggested here are believed to be adequate.

As in Table B.1, $Z$ is likely to be a detection limit rather than an actual concentration, or, if uncensored readings are reported, they will likely be below an effective detection limit, which can be used as a value for $Z$. In either case, $Z$ will not be random, at least not in a way that has much bearing on actual concentrations. However, if the data are uncensored and above detection limits, then because $Z$ is random, an approximation will be incurred by taking $c^{\prime}=Z$.

The preceding discussion is based on bounds that do not assume anything about the relationship of $P\left(C>c^{\prime}\right)$ to $P(C>A L)$, where $A L$ is an action level. Tighter bounds and reduced sampling requirements are reasonable under certain assumptions about the behavior of $P\left(C>c^{\prime}\right)$ for $c$ in the range of $c^{\prime}$ to $A L$. One way to justify these assumptions is through mass balance or other bounds on the maximum possible contaminant input into a cylinder. This approach is discussed further in the following section. So far, however, we have not been able to establish bounds necessary to justify this approach.

\section{B.4 Statistical Approach Based on a Bounding Assumption (R. L. Schmoyer)}

We would like to bound the probability, $P(C>A L)$, that $C$ exceeds an action level $A L$. Because of statistical uncertainty, this translates to finding an UCB for $P(C>A L)$. Suppose we sample $n$ cylinders and observe all $n$ concentrations to be less than or equal to $Z$ (e.g., assume $Z$ to be the largest concentration). We can then compute a UCB for $P(C>Z)$.

Assume that $Z<A L$. Without additional assumptions, perhaps the best UCB we could come up with for $P(C>A L)$ is based on the inequality $P(C>A L)=P(C>Z)$ and is simply the same UCB we compute for $P(C>Z)$. Call this the naive UCB.

To see how a UCB more efficient than the naive UCB might be calculated, consider the following three assumptions about $P(C>c)$. (1) As a function of $c$, $P(C>c)$ is sigmoidal (concave, then convex), as in Fig. B.1. (2) All of the concentrations in the observed samples are in the upper (convex) part of the tail of $P$ (see Fig. B.1). (3) A bound (Bound) not too far from $A L$ can be found such that $P(C>$ Bound $)=0$.

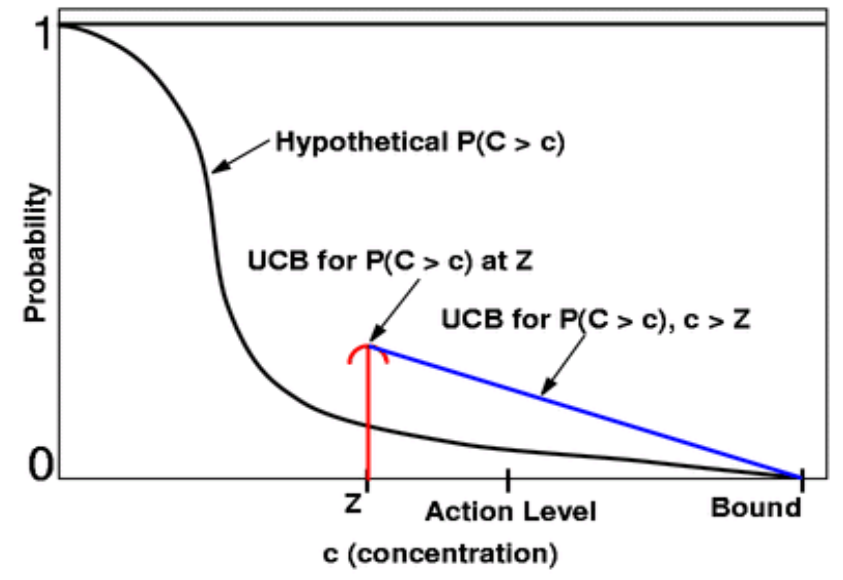

Fig. B.1. Hypothetical probability distribution function for cylinder concentrations. $Z$ represents a maximum concentration observed in practice. 
Assumption (1) about the sigmoid curvature is certainly subject to debate and not one likely to be verifiable. Nevertheless, sigmoidicity is a property of essentially all parametric functions used to model contaminant concentrations (e.g., lognormal, Weibull, gamma), and, by itself, the assumption of sigmoidicity does not require any particular parametric form for $P(C>c)$.

As illustrated in Fig. B.1, a suitably small Bound can be combined with a UCB for $P(C>Z)$ to yield a UCB for $P(C>A L)$. If Bound - $A L$ is not too much greater than $A L-Z$, then appreciable savings are achieved over the naive UCB. For example, suppose Bound - $A L=2(A L-Z)$. Then the UCB for $P(C>A L)$ is two-thirds the UCB for $P(C>Z)$. Thus, if the UCB for $P(C>Z)$ is less than say 0.06667 , then the UCB for $P(C>A L)$ is less than 0.05 . Demonstrating that the UCB for $P(C>Z)$ is less than 0.06667 generally requires substantially fewer observations than demonstrating $\mathrm{UCB}=0.05$, which would be required using the naive approach.

For example, Table B.5 shows some sample sizes required for $95 \%$ UCBs to be below the 0.05 and 0.06667 specifications. Clearly, the savings can be considerable. For a population of 1000 cylinders, the required sample size is 56 rather than 43 . At $\$ 20,000$ per sampled cylinder, the savings would be $\$ 260,000$.

Table B.5. Sample sizes needed to make 95\% UCB less than 0.05 - naive and sigmoid-and-bound approaches

\begin{tabular}{|c|c|c|}
\hline Population size & $\begin{array}{c}\text { Sample size required } \\
\text { for UCB }=0.05 \\
\text { (naive approach) }\end{array}$ & $\begin{array}{c}\text { Sample size required } \\
\text { for UCB }=0.06667 \\
\text { (sigmoid-and-bound approach) }\end{array}$ \\
\hline 50 & 31 & 26 \\
\hline 100 & 39 & 34 \\
\hline 200 & 47 & 38 \\
\hline 500 & 54 & 41 \\
\hline 1,000 & 56 & 43 \\
\hline 10,000 & 59 & 44 \\
\hline Infinite & 59 & 44 \\
\hline
\end{tabular}

B.5 Selection of Optimum Number of Samples and Confidence Levels (J. R. Hightower)

A cost/benefit analysis was performed to establish the number of cylinders that should be sampled in a well-designed statistical sampling campaign. This analysis is described as follows.

This discussion focuses on estimates of the probability that concentrations of contaminants exceed some value (a detection limit, an action level, the largest observable value, etc.), rather than, for example, concentration means and standard deviations. Formulating the problem in 
these terms is appropriate in this setting where results below levels of detection and detectable amounts, if any, well below action levels [see Sect. B.1] are expected.

Using this approach, the typical characterization statement that can be made about a population that has been statistically sampled is as follows: for a number of samples, $n$, the UCB is $X \%$ that $Y \%$ is the probability that the concentration of contaminant $i$ in the population being sampled is greater than $Z$. Stated somewhat less rigorously, we can say that for a number of samples, $n$, the probability is $X \%$ that the concentration of contaminant $i$ contained in no more than $Y \%$ of the population of cylinders is greater than $Z$. The population of $\mathrm{DUF}_{6}$ cylinders for characterization is to be chosen from the periods of operation of the three gaseous diffusion plants that are judged to have the highest known risk of containing transuranics and fission products based on operating histories of the plants. This population can then be statistically characterized based on random samples.

In somewhat simplistic terms, the number of cylinders, $n$, to be sampled from a selected population and analyzed for contaminants depends on the values of $X$ and $Y$ that are chosen in the characterization statement ( $X$ and $Y$ collectively define the confidence level of the characterization) and the number of cylinders in the population. In general, the larger the values of $X$ and $(100-Y)$ that are desired (i.e., the higher the desired confidence in the statistical sampling), the greater will be the number of cylinders that need to be sampled and analyzed, and the greater will be the cost of characterization. The value of $Z$ is determined from the characterization measurements themselves.

The extent of sampling should balance sampling costs with the payback for having sample analysis results. The appropriate confidence levels can be established based on an economic analysis that minimizes the sum of characterization costs plus expected additional operating costs that might be incurred if conditions outside the bounds of the characterization statement are encountered. For example, if during conversion, contaminant concentrations exceed the value of $Z$ (from the characterization statement), the plant operator may have to spend more money to accommodate the higher concentration (see Sect. 4.3).

The desired characterization statement is as follows: the probability is $X \%$ that the quantity of contaminant $i$ contained in no more than $Y \%$ of each identified population of cylinders is greater than $Z$. The optimum confidence levels (the combination of $X$ and $Y$ ) to set as the basis of statistical sampling can be determined by selecting values that result in a minimum of the sum of sampling costs plus the expected costs that are incurred as a result of contaminants in cylinders selected for processing lying outside the bounds determined in the sampling process (i.e., a concentration is encountered during processing that is greater than $Z$ ).

The information required to perform this optimization calculation is (1) the population size to be sampled, (2) the cost in dollars per cylinder for sampling and analysis, and (3) a basis for estimating additional costs incurred if concentrations are greater than $Z$ (typically a function of $Z$ and numbers of cylinders affected). It is assumed that the plant designer has provided in the plant design the capabilities for handling cylinders of concentrations equal to or less than $Z$ (perhaps with some safety factor). 
In determining the optimum confidence levels (and hence the optimum number of samples), a range of $X, Y$ pairs is examined. For each pair of $X, Y$ values in the range $0<X,(100-Y)<100$ to be examined ( $X$ and $Y$ expressed as percentages) and the given population size, the number of required cylinders to be sampled can be calculated through established statistical relationships. Then for each $X, Y$ pair, the cost of sampling is estimated using the following relationship:

$$
C_{\text {consequence }}=C_{\text {cylinder }} \times P \times(Y / 100) \text {, }
$$

where

$C_{\text {consequence }}$ is the maximum added cost to be incurred by a vendor because the characterization did not identify conditions actually encountered,

$C_{\text {cylinder }}$ is the added cost per cylinder due to high levels of contaminants,

$P$ is the number of cylinders in the selected population, and

$Y$ is the fraction of the population established in the statistical sampling for which there is uncertainty about contaminant concentrations.

The expected cost is the probability that the consequence will take place multiplied by the level of the consequence (i.e., the estimated cost consequence):

$$
C_{\text {expected }}=[(100-X) / 100] \times C_{\text {consequence }} \text {. }
$$

The cost of characterization is

$$
C_{\text {characterization }}=n \times C_{\text {analysis }} \text {, }
$$

where

$n$ is the numbers of cylinders selected from the population to analyze, and

$C_{\text {analysis }}$ is the total cost per cylinder for measuring contaminants.

If the sum of cost of characterization plus expected cost is plotted vs the number of samples, $n$ (which can be related to $X, Y$ pairs), the sum will show a minimum value in the range $0<X$, $(100-Y)<100$. The set of $X, Y$ values and the corresponding number of samples that produce the minimum value are the optimum values we are seeking.

The optimization calculation described previously for the four identified populations was performed, and the results are summarized as follows:

The range of $X, Y$ values (confidence levels) investigated and the required number of samples to achieve those levels are shown in Table B.6. 
Table B.6. Required number of samples to achieve desired confidence levels

\begin{tabular}{|c|c|c|}
\hline $\begin{array}{c}\text { Confidence } \\
\text { parameter, } \\
X(\%)\end{array}$ & $\begin{array}{c}\text { Confidence } \\
\text { parameter, } \\
Y(\%)\end{array}$ & $\begin{array}{c}\text { Required number of } \\
\text { samples from an } \\
\text { infinite population, } n\end{array}$ \\
\hline 80 & 20 & 8 \\
\hline 85 & 15 & 12 \\
\hline 90 & 10 & 22 \\
\hline 95 & 5 & 59 \\
\hline
\end{tabular}

For population sizes greater than 1000 , the required number of samples, $n$, approaches an asymptote and is thus constant and independent of population size.

The optimum values of $n$ calculated for a range of cost consequence and cost per cylinder for analysis are provided in Table B.7.

Table B.7. Optimum numbers of samples for a range of cost parameters

\begin{tabular}{|c|c|c|c|}
\hline $\begin{array}{c}\text { Additional cost impact } \\
\text { per cylinder, } C_{\text {cylinder }}\end{array}$ & $\begin{array}{c}\text { Unit cost for } \\
\text { analysis, } \\
C_{\text {analysis }}=\$ 20,000\end{array}$ & $\begin{array}{c}\text { Unit cost for } \\
\text { analysis, } \\
C_{\text {analysis }}=\$ 10,000\end{array}$ & $\begin{array}{c}\text { Unit cost for } \\
\text { analysis, } \\
C_{\text {analysis }}=\$ 6,000\end{array}$ \\
\hline$\$ 100$ & 2 (extrapolated) & 8 & 8 \\
\hline$\$ 500$ & 8 & 12 & 12 \\
\hline$\$ 1,000$ & 12 & 22 & 22 \\
\hline$\$ 2,000$ & 22 & 22 & 22 \\
\hline$\$ 5,000$ & 22 & 22 & 59 \\
\hline
\end{tabular}

We have estimated the number of cylinders in each of the four populations that were identified previously. We have selected a method for sampling and analysis that has estimated the cost per cylinder examined to be about $\$ 20,000$. We have also estimated that the cost impact for encountering concentrations above the value $Z$ determined from the characterization is $\$ 100-\$ 400$ per additional cylinder that must be treated. For this analysis, a conservative value of $\$ 500$ per additional cylinder was assumed. From Table B.7 we see that for those cost parameters, the economics does not justify taking large numbers of samples. We recommend that 12 samples be taken. This number could be modified, depending on initial results. 


\section{B.6 References}

B.1. Smith, R. F., "Purity of Cascade Product, Cascade Tails, and Toll UF 6 for FY-81," internal correspondence to P. D. Woodridge, Union Carbide Nuclear Division, February 8, 1982.

B.2. Smith, R. F., "Purity of Cascade Product, Cascade Tails, and Toll UF 6 for FY-82," internal correspondence to P. D. Woodridge, Union Carbide Nuclear Division, January 4, 1983.

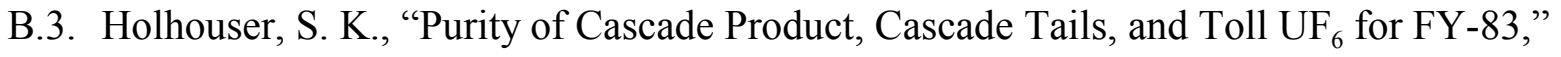
internal correspondence to P. D. Woodridge, Union Carbide Nuclear Division, February 29, 1984.

B.4. Holhouser, S. K., "Summary of FY-1984 UF 6 Analyses," internal correspondence to P. D. Woodridge, Martin Marietta Energy Systems, Inc., April 12, 1985.

B.5. Holhouser, S. K., "Summary of FY-1985 UF 6 Analyses," internal correspondence to P. D. Woodridge, Martin Marietta Energy Systems, Inc., February 21, 1986.

B.6. Holhouser, S. K., "Summary of FY-1986 UF 6 Analyses," internal correspondence to P. D. Woodridge, Martin Marietta Energy Systems, Inc., January 7, 1987.

B.7. Holhouser, S. K., "Summary of FY-1987 UF 6 Analyses," internal correspondence to P. D. Woodridge, Martin Marietta Energy Systems, Inc., December 30, 1987.

B.8. Holhouser, S. K., "Summary of FY-1988 UF 6 Analyses," internal correspondence to P. D. Woodridge, Martin Marietta Energy Systems, Inc., April 3, 1989.

B.9. Jolly, D. R., Summary of FY-1989 UF ${ }_{6}$ Analysis, PGDP Report KY/L-1562, Paducah Gaseous Diffusion Plant, Paducah, Ky., February 1990.

B.10. Jolly, D. R., Summary of FY-1990 UF ${ }_{6}$ Analysis, PGDP Report KY/L-1608, Paducah Gaseous Diffusion Plant, Paducah, Ky., March 1991.

B.11. D. R. Jolly, Summary of FY-1992 and FY-1993 UF ${ }_{6}$ Analysis, PGDP Report KY/L-1689, Paducah Gaseous Diffusion Plant, Paducah, Ky., December 1993. 


\title{
Appendix C
}

\section{Upper Bound Estimates of Pu, Np, and Tc Concentrations in $\mathrm{DUF}_{6}$ Cylinders}

\author{
L. R. Dole
}

\section{C.1 Objective and Scope}

The objective of this section is to estimate the upper bound concentrations of the ${ }^{239} \mathrm{Pu},{ }^{237} \mathrm{~Np}$, and ${ }^{99} \mathrm{Tc}$ in the stored $\mathrm{DUF}_{6}$ cylinders, using the currently available data.

\section{C.2 Background}

The principal source of data was a draft DOE Oak Ridge Operations interim report on the recycled uranium flows at gaseous diffusion plants [Ref. C.1]. This source relied heavily on the 1984 Smith report [Ref. C.2]. In addition, the Paducah site mass balance was finished during this study [Ref. C.3]. Also, PGDP summaries of $\mathrm{UF}_{6}$ tail analyses for individual years (FY 1981-1990 and FY 1992-1993) were made available [see Appendix B]. However, none of these years are from periods when substantial amounts of reactor returns were processed at the PGDP (1953-1964, 1969-1970, and 1972-1976), although small quantities ( $<<1 \%$ of total uranium throughput) of reactor returns were reported to be processed during the period 1986-1989 [Ref. C.1].

Starting in 1953, recycled uranium from the production reactors at Hanford and, later, Savannah River was processed at the uranium enrichment facilities. After the separation of plutonium and fission products from the uranium in the REDOX and PUREX reprocessing plants at Hanford and Savannah River, the recycled uranium, in the form of $\mathrm{UO}_{3}$, was sent to diffusion facilities [Ref. C.4]. The $\mathrm{UO}_{3}$ was converted first to $\mathrm{UO}_{2}$ and then to $\mathrm{UF}_{4}$, which was then converted to $\mathrm{UF}_{6}$. The final step in the conversion to $\mathrm{UF}_{6}$ produced a fine "ash" that contained nonvolatile components of unreacted $\mathrm{UF}_{4}$, uranium decay daughters, and other impurities, including very small amounts of activation and fission products. (Most of the transuranics and fission products had been removed during the plutonium/uranium separations processes in the fuel reprocessing plant.) Although the $\mathrm{UF}_{6}$ produced was filtered through a $10-\mu \mathrm{m}$ canister filter, some of the ash containing transuranics and technetium was transferred into the feed cylinders. Some plated out onto the internal surfaces of the feed cylinders, and some remained entrained in the $\mathrm{UF}_{6}$, which was subsequently fed into the diffusion cascades for enrichment.

Table C.1 summarizes examples of TRU and technetium assays of ash formed in the feed preparation plant's flame tower that converted $\mathrm{UF}_{4}$ to $\mathrm{UF}_{6}$. These four data analyses of Paducah Tower Ash T-Hopper samples [Ref. C.5] were taken at Paducah in 1980, 2 to 3 years after this feed preparation plant had finished its last major campaign with recycled reactor returns in FY 1977.

Also transferred from the flame tower to the feed cylinders were volatile fluorine compounds of the TRU contaminants, such as $\mathrm{PuF}_{6}, \mathrm{NpF}_{6}$, and $\mathrm{TcO}_{3} \mathrm{~F}$. Once in the feed cylinders, these volatile 


\begin{tabular}{|c|c|c|c|c|}
\hline \multicolumn{5}{|c|}{$\begin{array}{c}\text { Table C.1. Summary of } \mathrm{UF}_{4} \text { ash assays on four samples taken from the } \\
\text { Paducah Tower Ash T-Hoppers in } 1980\end{array}$} \\
\hline & $\%{ }^{235} \mathrm{U}$ & ${ }^{239} \mathrm{Pu}\left(\mathrm{ppb}_{\mathrm{U}}\right)^{a}$ & ${ }^{237} \mathrm{~Np}\left(\mathrm{ppb}_{\mathrm{U}}\right)$ & ${ }^{99} \mathrm{Tc}\left(\mathrm{ppb}_{\mathrm{U}}\right)$ \\
\hline Average & 0.6489 & 444 & 8,300 & 1,525 \\
\hline Std. deviation & 0.0489 & 353 & 6,500 & 553 \\
\hline Maximum & 0.6923 & 940 & 16,800 & 2,000 \\
\hline Minimum & 0.5840 & 105 & 1,100 & 960 \\
\hline Count & 4 & 4 & 4 & 4 \\
\hline
\end{tabular}

plutonium and neptunium compounds reacted with the entrained nonvolatile $\mathrm{UF}_{4}$ and other impurities to form $\mathrm{UF}_{6}$ and very fine, dispersed particles of nonvolatile $\mathrm{PuF}_{4}$ and $\mathrm{NpF}_{4}$ compounds. These very fine TRU particles were dispersed throughout the solidified $\mathrm{UF}_{6}$. Also, volatile $\mathrm{PuF}_{6}$ and $\mathrm{NpF}_{6}$ compounds reacted with metal surfaces of the feed cylinders, plated out, and formed a nonvolatile residue on the walls of the feed cylinders. Small fractions of these nonvolatile TRU particulates are thought to have been resuspended and transported from the feed cylinders into the enrichment cascades along with any remaining unreacted volatile fluorides. However, most of the nonvolatile TRU residues remained behind in the feed cylinder heels and were only removed by washing the cylinders prior to their periodic hydrostatic testing and recertification.

The key periods in which reactor returns were processed in the feed preparation process plants at Oak Ridge and Paducah and fed to the enrichment cascades at Oak Ridge, Paducah, and Portsmouth are as follows:

- The ORGDP hexafluoride feed plant operated between 1952 and 1961.

- The PGDP hexafluoride feed plant operated from 1953 to 1977. (It was not operated between 1964 and 1968.)

- Recycled uranium was fed to the ORGDP from 1958 to 1964, from 1970 to 1974, and from 1976 to 1978.

- Recycled uranium was fed to the PGDP from 1953 to 1964, from 1969 to 1970, and from 1972 to 1976 . Kilogram quantities were fed from 1986 to 1989.

- $\quad$ Recycled low-assay uranium was fed to the PORTS in 1974.

Table C. 2 summarizes the reported delivery and processing of the recycled reactor returns $\left(\mathrm{UO}_{3}\right)$ at the two diffusion plants' hexafluoride feed preparation facilities and the three enrichment cascades during these periods. 


\begin{tabular}{|l|c|c|c|}
\hline \multicolumn{4}{|c|}{$\begin{array}{c}\text { Table C.2. Quantities of recycled reactor returns } \\
\text { processed in }{ }_{3} \text { ) reported to have been } \\
\text { facilities at Oak Ridge and Paducah and fed to the cascades }\end{array}$} \\
\hline Plant & $\begin{array}{c}\text { Recycled uranium } \\
\text { delivered as } \mathrm{UO}_{3} \\
\text { (MTU) }\end{array}$ & $\begin{array}{c}\text { Recycled uranium fed } \\
\text { to cascade as } \mathrm{UF}_{6} \\
\text { (MT) }\end{array}$ & $\begin{array}{c}\text { Recycled uranium fed } \\
\text { to cascade as uranium } \\
\text { (MTU) }\end{array}$ \\
\hline ORGDP & 16,800 & 5,300 & 3,500 \\
\hline PGDP & 81,540 & 89,100 & 60,200 \\
\hline PORTS & $<100$ & $1,200^{a}$ & 816 \\
\hline Total & $\sim 98,400$ & $\sim 95,600$ & $\sim 64,590$ \\
\hline \multicolumn{2}{|c|}{ Includes reactor returns from research reactors and specialty users. } \\
\hline \multicolumn{4}{|c|}{} \\
\hline
\end{tabular}

The associated amounts of ${ }^{239} \mathrm{Pu},{ }^{237} \mathrm{~Np}$, and ${ }^{99} \mathrm{Tc}$ in these delivered quantities of recycled uranium are estimated in Table C.3.

\begin{tabular}{|l|c|c|c|}
\hline \multicolumn{4}{|c|}{$\begin{array}{c}\text { Table C.3. Quantities of } \\
\text { delivered to the gaseous diffusion plants' hexafluoride feed } \\
\text { preparation facilities in the recycled reactor returns }\end{array}$} \\
\hline \multicolumn{1}{|c|}{ Plant } & $\mathrm{Pu}, \mathrm{g}$ & $\mathrm{Np}, \mathrm{kg}$ & ${ }^{99} \mathrm{Tc}, \mathrm{kg}$ \\
\hline ORGDP & 60 & 3.5 & 103 \\
\hline PGDP & 300 & 22.1 & 684 \\
\hline PORTS & (No data available) & (No data available) & $85^{a}$ \\
\hline Total & 360 & 25.6 & 872 \\
\hline \multicolumn{2}{|c|}{${ }^{a}$ Enriched Paducah $\mathrm{UF}_{6}$ product. } \\
\hline \multicolumn{4}{|l}{} \\
\hline
\end{tabular}

\section{C.3 Estimates of Pu, Np, and Tc Introduced into the Feed Cylinders}

Smith [Ref. C.2] and Parks [Ref. C.1] estimated that $65 \%$ or more of these contaminants were retained in the feed preparation facilities and their filter systems. Table C. 4 summarizes the estimated quantities of contaminants that passed from the feed preparation facilities to the feed cylinders. These estimated quantities also represent bounding values of the total quantities of transuranics and technetium that would be present in the entire inventory of DUF 6 . 


\begin{tabular}{|l|c|c|c|}
\hline \multicolumn{4}{|c|}{$\begin{array}{c}\text { Table C.4. Estimates of }{ }^{239} \mathbf{P u},{ }^{237} \mathbf{N p} \text {, and }{ }^{99} \mathrm{Tc} \text { delivered to the gaseous } \\
\text { diffusion plants' cascades in the recycled reactor returns feed cylinders }\end{array}$} \\
\hline \multicolumn{1}{|c|}{ Plant } & $\mathrm{Pu}, \mathrm{g}$ & $\mathrm{Np}, \mathrm{kg}$ & ${ }^{99} \mathrm{Tc}, \mathrm{kg}$ \\
\hline ORGDP & $21^{a}$ & $1.2^{a}$ & 103 \\
\hline PGDP & $3^{b}$ & $16.6^{b}$ & $616^{b}$ \\
\hline PORTS & (No data available) & (No data available) & 85 \\
\hline Total & 24 & 17.8 & 804 \\
\hline $\begin{array}{l}{ }^{a} \text { Based on estimates that } 65 \% \text { is retained in feed preparation facilities. } \\
{ }^{b} \text { Based on Ref. C.3. }\end{array}$ \\
\hline
\end{tabular}

\section{C.4 Estimates of Pu, Np, and Tc Introduced into the Cascades}

As reported in Ref. C.1, the maximum amounts of these contaminants that could have been fed into the cascades at these plants are summarized in Table C.5. However as reported in Ref. C.1, no more than $80 \%$ of the volatile technetium species may have been transferred to the cascades. Also, the volatile forms of plutonium and neptunium are chemically unstable in the feed cylinders' internal environment. Therefore, substantial fractions of these compounds would be expected to have been reduced quickly to nonvolatile forms and remain in the feed cylinders. In Ref. C.2, Smith estimated that up to $40 \%$ of the neptunium was probably left behind as nonvolatile forms in the cylinders' heels or plated out onto their metal surfaces. Then, since $\mathrm{PuF}_{6}$ readily reacts with $\mathrm{UF}_{4}$ to form nonvolatile $\mathrm{PuF}_{4}$ and $\mathrm{UF}_{6}$, it would have been nearly completely converted to a nonvolatile fluoride compound. Some would plate out on the feed cylinder walls, and some would be dispersed in the $\mathrm{UF}_{6}$. Smith estimated that $99.9 \%$ of the plutonium remained in the feed cylinder heels.

Based on these estimated percentages, Table C.5 shows the upper limits of these nuclides that could have been transferred to the enrichment cascades.

\begin{tabular}{|c|c|c|c|}
\hline \multicolumn{4}{|c|}{$\begin{array}{l}\text { Table C.5. Quantities of }{ }^{239} \mathrm{Pu},{ }^{237} \mathrm{~Np} \text {, and }{ }^{99} \mathrm{Tc} \text { estimated to have been fed } \\
\text { into the diffusion cascades from the feed cylinders with reactor returns }\end{array}$} \\
\hline Plant & $\mathrm{Pu}, \mathrm{g}$ & $\mathrm{Np}, \mathrm{kg}$ & ${ }^{99} \mathrm{Tc}, \mathrm{kg}$ \\
\hline ORGDP & $<0.1^{a}$ & $0.48^{b}$ & $82^{c}$ \\
\hline PGDP & $0.1^{d}$ & $5.5^{d}$ & $559^{d}$ \\
\hline PORTS & $<0.02^{a}$ & (No data available) & $68^{c}$ \\
\hline Total & $<0.2$ & 6.0 & 709 \\
\hline \multicolumn{4}{|c|}{$\begin{array}{l}{ }^{a} 99.9 \% \text { of Pu remains in feed cylinder. } \\
{ }^{b} 60 \% \text { of Np remains in feed cylinder. } \\
{ }^{c} 20 \% \text { of Tc remains in feed cylinder. } \\
{ }^{d} \text { Based on Ref. C.3. }\end{array}$} \\
\hline
\end{tabular}




\section{C.5 Estimates of Transuranics and Technetium in Heels of Feed Materials}

Generally, the small quantities of contaminants that remain dispersed in the bulk $\mathrm{UF}_{6}$ phase in the feed cylinders are significantly less than the amounts that settle or plate out into the feed cylinder walls or remain in the heels. It may be only the small finely dispersed fractions of these contaminants that can be readily transferred with the $\mathrm{UF}_{6}$ when the cylinders are emptied into the cascades or the proposed conversion facility. Therefore, most of the contamination accumulates in the heels of the recycled feed and, in some cases, the product cylinders. Assuming retentions of $99.9,60$, and $20 \mathrm{wt} \%$ for $\mathrm{Pu}, \mathrm{Np}$, and Tc, respectively, Table C.6 estimates the quantities of transuranics and technetium that could have accumulated in the feed cylinder heels during the operating periods with reactor returns.

Most of the feed cylinders were periodically rinsed with mildly acidic aqueous solutions to remove the heels of $\mathrm{UF}_{6}$ and other fluoride compounds. This was done each time before the cylinders were "hydrotested" to certify them as fit for use.

In the early $1990 \mathrm{~s}$, the internal surfaces of two emptied, washed, and scraped Model 30A (2.5-MT) feed cylinders were examined [Ref. C.6]. These cylinders had been used from the early 1950s through the mid-1980s. This study found insoluble residues and even some undissolved green uranium fluoride. Heath Physics surveys of the inner surface discovered patches of residues that had count rates of 9000-750,000 counts per minute. Therefore, even rinsed feed cylinders can have measurable residues of uranium and transuranics.

Also, recycled feed cylinders, near the end of their service lives, were used for the storage of DUF $_{6}$ without washing [Ref. C.1]. These cylinders would have the nonvolatile residues from multiple charging with feed material, and their heels would have elevated levels of transuranics and technetium. The frequency at which this category of DUF $_{6}$ storage cylinder can be expected is not currently known with certainty. Therefore, the management and disposal of the empty feed cylinders must consider the presence of potential residual quantities of $\mathrm{Pu}, \mathrm{Np}$, and $\mathrm{Tc}$ in the heels of unwashed feed cylinders that were used to store $\mathrm{DUF}_{6}$.

Table C.6. Estimated upper bound quantities of ${ }^{239} \mathrm{Pu},{ }^{237} \mathrm{~Np}$, and ${ }^{99} \mathrm{Tc}$ remaining as heels in the reactor returns feed cylinders

\begin{tabular}{|l|c|c|c|}
\hline \multicolumn{1}{|c|}{ Plant } & $\mathrm{Pu}, \mathrm{g}^{a}$ & $\mathrm{~Np}, \mathrm{~kg}^{b}$ & ${ }^{99} \mathrm{Tc}, \mathrm{kg}^{c}$ \\
\hline ORGDP & 21 & 0.72 & 21 \\
\hline PGDP & 2.9 & 11.1 & 57 \\
\hline PORTS & (No data available) & (No data available) & 17 \\
\hline \multicolumn{2}{|c|}{24} & 11.8 & 95 \\
\hline
\end{tabular}


Assuming that a 10-MT feed cylinder leaves behind a $25-\mathrm{kg}$ heel when it is emptied, the $\mathrm{UF}_{6}$ heels could amount to $0.25 \mathrm{wt} \%$ of the total reactor return feed in Table C.2. Then, a conservative estimate of the potential concentrations of these contaminants can be made by assuming that the contaminant quantities in Table C.4 are concentrated in the remaining $0.25 \mathrm{wt} \%$ of the feed $\mathrm{UF}_{6}$ from the reactor returns. These concentration estimates are shown in Table C.7.

\begin{tabular}{|l|c|c|c|}
\hline \multicolumn{4}{|c|}{ Table C.7. Estimated concentrations of transuranics and technetium } \\
$\left(\mathbf{p p b}_{\mathbf{U}}\right)$ in feed material heels
\end{tabular}

These estimated concentrations for transuranics and technetium in feed material heels are substantially higher than suggested DOE action limits (see Sect. 3.4). While the relative amounts of the feed heels are small compared with the inventory of $\mathrm{DUF}_{6}$, the much higher concentrations of transuranics and technetium in the heels require that they be managed carefully. It is recommended that the highest values shown in Table C.7 for each nuclide be taken as the bounding concentration for that nuclide. Bhat [Ref. C.9] reports the ratio of measured values of ${ }^{238} \mathrm{Pu}$ to ${ }^{239} \mathrm{Pu}$ to be $0.88 \pm 0.73$. This mean ratio can be used to estimate the bounding concentrations of ${ }^{238} \mathrm{Pu}$ and ${ }^{239} \mathrm{Pu}$ from the total plutonium concentrations shown in Table C.7. Thus, the recommended values for bounding concentrations of transuranics and technetium in feed material heels are as follows:

$\begin{array}{lr}{ }^{238} \mathrm{Pu} & 5 \mathrm{ppb} \\ { }^{239} \mathrm{Pu} & 1,600 \mathrm{ppb} \\ { }^{237} \mathrm{~Np} & 54,000 \mathrm{ppb} \\ { }^{99} \mathrm{Tc} & 5,700,000 \mathrm{ppb}\end{array}$

Several empty feed cylinders have been identified that contain heels of feed and/or product from the periods when reactor returns were being fed to the cascades. Cylinder 003174 is such a cylinder with $13 \mathrm{lb}$ of feed material heel remaining. This cylinder had been filled at the PGDP $\mathrm{UF}_{6}$ feed plant with $\mathrm{UF}_{6}$ prepared from reactor returns material sometime after the cylinder's purchase date of June 1954. After the original charge in this cylinder had been fed to the cascades, the cylinder was filled with enriched product from Paducah and shipped to the PORTS, where the enriched material was fed to the Portsmouth cascade for further enrichment. This cylinder was similarly refilled with enriched product and emptied two more times without any washing, leaving its original heel of reactor returns feed material combined with the heels left from emptying enriched product three times into the cascades. The heels material in this cylinder was dissolved by washing with an acidic wash solution, and the solution was then analyzed for the dissolved constituents. The results of the measurements on this cylinder [Ref. C.7] show (Table C.8), as expected, the highest measured values for all of the transuranic and technetium 


\begin{tabular}{|l|c|c|c|c|c|c|c|}
\hline \multicolumn{7}{|c|}{ Table C.8. First and fourth washes from Paducah Cylinder 003174 } \\
\hline & $\begin{array}{c}{ }^{235} \mathrm{U} \\
\text { assay } \\
(\mathrm{wt} \%)\end{array}$ & $\begin{array}{c}{ }^{236} \mathrm{U} \\
\left(\mathrm{ppb}_{\mathrm{U}}\right)\end{array}$ & $\begin{array}{c}{ }^{99} \mathrm{Tc} \\
\left(\mathrm{ppb}_{\mathrm{U}}\right)\end{array}$ & $\begin{array}{c}{ }^{237} \mathrm{~Np} \\
\left(\mathrm{ppb}_{\mathrm{U}}\right)\end{array}$ & $\begin{array}{c}{ }^{238} \mathrm{Pu} \\
\left(\mathrm{ppb}_{\mathrm{U}}\right)\end{array}$ & $\begin{array}{c}{ }^{239} \mathrm{Pu} \\
\left(\mathrm{ppb}_{\mathrm{U}}\right)\end{array}$ & $\begin{array}{c}{ }^{241} \mathrm{Am} \\
\left(\mathrm{ppb}_{\mathrm{U}}\right)\end{array}$ \\
\hline First wash & 2.7602 & 188,000 & 270,000 & 19,600 & 0.0055 & 124 & 0.43 \\
\hline Fourth wash & 2.4826 & 187,000 & 152,000 & 23,400 & 0.059 & 120 & 0.57 \\
\hline
\end{tabular}

contaminants that were observed in the series of measurements supporting the development of this characterization strategy. This table shows results of the first wash and the fourth wash of a series of washes aimed at dissolving the heel material from the cylinder. The TRU-contaminated residue continues to leach out of or wash off the walls of the cylinder over several rinses.

Concentrations of the contaminants in the wash solution were a factor of 400-500 lower in the fourth wash than in the first wash, but the concentrations normalized to total uranium (shown in Table C.8) remained relatively constant from the first to the fourth wash. The concentrations of $\mathrm{Np}, \mathrm{Pu}$, and Am are all above the suggested DOE action limits discussed in Sect. 3.4, and they are sufficiently high that the solids, if not blended with lower concentration material, would need to be managed as TRU waste.

The measurements on cylinder 003174 confirm the generally high levels predicted by these calculations. The measured values should be compared with the values in the Table C.7 for the Paducah plant since the feed material in the heel material that was analyzed originated at Paducah. For the Paducah plant the calculated concentration for ${ }^{99} \mathrm{Tc}$ is within the range of the measured values; the calculated concentration for ${ }^{237} \mathrm{~Np}$ is about $2.1-2.6$ times higher than the measured values; and the calculated value for plutonium is about a factor of 9 lower than the measured values. There is no estimated value for the concentration of ${ }^{241} \mathrm{Am}$, so the measured value of $0.57 \mathrm{ppb}_{\mathrm{U}}$ is recommended as the best estimate for its bounding concentration in feed material heels.

\section{C.6 Estimated Bounds for Transuranics and ${ }^{99} \mathrm{Tc}$ in the DUF 6 Cylinders}

Most of the nuclides introduced to the cascades are not expected to reach the tails. This is because most of the volatile ${ }^{99} \mathrm{Tc}$ species are removed through the diffusion plants' purge cascade or report to the product stream. As a result, only a small fraction of the reactor return uranium's ${ }^{99} \mathrm{Tc}$ fed to the cascade will end up in the tails stream. When the $\mathrm{PuF}_{6}$ and $\mathrm{NpF}_{6}$ transferred to the cascades, they reacted with the metal piping and plated out. Therefore, most of the plutonium was found in the piping in the stages near where it was introduced since $\mathrm{PuF}_{6}$ is very reactive. In the case of the less reactive $\mathrm{NpF}_{6}$, neptunium was found more widely distributed in the cascade piping, and in some cases, neptunium appeared with technetium in the product stream. As a result, very little of the $\mathrm{Pu}, \mathrm{Np}$, and Tc migrates through the diffusion cascade to become dispersed in the $\mathrm{DUF}_{6}$.

A large number of significant measurements on transuranics and technetium in the $\mathrm{DUF}_{6}$ can be used as guides for recommending appropriate concentration bounds for these contaminants in the DUF $_{6}$ itself. 
In March 1984, Smith [Ref. C.2] summarized the historical impacts of reactor tails on the Paducah cascade. He reports sampling and analyzing two Paducah tails cylinders in June 1973 for ${ }^{99} \mathrm{Tc}$, ${ }^{237} \mathrm{~Np}$, and ${ }^{239} \mathrm{Pu}$. In FY 1973, reactor returns made up $65 \%$ of the total feed to the cascade. In June 1973, when these samples were taken, over $96 \%$ of the total cascade feed was reactor returns. The technetium levels measured in these two tails cylinders were $<1 \mathrm{ppb}$, the detection limit of these analyses. During this month, the concentration of technetium in a cascade product cylinder was $20 \mathrm{ppm}$, the highest ever measured for the product stream.

Also in these two Paducah tails cylinders in June 1973, neptunium and plutonium were found to be $<1$ and $<0.001 \mathrm{ppb}$, respectively. These were analyses of liquid samples withdrawn from the bulk $\mathrm{UF}_{6}$ in the cylinders, and they do not show any measurable dispersion of transuranic contamination in the bulk DUF ${ }_{6}$ present in the cascade tail cylinders.

Under the conditions of the most severe loading ever recorded of reactor returns to the cascades, no measurable Tc, $\mathrm{Np}$, or $\mathrm{Pu}$ were found dispersed in the $\mathrm{DUF}_{6}$ tails stream. Therefore, it follows that the most significant mechanism by which transuranics end up in the tails cylinders is by cross-contamination from the heels of unwashed, recycled feed and product cylinders, the former being the most significant.

In a letter from C. R. Beverly to J. C. Hodges, "Np-237, Pu-239/240, and Tc-99 in Paducah Gaseous Diffusion Plant (PGDP) Tails and Product," dated March 19, 1992 [Ref. C.8], the following statements are made:

- "In summary, Tc-99 has never been positively identified in Paducah tails $\mathrm{UF}_{6}$, based on 153 cylinders analyzed in the period from 1972 through 1991." The information supporting this statement identified results from 37 tails cylinders filled during the period 1972-1981.

- "Np-237 has never been detected in PGDP tails and has not been detected in PGDP product since 1980." Information supporting this statement identified results from 40 tails cylinders analyzed during the period 1973-1982.

- "In summary, plutonium has never been detected in Paducah tails $\mathrm{UF}_{6}$, and it is questionable whether it has been detected in Paducah product $\mathrm{UF}_{6}$." Information supporting this statement identified results from 60 tails cylinders analyzed during the period 1973-1982.

Furthermore, PGDP summaries of tail analyses for FY 1981-1990, FY 1992, and FY 1993 were available for this analysis [see Appendix B]. These summaries included some tails cylinders from ORGDP and PORTS that were sent to PGDP. None of these years is from the era when substantial amounts of reactor returns were processed at the PGDP, although kilogram quantities of reactor returns were processed from 1986 to 1989 [Ref. C.1]. Out of 153 tails cylinder samples from the three plants, neptunium was detected only once at $5 \mathrm{ppb}$, the limit of detection for neptunium in 1986. Plutonium was not detected in any of 152 samples. (The detection limit was $0.01 \mathrm{ppb}$.) Out of 219 samples, technetium was detected only twice at $0.01 \mathrm{ppm}$, the limit of detection for technetium in FY 1991-1992; otherwise, it was not detected. If it is assumed that the samples were truly random, these results indicate a $98 \%$ probability that no more than $2.5 \%$ 
of the cylinders generated during this period of reporting at Paducah have concentrations of the three contaminants greater than the detection limits.

Based on these large number of observations of $\mathrm{Pu}, \mathrm{Np}$, and $\mathrm{Tc}$ in $\mathrm{DUF}_{6}$ cylinders and the expected behavior of these materials in the cascades, bounding concentrations of $\mathrm{Pu}, \mathrm{Np}$, and Tc dispersed in the $\mathrm{DUF}_{6}$ cylinders are expected to be no higher than the detection limits of these nuclides. These values are summarized here in Table C.9.

\begin{tabular}{|c|c|}
\hline $\begin{array}{c}\text { Table C.9. Bounding concentrations of dispersed } \\
\text { contamination in the DUF } \\
\text { cylinders } \\
\text { based on } \mathbf{U F}_{\mathbf{6}} \text { measurements }\end{array}$ \\
\hline Contaminant & $\begin{array}{c}\text { Upper concentration bounds } \\
\left(\mathrm{ppb}_{\mathrm{U}}\right)\end{array}$ \\
\hline $\mathrm{Pu}$ & 0.01 \\
\hline $\mathrm{Np}$ & 5 \\
\hline${ }^{99} \mathrm{Tc}$ & 10 \\
\hline
\end{tabular}

Additional measurements of these contaminants in depleted uranium have been provided by the U.S. Army. Depleted Uranium Armor Packages for the M1 Series Main Battle Tank are obtained from the Specific Manufacturing Capability (SMC) Program Office at DOE-Idaho Operations for installation by an Army contractor. Processed raw depleted uranium material is sent by DOEIdaho to a DOE-Idaho vendor, who has a Nuclear Regulatory Commission (NRC) license to make it into "billets" (ingots) ready for processing into armor packages. The billets are then given back to DOE-Idaho, who completes the armor packages. The packages are then transferred to the Army contractor for installation under an NRC license, and in turn to the Army, who fields the tank under a separate NRC license.

To support the NRC license amendment activities for the subcontractor accommodating the contamination by transuranics and technetium in the depleted uranium, the Army commissioned the sampling and analysis by Idaho National Engineering and Environmental Laboratory of 12,000,000 lb (5450 MT) of depleted metal prepared at Fernald from depleted $\mathrm{UF}_{4}$ supplied from the PGDP [Ref. C.9]. This sampling and analysis activity sought to measure concentrations of ${ }^{241} \mathrm{Am},{ }^{237} \mathrm{~Np},{ }^{238} \mathrm{Pu},{ }^{239} \mathrm{Pu}$, and ${ }^{99} \mathrm{Tc}$ present in the depleted uranium. The quantity of depleted uranium sampled represented the material that would have occupied approximately $80010-\mathrm{MT}$ DUF $_{6}$ cylinders.

In the sampling and analysis program, 20 samples were taken randomly from the uranium metal and analyzed for ${ }^{241} \mathrm{Am},{ }^{237} \mathrm{~Np},{ }^{238} \mathrm{Pu},{ }^{239} \mathrm{Pu}$, and ${ }^{99} \mathrm{Tc}$. Of the 20 samples analyzed, 6 showed detectable levels of ${ }^{99} \mathrm{Tc}, 18$ showed detectable levels of ${ }^{239} \mathrm{Pu}, 19$ showed detectable levels of ${ }^{238} \mathrm{Pu}, 8$ showed detectable levels of ${ }^{237} \mathrm{~Np}$, and 16 showed detectable levels of ${ }^{241} \mathrm{Am}$. The highest measured concentrations are summarized in Table C.10. 
The measured values for $\mathrm{Np},{ }^{239} \mathrm{Pu}$, and $\mathrm{Tc}$ are very slightly higher than the detection limit values shown in Table C.9, and these measurements provide the most reliable measurements for ${ }^{241} \mathrm{Am}$ associated with $\mathrm{DUF}_{6}$. It is recommended that the values in Table C. 10 be considered the bounding values for the transuranics and technetium found dispersed in $\mathrm{DUF}_{6}$ cylinders for the purposes of design of conversion facilities.

\begin{tabular}{|c|c|}
\hline \multicolumn{2}{|c|}{$\begin{array}{c}\text { Table C.10. U.S. Army results of analysis } \\
\text { of depleted uranium metal produced } \\
\text { from Paducah } \mathbf{U F}_{\mathbf{6}}\end{array}$} \\
\hline Nuclide & $\begin{array}{c}\text { Maximum observed concentration } \\
\left(\mathrm{ppb}_{\mathrm{U}}\right)\end{array}$ \\
\hline${ }^{241} \mathrm{Am}$ & 0.0013 \\
\hline${ }^{237} \mathrm{~Np}$ & 5.2 \\
\hline${ }^{238} \mathrm{Pu}$ & 0.00012 \\
\hline${ }^{239} \mathrm{Pu}$ & 0.043 \\
\hline${ }^{99} \mathrm{Tc}$ & 15.9 \\
\hline
\end{tabular}

\section{C.7 References}

C.1. Parks, J. W., et al., Recycled Uranium Processed at the Oak Ridge, Paducah, and Portsmouth Gaseous Diffusion Plants, U.S. Department of Energy, Oak Ridge Operations, Oak Ridge, Tenn., September 30, 1999 (Draft).

C.2. Smith, R. F., Historical Impact of Reactor Tails on the Paducah Cascade, KY/L-1239, Paducah, Ky., March 1984.

C.3. Recycled Uranium Mass Balance Project Paducah Gaseous Diffusion Plant Site Report, BJC/PGDP-167, Bechtel Jacobs Company, Paducah, Ky., June 14, 2000.

C.4. Rucker, T. L., Isotopic Distribution of Contamination Found at the U.S. Department of Energy Gaseous Diffusion Plants, Science Applications International Corporation, Oak Ridge, Tenn., October 29, 1999.

C.5. Neyer, J., FMEP, Fernald, Ohio, private communication, August 31, 2000.

C.6. Rao, M., Ellis, Q., and Freels, D., Characterization of Internal Surfaces of Two Emptied $30 \mathrm{AF}_{6}$ Storage Cylinders, K/TCD-1090 (Internal), Lockheed Martin Energy Systems (undated).

C.7. Taylor, M. S., Bechtel Jacobs Company LLC, Oak Ridge, Tenn., personal communication to J. R. Hightower, ORNL, Oak Ridge, Tenn., September 11, 2000. 
C.8. Beverly, C. R., Paducah Gaseous Diffusion Plant, "Np-237, Pu-239/240, and Tc-99 in Paducah Gaseous Diffusion Plant (PGDP) Tails and Product," letter to J. C. Hodges, Paducah Gaseous Diffusion Plant, dated March 19, 1992.

C.9. Bhat, R. K., Analysis of Transuranics and Other Contaminants in Depleted Uranium Armor, Memorandum for Commander, U.S. Tank and Automotive Command, Warren, Mich., January 19, 2000. 


\title{
Appendix D
}

\section{Other Characterization Information}

\author{
L. D. Trowbridge \\ S. J. Pawel
}

Information in this appendix is provided as supporting material for developing the tails cylinder characterization strategy. It has been divided into two sections - one on the physical condition of the cylinders and the other on chemical or radiological contaminants.

\section{D.1 Physical Condition of Cylinders}

The physical condition and mechanical integrity of cylinders are important from the standpoint of transport and $\mathrm{UF}_{6}$ removal. From a statistical standpoint, much of the needed information may be available as a result of studies under way in the $\mathrm{DUF}_{6}$ cylinder program. This section summarizes the available information.

The mild steel of the $\mathrm{DUF}_{6}$ cylinders has been exposed to environmental weathering for periods up to 50 years. The cylinders originally were painted, but various autoclave cycles and extended weathering have caused the paint to degrade on all except the newest cylinders or those recently refurbished. Generally speaking, the top two-thirds or more of most cylinders exhibits only mild uniform weathering (about 5-15 mils of general metal loss) that is characterized by a thin, adherent rust layer with only modest surface roughening due to the corrosion process.

However, in some storage yard locations, some bottom-row cylinders have settled and are in contact with the ground (or at least with standing rainwater) for extended periods as a result of frost heave and deterioration of the asphalt/concrete surface. For cylinders subjected to these substandard storage conditions (which have since been largely eliminated), accelerated corrosion may occur over areas up to about $2 \mathrm{ft}$ wide running the full length of the cylinder underside (but usually a much smaller area). Areas of accelerated corrosion exhibit thicker rust packs and development of significant surface relief with scattered pitting. When pits are observed, they are typically relatively rounded hemispheres roughly 30-60 mils deep. Pits approaching 100 mils deep have been observed far more rarely. It should be noted that top-row cylinders can also exhibit corrosion along the bottom portion due to being previously stored in the bottom row of a two-tier stack configuration.

The wall thickness of each individual cylinder is not known. However, using both manual and automated ultrasonic thickness measurements, a representative sampling of the cylinder inventory has been assessed. Cylinders measured for wall thickness were selected to statistically represent each of the subpopulations (storage groupings and history) of the inventory.

Approximately 1000 cylinders have been evaluated for minimum wall thickness and a best estimate of original wall thickness. The results have been used to generate a "corrosion model" that predicts wall thickness distributions for the cylinder inventory as a function of time. Details of the current model [Ref. D.1] are outside the scope of this report, but the model can be used to 
predict numbers of cylinders within each storage yard with certain "limiting" wall thickness values.

Presently, the American National Standards Institute (ANSI) N14.1 [Ref. D.2] requires that cylinders meet a minimum wall thickness requirement to be considered acceptable for contents transfer or off-site shipment operations. [An action is presently before the appropriate subcommittee of ANSI to change some of the current requirements to conform more closely with the American Society of Mechanical Engineers (ASME) Boiler and Pressure Vessel Code, or B\&PV Code, but it is not clear when any proposed changes might become effective.] For the "thin-wall" cylinder design (originally 5/16 in. thick; these comprise approximately $99 \%$ of the cylinder inventory), the minimum thickness requirement in ANSI N14.1 is 250 mils at the thinnest point. For the "thick-wall" design (originally $5 / 8$ in. thick), the minimum thickness is 500 mils. These minimum thickness values appear to be based in large measure on a somewhat arbitrary corrosion allowance rather than any structural requirement for pressurization or transport.

For the present year, the corrosion model indicates that the most accurate estimate of the total number of thin-wall cylinders with a minimum thickness less than 250 mils at any point is on the order of 3900 (out of a total population of about 57,600 cylinders). Even among these potentially degraded cylinders, the wall thickness over $95 \%$ or more of the total surface (body plus heads) is likely to be 300 mils or greater. Individual cylinders can be assessed and "exempted" from ANSI N14.1 requirements, but the process is paperwork and time intensive and requires multiple levels of DOE approval.

A more definitive wall thickness requirement can be elucidated from the ASME B\&PV Code (under which these cylinders were designed and procured). Each specific vessel design is supported by structural calculations (including appropriate factors of safety) that justify the nameplate conditions (typically up to $300^{\circ} \mathrm{F}$ or $100 \mathrm{psi}$ ) at which the cylinders are rated. A comprehensive review of these requirements [Ref. D.3] indicates that minimum wall thicknesses considerably less than 250 mils may be tolerated while maintaining code-vessel status. Specifically, even for the most conservative designs, 219 mils thick adjacent to welds (and 175 mils remote to welds) for the thin-wall design is sufficient to maintain the pressure rating of the vessel. (On the heads, the minimum values are typically $1-4$ mils less.)

These ASME B\&PV Code thickness minimums are calculated based on the cylinder shell/head having a uniform minimum thickness (the same everywhere on the cylinder). In practice, only tiny areas on any given cylinder approach a limiting minimum thickness. The National Board Inspection Code (NBIC) [Ref. D.4] provides guidelines for evaluating localized wall thinning due to pitting that can be summarized as follows:

"Widely scattered pits may be disregarded provided that:

1. their depth is not more than one half the required thickness of the pressure vessel wall (exclusive of the corrosion allowance);

2. the total area of the pits does not exceed $7 \mathrm{in}^{2}\left(45 \mathrm{~cm}^{2}\right)$ in any $8 \mathrm{inch}(203 \mathrm{~mm})$ diameter circle; and 
3. the sum of their dimensions along any straight line within the circle does not exceed 2 inches $(50.8 \mathrm{~cm}) . "$

No cylinder is known to have a pit depth/distribution that is unacceptable according to the NBIC guidelines. Furthermore, although the corrosion model is not currently set up to predict this quantity, it is expected that the number of individual cylinders that could not pass the NBIC guidelines for wall thickness criteria is fewer than ten across the entire inventory. In any case, cylinders have been out of service in the pressure-duty sense for a sufficient period that they most probably require individual recertification (NBIC or owner/user inspection) to be placed back into pressure service.

Clearly, contents transfer can also be accomplished by means other than autoclave duty at nameplate boundary conditions. ASME B\&PV Code calculations have been generated for hot feeding at $235^{\circ} \mathrm{F}$ [Ref. D.3] (e.g., cylinder pressure of only 65.3 psi rather than $100 \mathrm{psi}$ ). Under these conditions, the cylinders maintain pressure vessel status for "everywhere" wall thicknesses of 154 mils near welds for the thin-wall design (compared with 219 mils for $100 \mathrm{psi}$ ).

In addition to the above considerations, an experimental program to examine handling and stacking stresses has collected significant data. Handling stresses have been measured (cylinders instrumented with strain gages) or calculated (finite-element analysis) for a wide variety of operations (stacking, handling, rotation) and cylinder loading conditions (saddle surface and spacing, yard surface, four-point loading, etc.). Perhaps the most significant result is that for all of the operations, including cylinders somewhat degraded by corrosion (minimum wall thickness about 200 mils) as well as new cylinders, the maximum measured stresses were safely below ASME allowable levels for operation of a pressure vessel and almost negligible compared with the ASME allowable levels for localized elastic stresses. Information of this type appears in several cylinder project documents, but reference to the most critical pieces of information can be found in an internal memo [Ref. D.5].

Another factor potentially affecting the serviceability of cylinders, at least indirectly, is external PCB contamination. Recently, a group of 48T 10-ton cylinders was repainted in a facility located in the K-1066-E yard at the ETTP, formerly the ORGDP. As part of the process, the cylinders (originally residing in the K-1066-K yard) were blasted with recycled steel grit prior to application of the new coating. Sampling of debris for waste disposal (spent blasting media along with rust and paint removed from cylinders during blasting) revealed unexpected PCB contamination. To determine the source of the contamination, rust and paint chip debris from the ends of individual cylinders from the mother population of cylinders in K-1066-K yard were statistically sampled and analyzed [Ref. D.6]. Results indicated a wide range of PCB concentrations $(<1$ to $1900 \mathrm{ppm})$. It is clear that PCBs now contaminate the surface of the $\mathrm{K}$-yard cylinders at ETTP, but the source of the PCBs has not been confirmed. This population of cylinders had a very dated paint system that could have contained PCBs (as was somewhat routine in the 1950s), or it may be that autoclave oil or some related constituent from past cylinder operations contaminated the cylinder surface. In any case, the potential for PCB contamination from old paint residues or from other sources such as autoclaves is not unique to the ETTP site. Assessment and sampling for PCBs at the other cylinder yard sites have not yet been completed. 


\section{D.2 Other Chemical Impurities}

In addition to $\mathrm{Tc}, \mathrm{Np}$, and $\mathrm{Pu}$, other chemical components have been cited as being of concern in $\mathrm{UF}_{6}$ feed over the years. Directly related to reactor return feed were several fission product radioisotopes which bore sufficient chemical similarity to $\mathrm{UF}_{6}$ that there was a concern that they could (to a degree) accompany the $\mathrm{UF}_{6}$ in the feed stream. Occasionally other nonradioactive chemical impurities unrelated to reactor returns have created concern.

Radiochemical Impurities (Other Than Np, Pu and Tc). From time to time ${ }^{95} \mathrm{Zr},{ }^{103} \mathrm{Ru},{ }^{106} \mathrm{Ru}$, ${ }^{141} \mathrm{Ce},{ }^{144} \mathrm{Ce}$, and ${ }^{125} \mathrm{Sb}$ have been mentioned as being of potential concern in reactor return feed [Refs. D.7-D.10]. The concern generally was from the point of view of activity, as these species, depositing on internal surfaces of cascade or feed station hardware, could create zones of high activity, complicating maintenance and operations. By the end of the reactor return feed period, the main nuclide of concern (after Tc, $\mathrm{Pu}$, and $\mathrm{Np}$ ) seemed to be ${ }^{106} \mathrm{Ru}$ [Ref. D.9]. In addition to the above isotopes, ${ }^{137} \mathrm{Cs}$ and ${ }^{241} \mathrm{Am}$ have been mentioned as being potentially present in the ash from uranium fluorination. As such, trace carryover into feed cylinders could be possible (depending on the thoroughness of methods designed to prevent such transport). Americium fluorides are not known above $\mathrm{AmF}_{4}$, and the vapor pressure of that compound extrapolates to $10^{-21} \mathrm{~atm}$ at $150^{\circ} \mathrm{C}$ [Ref. D.11]. Cesium would be in the form of CsF, which has a vapor pressure at $150^{\circ} \mathrm{C}$ computed at $10^{-15} \mathrm{~atm}$ [Ref. D.12]. While these figures are not absolutely zero, the most plausible transport mechanism into the cascade is associated with entrained particulate matter.

The half-lives of these species are fairly short, however, when considered from the perspective of decades. Even if present originally, only ${ }^{125} \mathrm{Sb}$ and ${ }^{106} \mathrm{Ru}$ would be present in measurable quantities at the present time. Using a starting date for decay of 1973 (the peak of the last major reactor return feed campaign) and a start-of-processing date of $2005,{ }^{125} \mathrm{Sb}$ (half-life $=2.77$ years) would be reduced by a factor of 1000 from its original level, and ${ }^{106} \mathrm{Ru}$ (half-life $=1.01$ years) would be reduced by a factor of a billion. The other isotopes mentioned, and the daughters of all these nuclides, have shorter half-lives and would have completely decayed by the end of this period. Antimony would be present in the form of $\mathrm{SbF}_{5}$, which has a strong tendency to complex with inorganic fluorides (such as the fluoride film on the surface of the steel cylinder or the nickel cascade piping). It thus would have adsorbed on cylinder or cascade surfaces before reaching the tails stream. Hence, the only credible route for $\mathrm{SbF}_{5}$ to the tails would be via the heels of a reused feed cylinder.

The likelihood of any of these species being present in the tails in appreciable amounts does not appear to warrant a sampling campaign directed at their detection. Only if such sampling could be conducted in conjunction with the primary radiochemical analysis would it be warranted.

Stable Isotope Chemical Impurities. Over time, impurities such as chromium (in the form of fluorides or oxyfluorides and arsenic (in the form of $\mathrm{AsF}_{5}$ ) have been found in the feed. For example, during a brief episode in the late $1980 \mathrm{~s}$, a new source of raw materials for $\mathrm{UF}_{6}$ feed manufacture contained higher-than-normal levels of arsenic in the feed, which led to accelerated feed cylinder valve corrosion [Ref. D.13]. Once recognized, the problem was quickly alleviated. The volatile species of these elements, however, are prone to adsorption on inorganic fluoride surfaces (e.g., $\mathrm{NiF}_{2}$ and $\mathrm{FeF}_{3}$ ), and, in any case, are considerably lighter than $\mathrm{UF}_{6}$. Thus, when 
introduced to the cascade, they will tend to concentrate in the product stream, if they exit the cascade at all. The tails stream is unlikely to receive any appreciable quantities of these (or other unrecognized volatile impurities) and certainly not at the levels which were of concern in the feed. Analysis for such species does not appear to be warranted in the bulk tails $\mathrm{UF}_{6}$. Checking for the presence of these elements is likely to be useful only as part of a cylinder heels compositional analysis (largely directed at determining what elements will need to be dealt with in the empty cylinders).

Some trace level of essentially innocuous gases may always be present in tails cylinders. Components (or reaction products) of air inleakage may be present (e.g., $\mathrm{N}_{2}, \mathrm{O}_{2}$, HF from reaction with water vapor). Similarly, traces of coolants may be present (CFC-114; in the early history of the cascade, R-437 or R-816). The levels should be minimal and are unlikely to have any process impact during conversion. The overall pressure of gases in the cylinder is of more concern than the individual components.

A special case of chemical contamination of cylinders involves PCBs. In a small subset of the cylinders, PCB contamination has been found on the external surfaces of cylinders. This would not have a direct impact on the conversion process but might be of concern in dealing with the effluents from autoclaving.

Conclusions. Based on the information discussed previously, it does not appear that specific analyses should be made solely for the purpose of finding the various non- $\mathrm{Tc} / \mathrm{Np} / \mathrm{Pu}$ species in the diffusion plant tails cylinders. To the extent that general radiochemical analyses (e.g., gamma spectroscopy) are performed, the presence of the longer-lived isotopes mentioned should be examined. Similarly, if elemental analyses are performed, particularly on cylinder heels, the elements mentioned should be among those sought, but the search should not focus solely on those elements.

\section{D.3 References}

D.1. Lyon, D. F., Prediction of External Corrosion for Steel Cylinders-1998 Report, ORNL/TM-13568, Oak Ridge National Laboratory, Oak Ridge, Tenn., February 1998.

D.2. "American National Standard for Nuclear Materials: Uranium Hexafluoride_-Packaging for Transport," ANSI N14.1-1995, American National Standards Institute.

D.3. Lykins, M. L., Portsmouth Gaseous Diffusion Plant, Portsmouth, Ohio, and Frazier, M., Frazier and Associates, Cincinnati, Ohio, "Minimum Wall Thickness Calculations for the UF $_{6}$ Storage Cylinders Using ASME Code Section VIII," POEF-38-342-96-507, internal correspondence to M. S. Taylor, November 5, 1996.

D.4. National Board Inspection Code, Part RB (in particular, Sects. 3237 and 3238, part I), The National Board of Boiler and Pressure Vessel Inspectors, New York, 1995. 
D.5. Pawel, S. J., Cylinder Condition Acceptance Requirements for Multiple Cylinder Functions, ORNL/CST-SP-072998-01, internal correspondence to M. S. Taylor, Bechtel Jacobs Corporation, July 29, 1998.

D.6. ETTP UF ${ }_{6}$ Cylinder Project PCB Characterization Plan, BJC/OR-365, August 13, 1999.

D.7. Stephenson, M. J., Merriman, J. R., and Kaufman, H. L., Removal of Impurities from Uranium Hexafluoride by Selective Sorption Techniques: Progress Report for 1966, K-1713, Oak Ridge Gaseous Diffusion Plant, Oak Ridge, Tenn., 1967.

D.8. Stephenson, M. J., and Pashley, J. H., Removal of Impurities from Uranium Hexafluoride by Selective Sorption Techniques: Third Progress Summary Report, K-1775, Oak Ridge Gaseous Diffusion Plant, Oak Ridge, Tenn., 1973.

D.9. Johnson, D. R., Jones, C. G., and Harris, R. L., Assessment of Trapping Technology for Removal of Radioactive Impurities from $U_{6}$ Reactor Return Feed, K/PS-526, Oak Ridge Gaseous Diffusion Plant, Oak Ridge, Tenn., 1983.

D.10. Smith, R. F., Historical Impact of Reactor Tails on the Paducah Cascade, KY/L-1239, Paducah Gaseous Diffusion Plant, Paducah, Ky., March 1984.

D.11. Katz, J. J., and Sheft, I., "Halides of the Actinide Elements," Adv. Inorg. Chem. Radiochem. 2, 195 (1960).

D.12. Derived from data in Chase, M. W., et al., "JANAF Thermochemical Tables, Third Edition," J. Phys. Chem. Ref. Data 14, Suppl. 1 (1985).

D.13. Russell, R. G., and Otey, M. G., Arsenic Removal from Gaseous Streams, KY/L-1556, Paducah Gaseous Diffusion Plant, Paducah, Ky., 1989. 


\title{
Appendix E
}

\section{Options for Sampling and Analysis of $\mathrm{DUF}_{6}$ Cylinder Contents}

\author{
M. I. Morris
}

\section{E.1 Objective}

This appendix reviews options and recommends approaches for carrying out sampling of the cylinders and performing needed constituent analyses. Possible sampling methods are described, including the drawbacks of the autoclave/liquid sampling method, as well as the application of NDA technology that was developed as part of the DOE Environmental Management program.

The relative costs of the methods are also discussed.

\section{E.2 Results}

\section{Radiochemical Analysis}

The following information was provided by D. Mann (865-574-9614) and D. Derreberry (865-574-4399) of the Analytical Services Organization, LMES.

\begin{tabular}{|c|c|c|c|c|c|}
\hline \multirow{2}{*}{ Isotope } & \multicolumn{2}{|c|}{$\begin{array}{c}\text { Minimal detectable } \\
\text { activity }\end{array}$} & \multirow{2}{*}{ Type of analysis } & \multicolumn{2}{|c|}{ Cost per sample with data package } \\
\hline & $\mathrm{pCi} / \mathrm{g} \mathrm{U}$ & $\mathrm{ppb} / \mathrm{g} \mathrm{U}$ & & $\begin{array}{l}\text { Five or more } \\
\text { samples }\end{array}$ & One sample \\
\hline${ }^{99} \mathrm{Tc}$ & 20 & 2 & Liquid scintillation & $\$ 320$ & $\$ 450$ \\
\hline${ }^{237} \mathrm{~Np}$ & 10 & 15 & Alpha spectrometry & $\$ 350$ & $\$ 480$ \\
\hline${ }^{239} \mathrm{Pu}$ & 10 & 0.2 & Alpha spectrometry & $\$ 350$ & $\$ 480$ \\
\hline
\end{tabular}

The key to an accurate analysis lies in the sample preparation steps, including the dilution and separation of the isotopes from the uranium. The required sample size is very small $(\sim 1 \mathrm{~g})$. The uranium interferes/masks the neptunium and plutonium peaks; hence, the more efficient the separation, the more accurate the analysis.

Chemical analyses of arsenic and ruthenium taken from the same sample would cost \$275-\$390, depending on the concentration of each element. The detection limits for arsenic and ruthenium are 50 and $5 \mathrm{ppb}$, respectively.

Other laboratories were contacted and agreed with the technical evaluation described above; these included Therm0-Nu-Tec (Mike McDougal, 865-481-0683) and NFT Sample Management Office (Jim Ealy, 865-576-2724). Their prices would be $\sim \$ 200$ per sample for the same analyses. 


\section{Nondestructive Analysis}

Individuals contacted included Fred Schultz, 865-988-9998, of Northwest Nuclear; Lloyd Collins, 865-576-1971, of the Analytical Services Organization, LMES; Ron Brodzinski, 509-376-3529, of PNNL; and Tom Rucker, 865-481-2993, of SAIC.

Two types of NDA analysis — gamma spectroscopy and neutron interrogation — are compared as follows:

\begin{tabular}{|l|l|l|}
\hline \multirow{2}{*}{} & \multicolumn{2}{|c|}{ Analysis } \\
\cline { 2 - 3 } & \multicolumn{1}{|c|}{ Gamma } & \multicolumn{1}{|c|}{ Neutron } \\
\hline Measurement & $\begin{array}{l}\text { Measures the specific gamma energy } \\
\text { of each isotope in the sample; the } \\
\text { stronger the gamma energy, the more } \\
\text { accurate the measurement }\end{array}$ & $\begin{array}{l}\text { Measures total neutron activity of the } \\
\text { sample; isotopes must be alpha } \\
\text { emitters }\end{array}$ \\
\hline Identification & $\begin{array}{l}\text { Can identify individual isotopes that } \\
\text { emit gamma rays }\end{array}$ & $\begin{array}{l}\text { Measures total neutron activity; } \\
\text { cannot distinguish between isotopes }\end{array}$ \\
\hline Accuracy & $\begin{array}{l}\text { Mainly measures surface activity; } \\
\text { reading would be minimal value; } \\
\text { sensitivity of gamma spectroscopy } \\
\text { depends on fraction of the isotopes } \\
\text { present on the walls of the cylinder, } \\
\text { and accuracy depends on the } \\
\text { constancy of that distribution }\end{array}$ & $\begin{array}{l}\text { Measures interstitial or all sample } \\
\text { activity; provides maximum value; } \\
\text { assumes uniform distribution; could } \\
\text { overestimate if activity is on walls }\end{array}$ \\
\hline Environment & $\begin{array}{l}\text { Environment does not typically affect } \\
\text { or interfere with measurement }\end{array}$ & $\begin{array}{l}\text { Environment could affect or interfere } \\
\text { with measurement; sensitive to } \\
\text { direction and shielding }\end{array}$ \\
\hline
\end{tabular}

Brodzinski believed neutron interrogation could measure total alpha levels as low as $0.5-1 \mathrm{ppm}$. This was based on modeling only and has not actually been done. Other investigators felt this was very optimistic. The cost for deploying the PNNL system would be approximately $\$ 50 \mathrm{~K}$ for setup and \$50-\$100 per sample, assuming 2-4 samples per hour. This does not include the cost of moving cylinders in the event that there should be interference from other cylinders.

Other investigators were in agreement that NDA was best applied to measuring approximate percentages or high levels of constituents (ppm). The levels we attempted to measure (ppb levels) could not be accomplished using NDA. High levels of ${ }^{239} \mathrm{Pu}(\mathrm{ppm})$ could be detected using gamma spectroscopy. Tom Rucker, of ETTP, has been working on some of these concerns and has noted that ${ }^{241} \mathrm{Am}$ has been found to be present with ${ }^{238} \mathrm{Pu}$.

If historical data are going to be used and compared with the current sampling and analysis results, another issue to be considered involves the methods used for sample preparation and 
analysis of both the current and historical data. The data cannot be compared if the methodology has changed significantly.

\section{E.3 Sampling}

Three different approaches have been identified for obtaining DUF 6 samples for analysis:

- Liquid sample retrieval using autoclave

- Solid sample retrieval by coring drill

- Gas and liquid sample retrieval using autoclave and cylinder washing

\section{Liquid Sample Retrieval Using Autoclave}

This is the standard sampling method. A cylinder is placed in an autoclave and heated until $\mathrm{UF}_{6}$ becomes a liquid. A small sample is then withdrawn and analyzed. The cylinder is allowed to cool and is then placed back in storage. Based on the December 1999 sampling campaign, the average cost per cylinder for sampling and analysis was $\$ 10,000$.

Advantages. Converting the $\mathrm{UF}_{6}$ to a liquid provides a high probability that the sample will be homogeneous and representative. However, if the contaminants remain as particulate solids, they may not be retrieved as part of the sample. Another advantage of this method is that the equipment is already in place, and the program could start immediately.

Disadvantages. Because the cylinders must be heated in an autoclave to convert the $\mathrm{UF}_{6}$ to a liquid, the cylinder must be in reasonably good physical condition and meet the WAC for autoclaving. Due to the degraded condition of most of the cylinders, it is estimated that only $5-20 \%$ of the cylinders would qualify for sampling when using the autoclave method. There are autoclaves in use at PORTS and PGDP but none at ETTP. Therefore, any cylinders stored at ETTP selected for sampling would have to be transported to PORTS or PGDP, adding to the cost.

\section{Solid Sample Retrieval by Coring Drill}

A solid sample approximately $500 \mathrm{~g}$ in size would be captured through the cylinder access port using a coring drill. This method and the equipment do not currently exist. The ORNL Robotics and Process Systems Division has submitted a proposal to develop the methodology and equipment at an estimated cost of $\$ 438 \mathrm{~K}$. This would be accomplished over a 6 -month period. The estimated cost for performing the sampling and analysis once the device is operational is approximately $\$ 3200$ per sample, not including disposal of the additional waste sample. The estimated cost of waste disposal per sample is $\$ 150-\$ 200$.

Advantages. The samples could be gathered at the cylinder storage facility and would not have to be transported outside the area. Any cylinder in the inventory could be sampled since no limitations are placed on the condition of the cylinder. 
Disadvantages. This methodology has not been attempted before; therefore, the possibility of failure, though remote, does exist. Failure would significantly impact the project schedule and cost. No equipment is currently in place, so there would be a lag time before any sampling could begin using this methodology. Also, the probability that a solid sample would not be as homogeneous as a liquid or gas sample is much greater. This process would also take a much larger sample than needed. Therefore, the excess sample would have to be disposed of, creating additional cost and waste management issues. Additional considerations include having this technique approved and providing the documentation certifying it, which would also add cost and time to the schedule.

\section{Gas and Liquid Samples Retrieval Using Autoclave and Cylinder Washing}

In this scenario, a cylinder would be emptied by heating it in the autoclave and driving off the $\mathrm{UF}_{6}$ as a gas either into the cascade or into another cylinder. Gas samples would be taken at various stages as the cylinder is emptied. The empty cylinder would then be washed, removing the heels and any particulate matter not volatilized. The wash water would subsequently be sampled and analyzed. This process would provide the highest reliability for obtaining the most representative sample. The washing operation is currently being performed on feed cylinders at PGDP. The cost per sample is approximately $\$ 10,000$ per cylinder.

Advantages. This method provides the most representative sample. The equipment is already in place and could be initiated immediately.

Disadvantages. As in the case of the liquid sampling methodology, the cylinders must be heated in an autoclave to convert the $\mathrm{UF}_{6}$ to a liquid; therefore, the cylinder must be in reasonably good physical condition and meet the autoclave acceptance criteria. Due to the degraded condition of most of the cylinders, it is estimated that only between $5-20 \%$ of the cylinders would qualify for sampling using the autoclave method. Autoclaves are in use at PORTS and PGDP, but none are at ETTP. In addition, the only cylinder wash station exists at PGDP. Therefore, any cylinders stored at ETTP or PORTS selected for sampling would have to be transported to PGDP, thus adding to the cost. 


\section{Appendix F}

\section{Identification and Selection of Populations of DUF ${ }_{6}$ Cylinders for Sampling}

\section{F.1 Analysis of Cylinder Inventory Data Base for Estimating Numbers of Cylinders (D. G. O’Connor and V. S. White)}

An analysis of available feed and production information was conducted for all three GDPs; a detailed analysis was conducted for the PGDP. Table F.1 provides a summary of the quantity of domestic reactor returns fed to the three GDPs for the period 1953 through 1976. Table F.2 provides details of the total feed and the $\mathrm{DUF}_{6}$ that were produced for the PGDP for the period 1953 through 1976 [Ref. F.1]. Similar detailed information for the total feed and DUF 6 produced at PORTS and ORGDP could not be obtained in the time available, but it is likely that such information could be made available.

Information obtained for the GDPs indicated that domestic reactor returns were fed from Hanford (normal and enriched) and the Savannah River Site (SRS). The GDPs received reactor returns as follows:

Paducah Gaseous Diffusion Plant

- Normal Hanford: 1953-1964, 1969-1970, and 1972-1973

- Enriched Hanford: 1973 and 1975-1976

- Savannah River: 1960-1964 and 1973-1974

Oak Ridge Gaseous Diffusion Plant

- Normal Hanford: 1958-1961, 1970, and 1974

- Enriched Hanford: None

- Savannah River: 1960-1962

Portsmouth Gaseous Diffusion Plant

- Normal Hanford: Yes, but time frame unknown at this time

- Enriched Hanford: None

- Savannah River: None

Table F.2 provides detailed information on the total feed that was processed at PGDP each year from 1953 through 1976. This information, together with the reactor returns feed information, allowed for the calculation of the percentage of total feed for a given year that was due to reactor returns feed. For six years the reactor returns feed constituted $25 \%$ or more of the total feed to the PGDP:

- $1958: 35 \%$

- $1959: 25 \%$

- 1969: $26 \%$ 
Table F.1. Domestic reactor returns feed at each GDP

(metric tons of $\mathrm{UF}_{6}$ )

\begin{tabular}{|c|c|c|c|c|}
\hline FY & $\begin{array}{l}\text { Hanford } \\
\text { (normal) }\end{array}$ & SRS & $\begin{array}{l}\text { Hanford } \\
\text { (enriched) }\end{array}$ & Total \\
\hline \multicolumn{5}{|c|}{ Paducah } \\
\hline 53 & 2,314 & 0 & 0 & 2,314 \\
\hline 54 & 6,069 & 0 & 0 & 6,069 \\
\hline 55 & 6,013 & 0 & 0 & 6,013 \\
\hline 56 & 10,919 & 0 & 0 & 10,919 \\
\hline 57 & 14,307 & 0 & 0 & 14,307 \\
\hline 58 & 11,318 & 0 & 0 & 11,318 \\
\hline 59 & 9,159 & 0 & 0 & 9,159 \\
\hline 60 & 9,305 & 37 & 0 & 9,342 \\
\hline 61 & 9,177 & 18 & 0 & 9,194 \\
\hline 62 & 9,928 & 392 & 0 & 10,320 \\
\hline 63 & 10,786 & 668 & 0 & 11,454 \\
\hline 64 & 8,910 & 1,446 & 0 & 10,357 \\
\hline 65 & 0 & 0 & 0 & 0 \\
\hline 66 & 0 & 0 & 0 & 0 \\
\hline 67 & 0 & 0 & 0 & 0 \\
\hline 68 & 0 & 0 & 0 & 0 \\
\hline 69 & 7,071 & 0 & 0 & 7,071 \\
\hline 70 & 6,682 & 16 & 0 & 6,698 \\
\hline 71 & 0 & 0 & 0 & \\
\hline 72 & 7,813 & 0 & 0 & 7,813 \\
\hline 73 & 11,453 & 2,039 & 1,155 & 14,647 \\
\hline 74 & 0 & 739 & 0 & 739 \\
\hline 75 & 0 & 0 & 614 & 614 \\
\hline 76 & 0 & 0 & 1,417 & 1,417 \\
\hline Subtotal & 141,223 & 5,357 & 3,186 & 149,765 \\
\hline \multicolumn{5}{|c|}{ Oak Ridge } \\
\hline 58 & 2,360 & 0 & 0 & 2,360 \\
\hline 59 & 720 & 0 & 0 & 720 \\
\hline 60 & 1,857 & 130 & 0 & 1,988 \\
\hline 61 & 358 & 1,378 & 0 & 1,736 \\
\hline 62 & 0 & 470 & 0 & 470 \\
\hline 70 & 580 & 0 & 0 & 580 \\
\hline 74 & 467 & 0 & 0 & 467 \\
\hline Subtotal & 6,343 & 1,979 & 0 & 8,322 \\
\hline \multicolumn{5}{|c|}{ Portsmouth } \\
\hline All years & 849 & 0 & 0 & 849 \\
\hline Totals & 148,415 & 7,335 & 3,186 & 158,936 \\
\hline
\end{tabular}


Table F.2. Paducah feed and tails data

\begin{tabular}{|c|c|c|c|c|c|c|c|}
\hline FY & $\begin{array}{l}\mathrm{RR}^{a} \text { feed } \\
\left(\mathrm{UF}_{6}, \mathrm{MT}\right)\end{array}$ & $\begin{array}{l}\text { Total feed } \\
\left(\mathrm{UF}_{6}, \mathrm{MT}\right)\end{array}$ & $\begin{array}{l}\mathrm{RR}^{a} \text { feed } \\
(\% \text { of feed })\end{array}$ & $\begin{array}{l}\text { Tails assay } \\
\left(\% \text { of }{ }^{235} U\right)\end{array}$ & $\begin{array}{l}\text { Total tails } \\
\left(\mathrm{UF}_{6}, \mathrm{MT}\right)\end{array}$ & $\begin{array}{l}\text { Number tails } \\
\text { cylinders }\end{array}$ & $\begin{array}{l}\text { Most attractive } \\
\text { for sampling }\end{array}$ \\
\hline 53 & 2,314 & 13,535 & $17 \%$ & $0.39-0.82$ & 11,253 & 834 & \\
\hline 54 & 6,069 & 36,646 & $17 \%$ & $0.29-0.51$ & 30,582 & 2,265 & \\
\hline 55 & 6,013 & 73,701 & $8 \%$ & $0.20-0.32$ & 65,221 & 4,831 & \\
\hline 56 & 10,919 & 96,844 & $11 \%$ & $0.16-0.20$ & 84,212 & 6,238 & \\
\hline 57 & 14,307 & 40,920 & $35 \%$ & $0.17-0.23$ & 25,842 & 1,914 & 1,914 \\
\hline 58 & 11,318 & 45,376 & $25 \%$ & $0.28-0.42$ & 33,673 & 2,494 & \\
\hline 59 & 9,159 & 60,910 & $15 \%$ & $0.30-0.34$ & 48,854 & 3,619 & \\
\hline 60 & 9,342 & 55,392 & $17 \%$ & 0.34 & 43,990 & 3,259 & \\
\hline 61 & 9,194 & 61,905 & $15 \%$ & 0.34 & 51,032 & 3,780 & \\
\hline 62 & 10,320 & 70,055 & $15 \%$ & 0.34 & 59,820 & 4,431 & \\
\hline 63 & 11,454 & 117,883 & $10 \%$ & $0.30-0.81$ & 106,093 & 7,859 & \\
\hline 64 & 10,357 & 110,918 & $9 \%$ & $0.29-0.30$ & 100,090 & 7,414 & \\
\hline 65 & 0 & 36,397 & $0 \%$ & 0.20 & 30,598 & 2,267 & 2,267 \\
\hline 66 & 0 & 37,466 & $0 \%$ & 0.20 & 31,903 & 2,363 & \\
\hline 67 & 0 & 31,428 & $0 \%$ & 0.20 & 27,082 & 2,006 & \\
\hline 68 & 0 & 39,290 & $0 \%$ & 0.20 & 35,192 & 2,607 & \\
\hline 69 & 7,071 & 26,997 & $26 \%$ & 0.20 & 18,093 & 1,340 & 1,340 \\
\hline 70 & 6,698 & 19,332 & $35 \%$ & 0.20 & 11,355 & 841 & 841 \\
\hline 71 & & 20,549 & $0 \%$ & 0.20 & 11,519 & 853 & \\
\hline 72 & 7,813 & 28,503 & $27 \%$ & 0.30 & 19,702 & 1,459 & 1,459 \\
\hline 73 & 14,647 & 22,636 & $65 \%$ & 0.20 & 16,646 & 1,233 & 1,233 \\
\hline 74 & 739 & 20,990 & $4 \%$ & 0.30 & 15,378 & 1,139 & \\
\hline 75 & 614 & 22,218 & $3 \%$ & 0.30 & 16,185 & 1,199 & \\
\hline 76 & 1,417 & 31,118 & $5 \%$ & 0.25 & 25,403 & 1,882 & \\
\hline Subtotal & 149,765 & $1,121,009$ & & & 919,719 & & 9,054 \\
\hline
\end{tabular}

${ }^{a} \mathrm{RR}=$ Reactor returns used as feed to the GDPs. Tails with higher assay levels were routinely refed to the GDPs. 
- $1970: 35 \%$

- $1972: 27 \%$

- 1973: $65 \%$

During planning efforts for this activity, it was learned that many of the $\mathrm{DUF}_{6}$ cylinders filled during the period before 1960 were refed to the GDPs [Ref. F.2]. As noted above, one of the periods of interest for possible DUF $_{6}$ cylinder sampling was prior to 1960 . It is also known that $\mathrm{DUF}_{6}$ cylinders with higher assay levels were routinely refed to the cascades. In order to determine which cylinders might have been considered for refeeding, the assay levels were evaluated for the years of interest. It was discovered that five of the six years cited above had assay levels less than or equal to $0.30 \%{ }^{235} \mathrm{U}$ :

- 1958: $0.17-0.23 \%{ }^{235} \mathrm{U}$

- 1969: $0.20 \%{ }^{235} \mathrm{U}$

- 1970: $0.20 \%{ }^{235} \mathrm{U}$

- $1972: 0.30 \%{ }^{235} \mathrm{U}$

- 1973: $0.20 \%{ }^{235} \mathrm{U}$

It is less likely that DUF 6 cylinders filled during these 5 years would have been refed; more likely, they still exist in the cylinder inventory today.

No information was provided in Ref. F.1 as to how many DUF ${ }_{6}$ cylinders were filled during operations, but the total amount of $\mathrm{DUF}_{6}$ produced for each year was provided in tons. Using a conversion factor of 1.479 to convert uranium to $\mathrm{UF}_{6}$ and assuming $27,000 \mathrm{lb}$ of $\mathrm{UF}_{6}$ was loaded into each $\mathrm{DUF}_{6}$ cylinder, an estimate of the number of cylinders filled each of the years of interest was determined. An estimated number of cylinders for each of the 5 years cited above is provided as follows:

- 1958: 1914 cylinders

- 1969: 1340 cylinders

- 1970: 841 cylinders

- 1972: 1459 cylinders

- 1973: 1233 cylinders

Based on this analysis, PGDP DUF 6 cylinders filled during the following three time periods would have a higher likelihood of containing impurities than would have been introduced by reactor returns feed:

- middle to late 1958

- middle to late 1969 through 1970

- middle to late 1972 through 1973

\section{F.2 Selection of Populations for Characterization (L. R. Dole)}

The populations of DUF 6 cylinders for characterization will be selected from the periods of operation of the three GDPs that are determined to have the highest known risk of containing 
transuranics and fission products based on operating histories of the plants. Some key periods of operation of the GDPs with recycled uranium are as follows:

- Recycled uranium fed to PGDP cascades: 1953-1964, 1969-1970, and 1972-1976 (only kilogram quantities were fed 1986-1989)

- Recycled uranium fed to ORGDP cascades: 1958-1962, 1970-1974, and 1976-1978

- Recycled uranium fed to PORTS cascades: 1955-1958, 1961, 1969, and 1974

Timelines were established for events during these periods that would influence the selection of populations of $\mathrm{DUF}_{6}$ cylinders to be sampled for PGDP. Equivalent details were not available for the other two GDPs during the development of this strategy. Using the available data, the time periods chosen were when the feed preparation process and/or the enrichment cascades were undergoing changes. The conditions that existed during these changes are believed to have resulted in an increased probability that contaminants were carried into the cascades and into the feed cylinders used for storing the $\mathrm{DUF}_{6}$.

It has been reported that some cylinders previously used to feed $\mathrm{UF}_{6}$ prepared from recycled uranium were used to store $\mathrm{DUF}_{6}$ without having nonvolatile heels removed prior to being filled [Ref. F.1]. This most likely occurred when cylinder models were changed. Since the transuranics and fission products would concentrate in the heels, the cylinders would be expected to have the highest quantities of these contaminants present. Also during these periods, barrier change-outs occurred, during which time neptunium and plutonium might have been removed with the old hardware but might also potentially have been mobilized as part of the cleanup operations and subsequently reintroduced into the cascades.

Four periods of operation at PDGP were identified during the reactor returns feed preparation and the cascade enrichment in which the potential for contamination of the DUF 6 cylinders by ${ }^{99} \mathrm{Tc}$, ${ }^{237} \mathrm{~Np}$, and ${ }^{239} \mathrm{Pu}$ may have been the highest. Cylinders generated during these periods would constitute one population that we propose be characterized because it is most likely to have the highest contaminant levels and can provide the upper bound estimates that vendors would need. Activities conducted during these periods that justify selecting these cylinders as a population for sampling are described as follows:

1955-1957. The earliest elevated reactor returns feed ( $\sim 35 \%$ of the total feed) to the Paducah cascade occurred during this period. The first barrier change-out campaign, which covered the first changeover from 30-in. Models A\&B to 48-in. Model T thin-walled cylinders, also took place during this time. This changeover preceded the implementation of an effective carryover cleanup train for the last step of the $\mathrm{UF}_{6}$ feed preparation. We propose that the cylinders generated in 1957 be selected to represent activities during this period. Approximately 1900 $\mathrm{DUF}_{6}$ cylinders with assays less than $0.23 \mathrm{wt} \%{ }^{235} \mathrm{U}$ were produced. These cylinders were not likely to have been refed and thus are probably still in the inventory (see Sect. F.1).

1964-1965. This period covered the first shutdown of the Paducah feed plant and the temporary cessation of reactor returns feed to the Paducah cascade. The models of cylinders were being changed from the 48-in. Model $\mathrm{O}$ to the 48-in. Model OM. This preceded the implementation of an effective carryover cleanup train for the last step of the $\mathrm{UF}_{6}$ feed preparation. Based on the 
information available at this time, it is believed that the most likely time for reactor return feed cylinders to have been used for $\mathrm{DUF}_{6}$ cylinders prior to having their heel removed would have been 1965, and we propose that cylinders generated in 1965 be included in this high-risk population. In 1965, approximately $2300 \mathrm{DUF}_{6}$ cylinders with assays less than $0.3 \mathrm{wt} \%{ }^{235} \mathrm{U}$ were filled.

1969-1970. This period was 2 years after resumption of processing reactor returns in the Paducah feed preparation plant, 1 year after resumption of the enrichment of the reactor returns in the Paducah cascade, and immediately after the period when the reactor return feed rates rose again to $\sim 35 \%$ of the total feed to the Paducah cascade and during a sudden decrease in reactor returns feed preparation rates. Cleanup technologies may have been in the process of being installed in the last stage of the $\mathrm{UF}_{6}$ fluorination during this time. The 48 -in. Model OM cylinder had been in use for 5 years in numbers equal to those for the Model $\mathrm{O}$. This was just before the second campaign to change out the cascade barriers and during the changeover to "A-stream coolers." This equipment was added to raise the temperature of the cascade, thus increasing the mobility of $\mathrm{TcO}_{3} \mathrm{~F}$. Approximately $2200 \mathrm{DUF}_{6}$ cylinders with assays less than $0.2 \mathrm{wt} \%{ }^{235} \mathrm{U}$ were filled during this period.

1972-1973. This period saw the highest-ever processing rates $(\sim 65 \%)$ of reactor returns in the Paducah cascade. The processing of reactor returns in the Paducah feed preparation plant was ending. The second barrier change-out campaign had begun, and the installation of A-stream coolers had also started. The activity level of ${ }^{99} \mathrm{Tc}$ in the Paducah product increased to over $200,000 \mathrm{dpm}$ per gram. The 48-in. Model OM cylinders had now been in service for a decade and were beginning to outnumber the Model O cylinders. During this period, $\sim 2700 \mathrm{DUF}_{6}$ cylinders with assays less than $0.2 \mathrm{wt} \%{ }^{235} \mathrm{U}$ were filled.

PDGP cylinders generated during the four periods make up the highest-priority population that should be characterized. They have the highest likelihood of high contaminant content. This population also has the highest probability of containing recycled uranium feed cylinders that were subsequently used for $\mathrm{DUF}_{6}$ storage without having contaminant-rich heels materials removed. The estimated number of cylinders that make up this highest-priority population is about 9100 (see Sect. F.1).

A second population from PGDP would be the cylinders generated during the remaining periods between 1953 and 1973 when reactor returns made up a high fraction of the total feed. A rough estimate of the number of cylinders in this population is about 5000 .

For complete characterization of the cylinder inventory, a third population from PGDP would be included. This population would consist of the cylinders generated from 1973 to the present. Some characterization information on $\mathrm{Pu}, \mathrm{Np}$, and $\mathrm{Tc}$ contaminants exists for these cylinders (see Sect. 3.1), but no information on ${ }^{241} \mathrm{Am}$ was sought. A rough estimate of the number of these cylinders is about 14,000 .

The other two populations of cylinders with elevated risks to be characterized are (1) the cylinders that were generated at ORGDP during periods of feeding reactor returns (1958-1962, 1970-1974, and 1976-1978), and (2) cylinders generated at the PORTS during periods of reactor 
returns (1955-1958, 1961, 1969, and 1974). The numbers of cylinders at ORGDP and PORTS during these periods were roughly 4800 and 1000, respectively. At this time, less is known about operations at these two sites than at PGDP, so further refinement in population definition is not possible.

The final population that may need to be considered consists of the remaining cylinders from ORGDP and PORTS. The number of cylinders in this population is estimated to be roughly 21,000 .

Since reactor returns made up much smaller fractions of total feed at ORGDP and PORTS, it is believed that $\mathrm{DUF}_{6}$ cylinders from these plants are much less likely to exhibit higher levels of the contaminants of interest than the cylinders generated during the periods of operation at PGDP described previously because of dilution with much larger quantities of uncontaminated feed. Measured results would not affect conclusions that can already be drawn from existing characterization and process knowledge.

\section{F.3 References}

F.1. Smith, R. F., Historical Impact of Reactor Tails on the Paducah Cascade, KY/L-1239, Paducah Gaseous Diffusion Plant, Paducah, Ky., March 1984.

F.2. M. S. Taylor, Bechtel Jacobs Company, LLC, personal communication to D. G. O'Connor, Oak Ridge National Laboratory, January 20, 2000. 
ORNL/TM-2000/242

\section{INTERNAL DISTRIBUTION}

1. J. M. Begovich

2. J. B. Clendenen

3. A. G. Croff

4. L. R. Dole

5. J. J. Ferrada

6. D. W. Lee

7-11. J. R. Hightower, Jr.

12. G. T. Mays

13. G. E. Michaels

14. M. I. Morris
15. D. G. O'Connor

16. S. J. Pawel

17. R. L. Schmoyer

18. J. R. Trabalka

19. L. D. Trowbridge

20. V. S. White

21. K. A. Williams

22. Central Research Library

23. ORNL Laboratory Records-RC

24. ORNL Laboratory Records-OSTI

\section{EXTERNAL DISTRIBUTION}

25. G. W. Benedict, DOE, Oak Ridge Operations Office, 200 Administration Road, Oak Ridge, TN 37831

26. L. D. Boggs, DOE, Oak Ridge Operations Office, 200 Administration Road, Oak Ridge, TN 37831

27-32. Gregg P. Brumburgh, Lawrence Livermore National Laboratory, MS L-196, P.O. Box 808, Livermore, CA 94551-0808

33. R. M. Knipp, U.S. Department of Energy, Immediate Office of the Director, NE-1, Room 5A-157, 1000 Independence Avenue, S.W., Washington, DC 20585

34. S. R. Martin, DOE, Oak Ridge Operations, P.O. Box 2008, Oak Ridge, TN 37831-6269

35. M. A. Reeves, DOE, Oak Ridge Operations Office, 200 Administration Road, Oak Ridge, TN 37831

36. R. W. Rucker, DOE, Oak Ridge Operations Office, 200 Administration Road, Oak Ridge, TN 37831

37-41. K. M. Shaw, U.S. Department of Energy, Office of Depleted Uranium Hexafluoride, NE-30, Room E-475, 19901 Germantown Road, Germantown, MD 20874-1290

42. P. I. Stumbo, DOE, Oak Ridge Operations Office, 200 Administration Road, Oak Ridge, TN 37831

43-47. A. F. Tavares, U.S. Department of Energy, Office of Depleted Uranium Hexafluoride, NE-30, Room 1I-062, 1000 Independence Avenue, S.W., Washington, DC 20585

48. M. S. Taylor, Bechtel Jacobs Company, LLC, P.O. Box 2003, MS-7239, Oak Ridge, TN 37831-7329

49. D. K. Wierwille, DOE, Oak Ridge Operations Office, 200 Administration Road, Oak Ridge, TN 37831

50. M. H. Williams, Associate Deputy Assistant Secretary, Nuclear/Facility Safety, EH-2, Room 7A-121, 100 Independence Avenue, S.W., Washington, DC 20585 